\title{
Wildlife in an anthropogenically-driven world: how humans have shaped the distribution, genetic composition, and gene expression of North American forest hawks (Genus: Accipiter)
}

\author{
Meghan K. Jensen
}

Follow this and additional works at: https://researchrepository.wvu.edu/etd

\footnotetext{
Recommended Citation

Jensen, Meghan K., "Wildlife in an anthropogenically-driven world: how humans have shaped the distribution, genetic composition, and gene expression of North American forest hawks (Genus: Accipiter)" (2017). Graduate Theses, Dissertations, and Problem Reports. 5886.

https://researchrepository.wvu.edu/etd/5886

This Dissertation is protected by copyright and/or related rights. It has been brought to you by the The Research Repository @ WVU with permission from the rights-holder(s). You are free to use this Dissertation in any way that is permitted by the copyright and related rights legislation that applies to your use. For other uses you must obtain permission from the rights-holder(s) directly, unless additional rights are indicated by a Creative Commons license in the record and/ or on the work itself. This Dissertation has been accepted for inclusion in WVU Graduate Theses, Dissertations, and Problem Reports collection by an authorized administrator of The Research Repository @ WVU. For more information, please contact researchrepository@mail.wvu.edu.
} 
Wildlife in an anthropogenically-driven world: how humans have shaped the distribution, genetic composition, and gene expression of North American forest hawks

(Genus: Accipiter)

Meghan K. Jensen

Dissertation submitted to the Davis College of Agriculture, Natural Resources and Design at West Virginia University

in partial fulfillment of the requirements for the degree of

Doctor of Philosophy

In

Forest Resources Science

Amy B. Welsh, Ph.D., Committee Chair

Todd E. Katzner, Ph.D.

Dana Huebert Lima, Ph.D.

Michael P. Strager, Ph.D.

Petra B. Wood, Ph.D.

Division of Forestry and Natural Resources

Morgantown, West Virginia

2017

Keywords: Accipiter, population genetics, microsatellites, RNA-seq, urbanization, lure owl, maximum entropy

Copyright 2017 Meghan K. Jensen 


\section{Abstract \\ Wildlife in an anthropogenically-driven world: how humans have shaped the distribution, genetic composition, and gene expression of North American forest hawks (Genus: Accipiter)}

\section{Meghan K. Jensen}

Humans are causing drastic environmental change on a global scale and this trend strongly influences the evolution of species. It is also becoming clear that tolerances to anthropogenic disturbance varies widely among organisms. Therefore, understanding the mechanisms by which wildlife cope with humans is a pressing question in modern ecology. North America's forest raptors (Genus: Accipiter) are a useful model for investigating the effects of humans on wildlife species. All three Accipiter species experienced historic demographic declines as a result of anthropogenic activities, yet each species has rebounded differently since these declines. One species in particular is now exploiting urban areas, despite the fact that all of these species were traditionally considered highly dependent on large contiguous forests for survival.

This dissertation consists of one introductory chapter, three chapters involving research to improve our current understanding of the impacts of anthropogenic activities on the raptors, and two chapters focused on the development of tools for improving future avian research. The first chapter provides background information on the history of Accipiter hawks in the eastern United States. There are also basic descriptions of some of the novel genetic tools that are becoming increasingly valuable in this and other wildlife studies. In addition, this chapter provides justification for the research and an outline of the project goals.

For the second chapter, I developed a spatial habitat model using Maximum Entropy to locate nesting habitat for northern goshawks (Accipiter gentilis) in New York State, a potential stronghold for this species in the east. This species is the most secretive of the Accipiters, considered highly sensitive to human disturbance, and a species of concern in many eastern states. The model predicted nesting habitat with high success $(\mathrm{AUC}=0.87)$, and ground-truthing efforts identified two previously unknown nest territories. In addition, my model provides some evidence of a shift in forest cover preference by goshawks nesting in New York, as coniferous land cover was the most important predictor in the model (67\%). Future modeling efforts should include additional and more detailed environmental input layers.

In the third chapter, I developed a new mechanical lure owl for trapping nesting raptors that exhibited both realistic head and wing movements. The mechanical owl was tested on six species of raptors and capture rates were similar or better than previously reported with a live lure owl for five of the six species. In addition, average time to capture was eight minutes faster with the mechanical owl as compared to a live owl when trapping northern goshawks $(\mathrm{p}<0.01)$. A mechanical owl costs less and is ethically more appropriate to live lure owls and thus, the use of this type of owl may be warranted in future raptor research.

For the fourth chapter, I investigated the genetic consequences of demographic declines in Accipiter hawks. I used microsatellite markers to test for evidence of significant genetic bottlenecks in northern goshawks and Cooper's hawks (A. cooperii) in the northeastern United States. There was some evidence to suggest a bottleneck in goshawks using the heterozygosity excess method, while the $M$ ratio method suggested a bottleneck in Cooper's hawks. However, similar to previous studies, I found that the results of bottleneck testing are strongly dependent 
on mutation model parameters, which are not available for Accipiter hawks and numerous other non-model organisms. Still, by using the results from tests on both species, I was able to ascertain useful information about the relative impact of historic declines. The Cooper's hawk likely experienced more drastic declines than goshawks, while the goshawk population has likely been small for a relatively long time. Finally, useful baseline information about the contemporary genetic structure of both species was gained from this research. There is no evidence of inbreeding in either population and both species have high levels of gene flow in the northeastern United States.

In the fifth chapter, I compared two commercially available buffers for stabilization of RNA from avian blood for downstream RNA processing. Avian blood presents a particular challenge because it contains nucleated red blood cells and most buffers have been developed for blood with non-nucleated red blood cells (e.g. mammalian blood). Each buffer was subjected to a variety of room temperature incubation periods and freeze treatments, to simulate different field sampling scenarios. RNAlater outperformed RNAProtect; RNAlater reliably stabilized RNA regardless of treatment. However, RNA integrity numbers (RIN) varied widely between samples (1.7 - 7.5). RNA from Cooper's hawk blood stored in RNAlater was sequenced and mapped to the golden eagle (Aquila chrysaetos) genome. Quality assessment suggested that reads were of high quality regardless of RIN value. However, reads that aligned to the reference genome had relatively low sensitivity $(<14 \%)$ and a wide range of precision $(10-61 \%)$. These results suggest that RNAlater can be used to obtain usable RNA for avian blood, but future research may be useful for improving stabilization buffers for species with nucleated red blood cells.

The sixth and final chapter focuses on the Cooper's hawk in urban environments. This species has recently been found nesting in high densities in urban centers and an extensive body of research has demonstrated differences between urban and exurban individuals. When colonizing urban areas, organisms can either adapt through heritable genetic mechanisms or acclimate through plastic mechanisms such as gene expression. Previous research suggested that highly mobile species may be more likely to acclimate since they are capable of moving away from potential stressors. Therefore, I used RNA-sequencing to compare gene expression patterns in the blood of urban and exurban adult and fledgling Cooper's hawks in the Albuquerque, NM area. I also tested all individuals for the presence of an urban-associated parasite (Trichomonas gallinae). I found one and thirteen differentially expressed (DE) transcripts between urban and exurban adults and fledglings, respectively $(\mathrm{q}<0.05)$. For fledglings, more abundant transcripts in the urban environment were mostly associated with nucleotide processing, while those in exurban environments were mostly associated with immune response. The single transcript identified as DE in the adults was more abundant in urban environments and is associated with nucleotide processing, metal ion binding, and platelet production in humans. The greater number of DE transcripts in the fledglings may suggest that changes in gene expression may be especially important for the sedentary offspring of a highly mobile avian urban exploiter. In addition, six fledglings tested positive for Trichomonas spp.; three in each environment. Yet, immune related transcripts were expressed in much higher levels in all exurban individuals, regardless of parasite presence. Future research is warranted to determine if toxin loading in urban environments may lead to immunosuppression of offspring and potentially explain previously described mortality in urban nestlings from trichomoniasis infection. 


\section{Dedication}

In memory of Dr. Timothy King (November $28^{\text {th }}, 1958-$ September $30^{\text {th }}, 2016$ )

For his kindness, wisdom, and devotion to science and the conservation of the Earth's most precious gift: biodiversity. A great role model and an inspiration for aspiring conservation geneticists, may he rest in peace. 


\section{Acknowledgements}

First and foremost, I would like to thank my dissertation committee. Thanks to my committee chair, Dr. Amy Welsh, for the constant guidance and encouragement throughout my years at West Virginia University. To Dr. Todd Katzner for his mentorship and commitment to my development as a researcher and to this project. I would also like to thank Dr. Dana Huebert Lima, Dr. Michael Strager, and Dr. Petra Wood for their helpful ideas, reviews, and critical evaluation of my research.

Second, I would like to recognize all that contributed funding for this project. Dr. Robert Whitmore, an accomplished West Virginia ornithologist, generously contributed the start-up funding for this project and I am happy that I could use this funding for further research on avian species. The Raptor Research Foundation Dean Amadon Grant provided funding for all of the field equipment used throughout this project and the American Wildlife Conservation Foundation provided funding for the creation of the mechanical owl. Additional funding was provided by the National Institute of Food and Agriculture, U.S. Department of Agriculture Hatch Project (WVA00637.0227396), the Daniel C. and Elizabeth D. Brown Faculty Development Fund from West Virginia University, the S. Knox Harper Grant from the Northern Allegheny Conservation Association, and an anonymous donor.

I would also like to thank Mark Manske, Dave "Big Gos" Brinker, Brian Millsap, and Bob Rosenfield. I appreciate your willingness to share with me your genetic samples and more importantly your knowledge and expertise on Accipiter hawks. Far and away the best part of this experience were the days in the field observing these amazing creatures with all of you. I also appreciate the sample contributions of numerous other researchers and wildlife rehabilitation centers: Erica Miller, Kate Slankard, Mariko Yamasaki, the Adirondack Wildlife Refuge, Avian Conservation Center of Appalachia, Avian Haven, Carbon County Environmental Education Center, Mercer County Wildlife Center, New England Wildlife Center, Owl Moon Raptor Center, Sharon Audubon, The Raptor Trust, Three Rivers Avian Center, Tufts Wildlife Center, West Virginia Raptor Rehabilitation Center, Wildlife Center of Virginia, and the York Center for Wildlife.

I was fortunate to have assistance from many people in the laboratory and in the field throughout this project. For help in the creation of my mechanical owl, "Johnny 5", I am indebted to Shanti Hamburg for engineering, and Jim Block and Steve Silwinski of the Buck 
Stops Here (Buffalo, NY) for taxidermy. Seth Yoho, Yuen Xin Lim, Avery Owers, Tatiana Crawford, and Lauren Schumacher aided in various laboratory procedures. Ryan Percifield and Niel Infante of the WVU Genomics Core contributed their expertise in sample processing and bioinformatic analysis. The Marshall University Genomics Core carried out all RNA-sequencing. Thanks to WVU High Performance Computing support staff, Lydia Stiffler, and Isaac Gibson for assistance with code. In the field, Dustin Coles, Connor Vara, Don Watts, Vince Slabe, Sarah Norton, Morgan McMurdy, and Malachia Evans provided invaluable assistance and they were always willing to go out in the field, even at the last minute, to find and trap birds. I had the pleasure of meeting and working with so many others while in the field throughout this project, and I thank each and every one of them. I cannot express enough gratitude to the skilled tree climbers, Jonas Borkholder, my best friend, and Terence Meehan, my life partner for their support and help in every facet of this project.

I want to thank the Wild Genomics (Welsh) lab, the Katzner lab members, and my fellow Wildlife and Fisheries graduate students, both past and present for all of their support. Also, thanks to my mentors that led me to science, wildlife, and/or genetics: Russ Warner, Dr. LeeAnn Sporn, Dr. Eric Simandle, Mark Manske, and Dr. Amy McMillan. Finally, thanks to my family and friends who provided encouragement, support, and always believed in me. 


\section{Table of Contents}

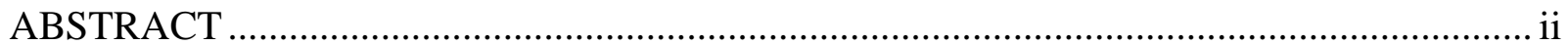

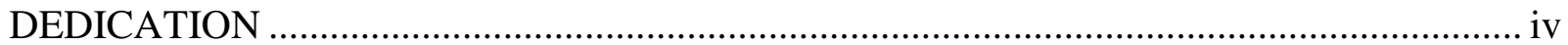

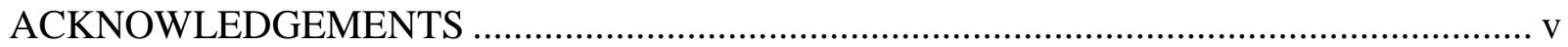

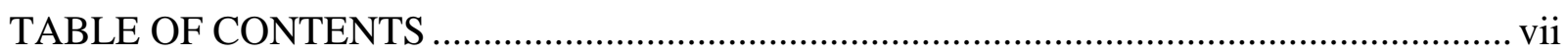

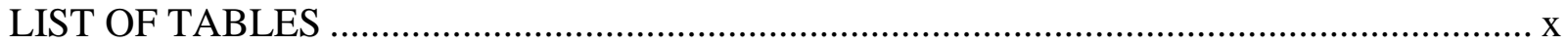

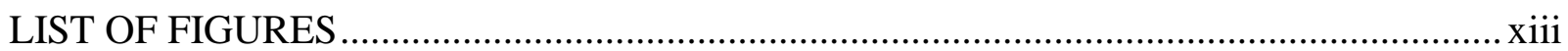

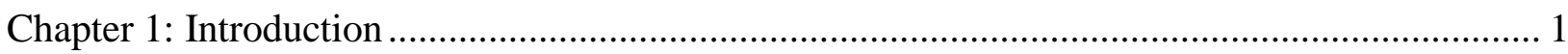

Accipiter life history and conservation ecology .................................................................. 2

Conservation Genetics, Genomics, and Accipiters ……................................................. 5

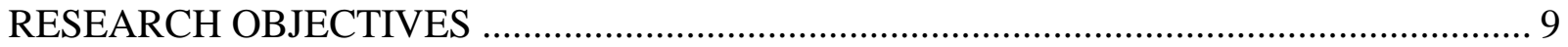

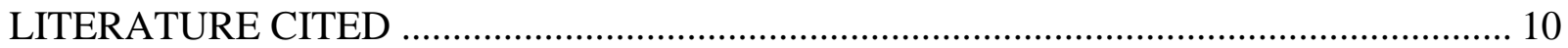

Chapter 2: Northern goshawk nest site modeling in New York State using MaxEnt: Prediction

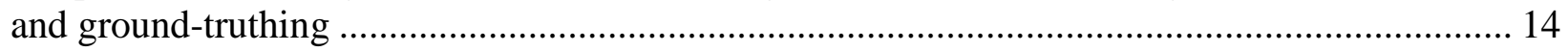

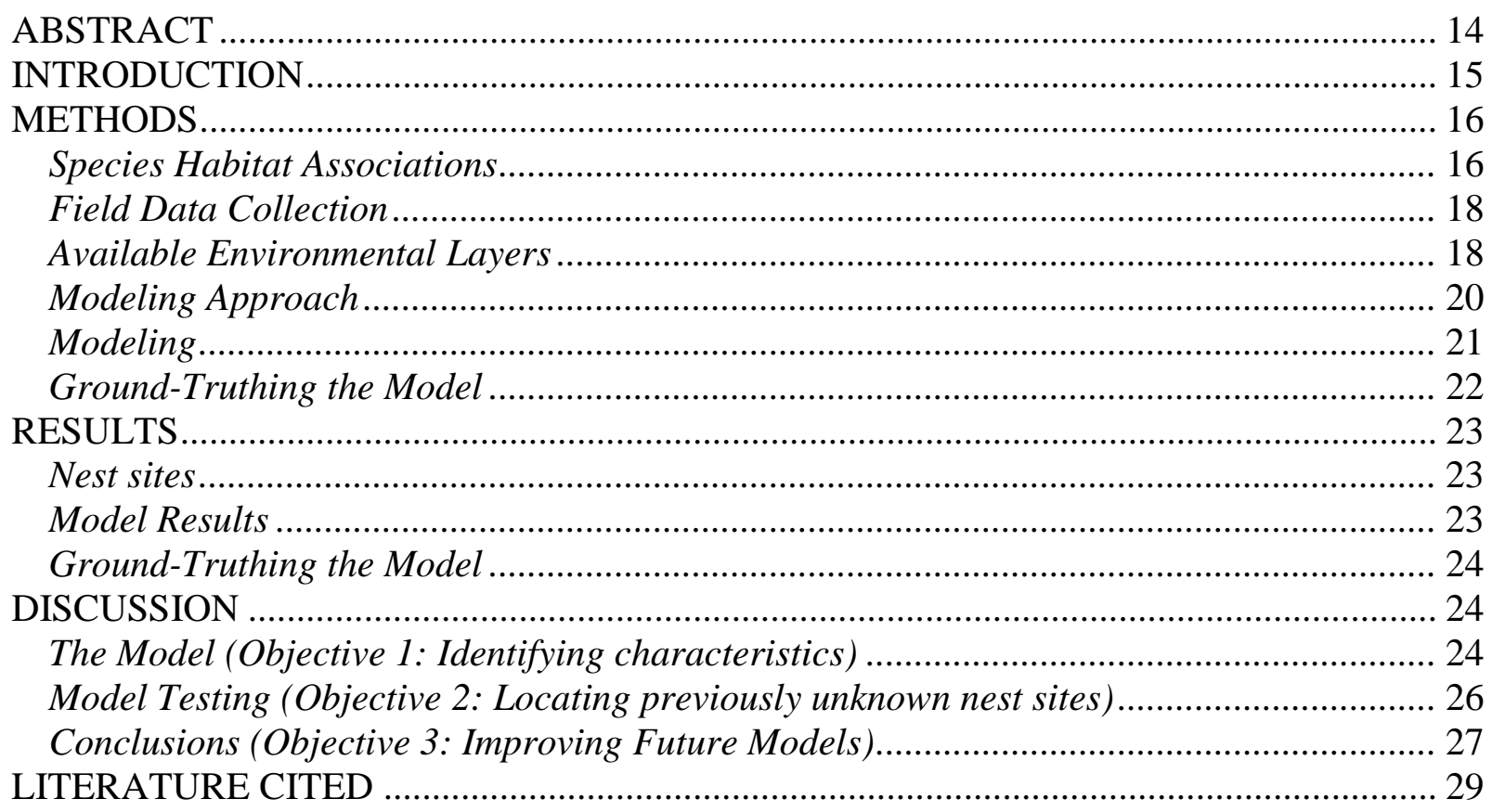

Chapter 3: An improved mechanical owl for efficient capture of nesting raptors........................ 40

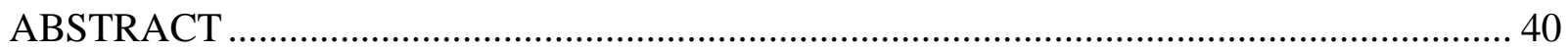

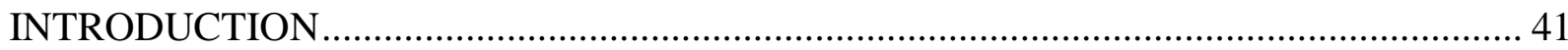

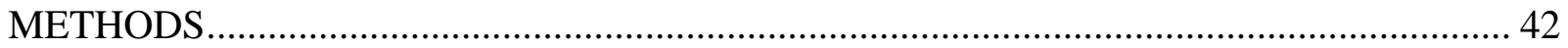

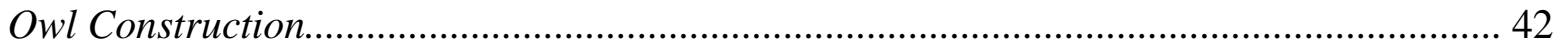

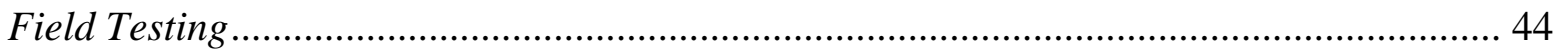




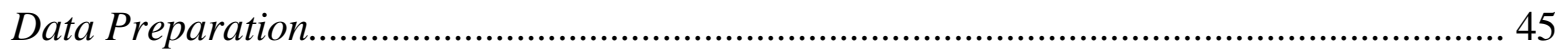

Data Analysis: Capture rates ...................................................................................... 46

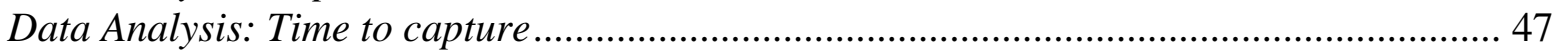

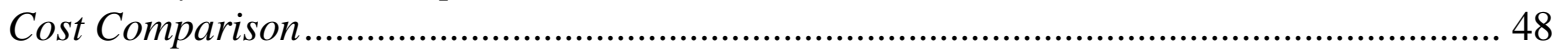

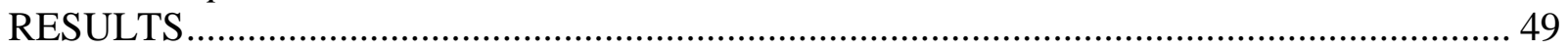

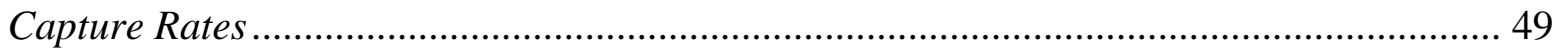

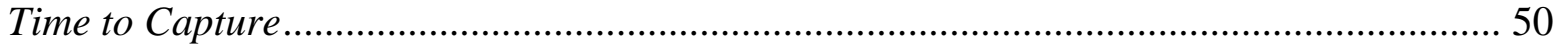

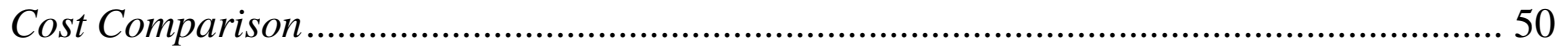

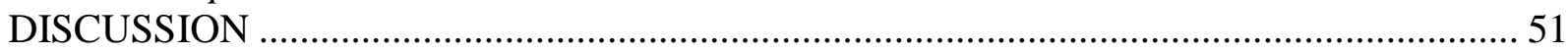

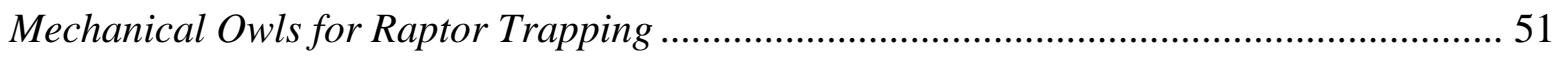

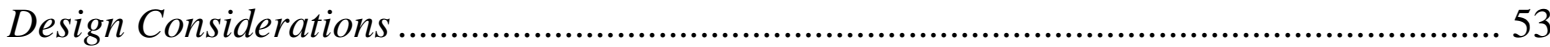

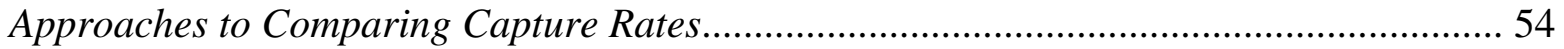

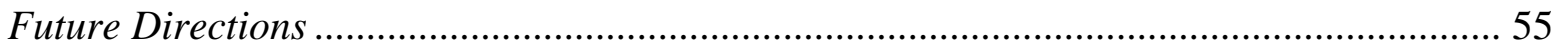

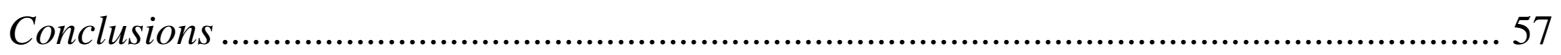

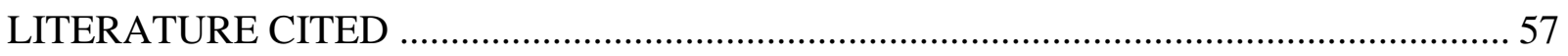

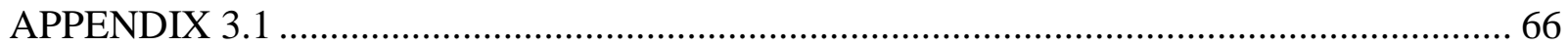

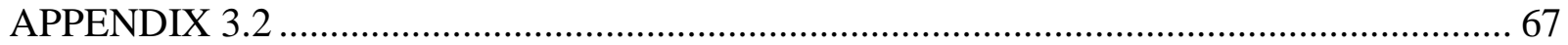

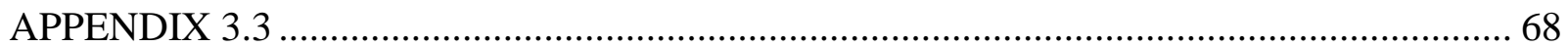

Chapter 4: Interpreting genetic bottlenecks: The utility of examining multiple closely related

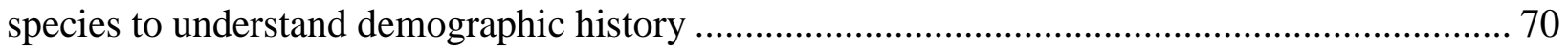

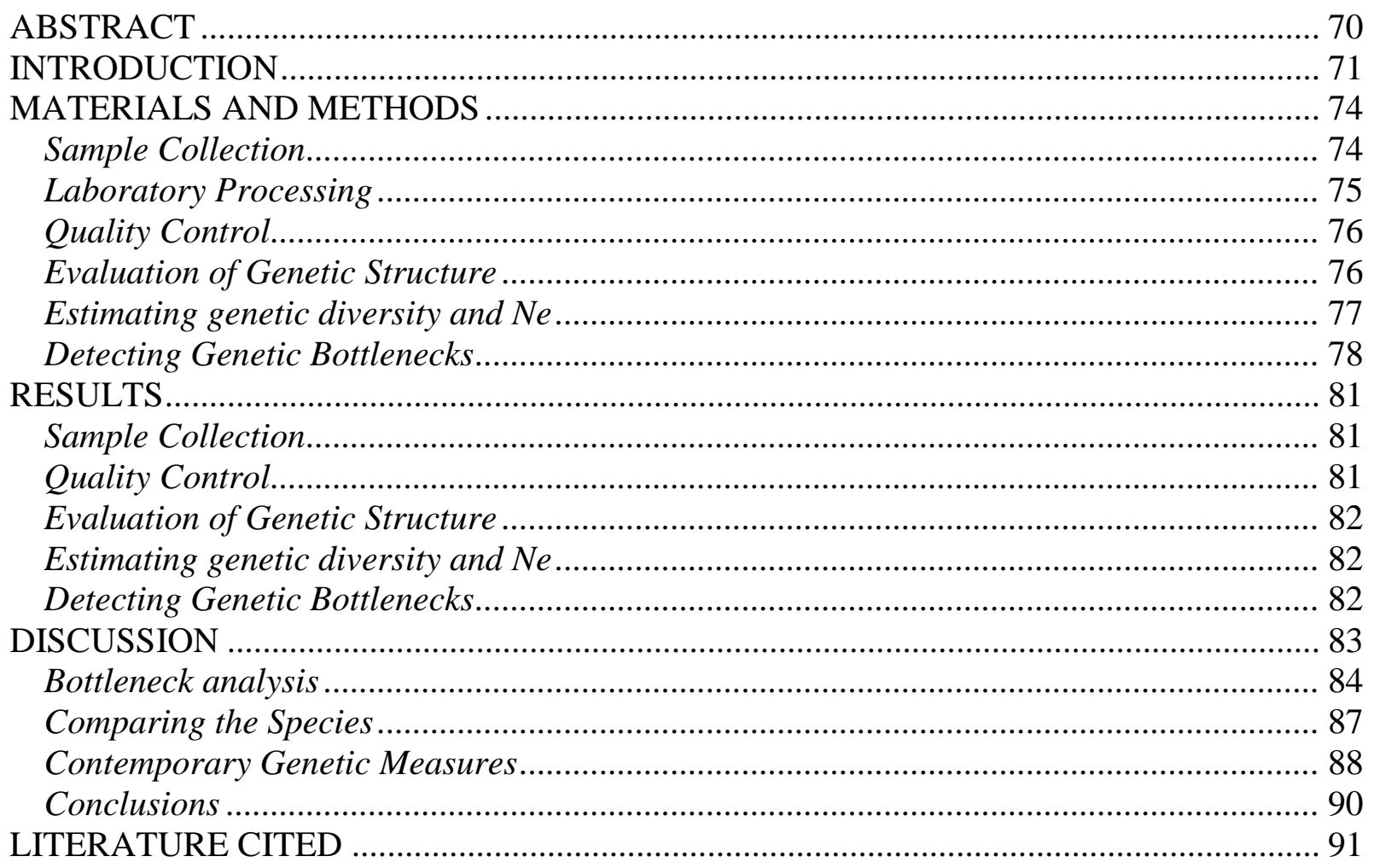

Chapter 5: Effectiveness of commercial RNA stabilization reagents when preserving avian blood for downstream RNA-seq analysis ................................................................................... 102 


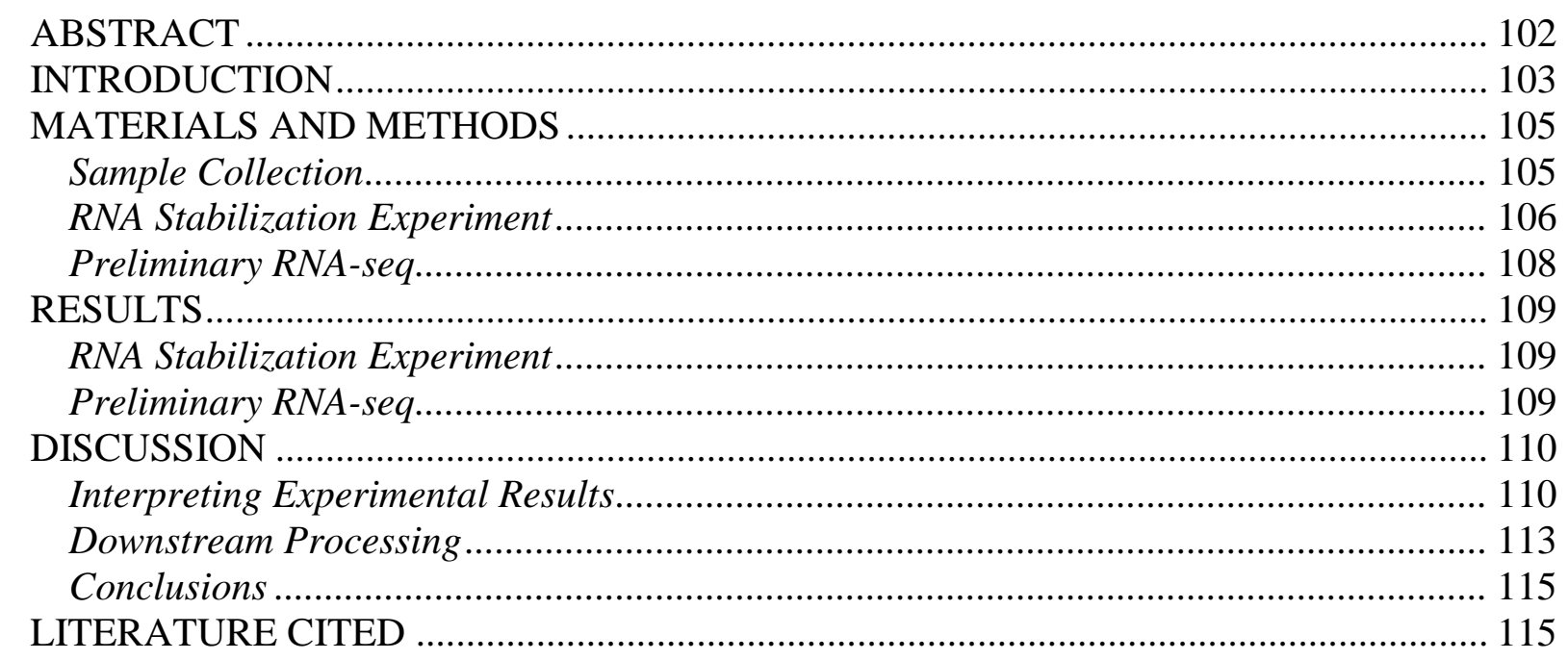

Chapter 6: Urbanization, gene expression, and acclimation: A case study of a recent urban exploiter ................................................................................................................ 122

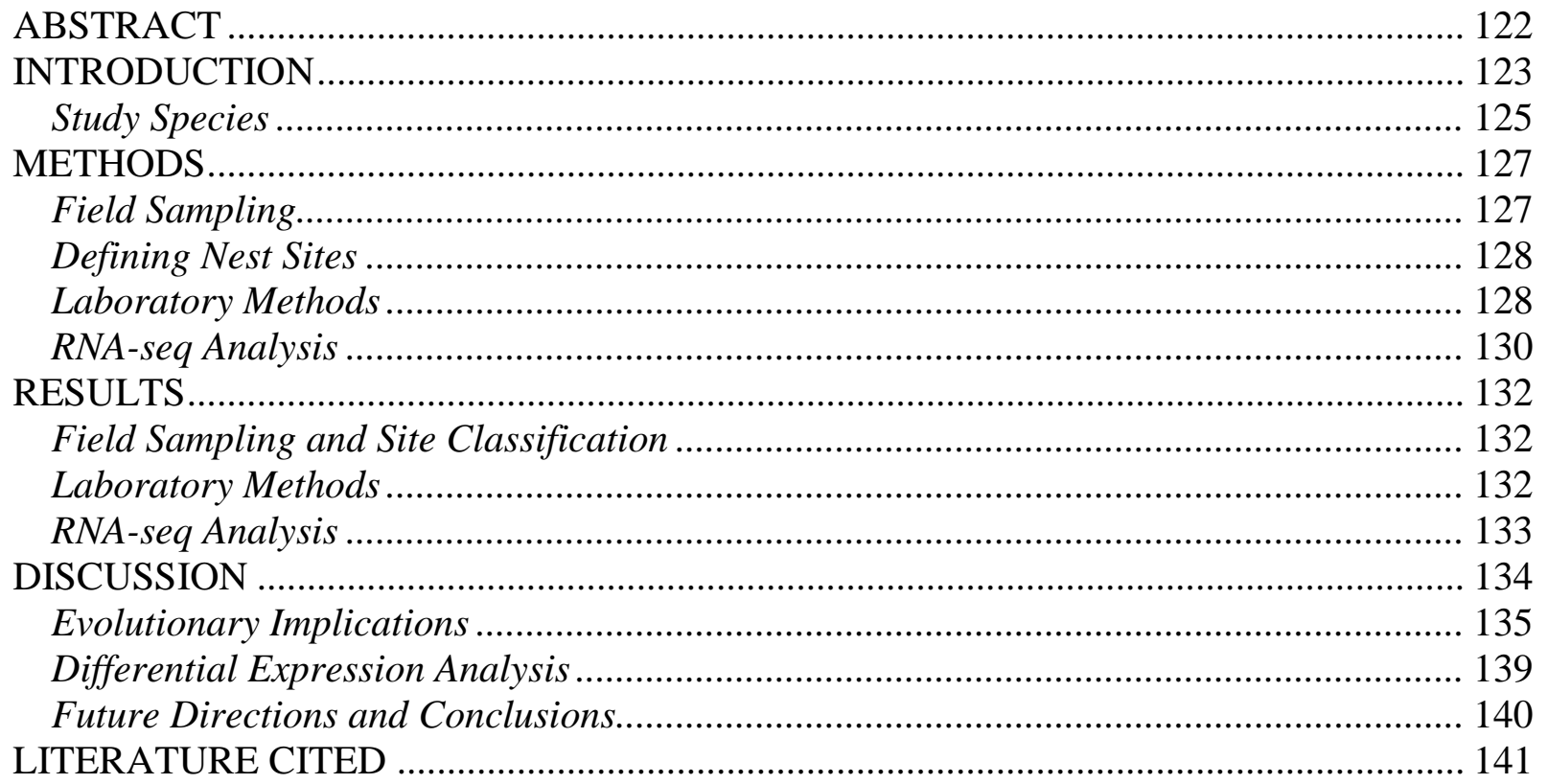




\section{List of Tables}

Table 2.1: List of environmental variable layers, their associated code in a MaxEnt model, their source, year of publication, and internet URL. Each layer was used in a MaxEnt model to determine potential northern goshawk nesting habitat in New York State. Two layers (heat load index and aspect) were created in ArcMap from the elevation layer, so these layers do not have a URL 33

Table 2.2: Percent contribution of all environmental layers to the MaxEnt model used for northern goshawk nest distribution modeling in New York State.

Table 2.3: Description of each forest parcel surveyed for goshawks during the 2016 breeding season. Locations were chosen based on the MaxEnt model results.

Table 3.1: Territory and individual capture rates for six species of raptors using mechanical or live owl lures. All mechanical owl capture rates come from my new design with head and wing movement. Location includes states in the USA where trapping attempts occurred with the mechanical lure owl. Live lure owl data are from previous studies with locations of trapping efforts shown in parentheses. Species include Cooper's hawk (COHA), ferruginous hawk (FEHA), merlin (MERL), northern goshawk (NOGO), red-shouldered hawk (RSHA), and sharpshinned hawk (SSHA). Individual capture rates were not reported in most published studies. ... 60

Table 3.2: Individual capture rates of my mechanical owl compared to those from previous mechanical owl datasets. Species include red-shouldered hawks (RSHA), Cooper's hawks (COHA), and sharp-shinned hawks (SSHA). Previous mechanical owl design included head and full body swiveling movement and this design was used both on the ground and in an elevated trap set. My owl included both head and wing movement and was only using with a trap set on the ground. 1 = Jacobs, 1996, Wisconsin, USA, 2 = Jacobs and Proudfoot, 2002, Wisconsin, USA

Table 3.3: Akaike's Information Criterion (AIC), the change in AIC ( $\Delta$ AIC), and model weight results for time to capture of northern goshawks based on owl type (mechanical vs. live), capture history (first capture vs. recapture), and order caught (first of the day vs. second of the day at a

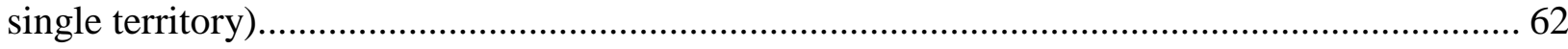

Table 3.4: Initial and annual cost estimates for a mechanical versus a live lure owl................. 63

Table 4.1: Inbreeding coefficient ( $\left.\mathrm{F}_{\mathrm{IS}}\right)$, observed heterozygosity $\left(\mathrm{H}_{\mathrm{o}}\right)$, expected heterozygosity $\left(\mathrm{H}_{\mathrm{e}}\right)$, allelic richness, and rarified allelic richness across all loci for northern goshawk (NOGO, $\mathrm{n}$ $=98$ ) and Cooper's hawk (COHA, $\mathrm{n}=192)$ populations in the northeastern United States. Markers without values were dropped from the analysis because they deviated from HardyWeinberg Equilibrium as a result of null alleles or scoring errors. 96

Table 4.2: Effective population size $\left(\mathrm{N}_{\mathrm{e}}\right)$ estimates for northern goshawk (NOGO) and Cooper's hawk (COHA) populations in the northeastern United States. Three different methods were used to estimate $\mathrm{N}_{\mathrm{e}}$ : heterozygote-excess (Zhdanova and Pudovkin, 2008), linkage disequilibrium 
(Waples and Do, 2008), and molecular coancestry (Nomura, 2008). Values in parentheses are estimated ranges based on $95 \%$ confidence intervals.

Table 4.3: Results of statistical tests (p-values) for heterozygosity excess from Wilcoxon signedrank tests on northern goshawk (NOGO) and Cooper's hawk (COHA) genetic datasets in program Bottleneck (Cornuet and Luikart 1996). Tests were run assuming the two-phase mutation model $(\mathrm{TPM})$. Var = in the geographic distribution of the TPM, $\mathrm{pg}_{\mathrm{g}}=$ proportion of mutations that are not one-step and $*$ denotes a significant p-value when $\alpha=0.05$..... 98

Table 4.4: Results from $\mathrm{M}$ ratio tests for genetic bottlenecks in the northern goshawk (NOGO) and Cooper's hawk (COHA) populations in the northeastern United States. Tests were run using various parameters estimated from published literature $\left(\mu=\right.$ mutation rate, $\Delta_{\mathrm{g}}=$ average size of a mutation that is larger than one-step, $\mathrm{p}_{\mathrm{g}}=$ proportion of mutations that are larger than one-step). Average $M$ is the mean ratio of number of alleles $(k)$ to the allele size range $(r)$, while $M_{c}$ is the critical $M$ value (95\% of values will fall above this threshold). Tests indicating a genetic bottleneck (where $\mathrm{M}_{\mathrm{c}}$ was higher than the average $\mathrm{M}$ ) for the empirical datasets are shown in bold and italic. Relaxed $\theta$ values were calculated using average $\mathrm{N}_{\mathrm{e}}$ values $(\mathrm{NOGO}=250, \mathrm{COHA}$ $=1750$ ), while conservative $\theta$ was calculated using high $\mathrm{N}_{\mathrm{e}}$ estimates ( $\mathrm{NOGO}=600, \mathrm{COHA}=$ 13,000).

Table 5.1: Sample and treatment parameters and information on extracted RNA for nucleated avian blood treated with two different RNA stabilization buffers. Quotation (") indicates that treatments were identical to the previous row (i.e. they are replicates). Red-tailed hawk (RTHA) samples were collected from captive birds at an avian conservation center in Morgantown, WV while Cooper's hawk (COHA) samples were collected in the field in Albuquerque, NM during the summer of 2014 or 2015. The modified protocol is that from Chiari and Galtier (2011) .... 118

Table 5.2: RNA integrity number (RIN), RNA quantity (ng/ $\mu \mathrm{L})$, and 260/280 ratio for 16 RNA samples collected from Cooper's hawks in Albuquerque, NM during July 2015. Data on total number of reads, number of uniquely aligned reads, number of reads that aligned multiple times, and the overall alignment percentage from the Illumina MiSeq run are also included for all samples. All 16 samples were preserved in RNAlater, frozen between 2-8 h of collection and extracted using the manufacturer's protocol for the Ambion RiboPure Blood Kit. COHA samples collected in 2014 into RNAprotect are not shown because all samples produced degraded, unusable RNA.

Table 5.3: Sensitivity and precision of Cooper's hawk RNA-seq reads when mapping to the golden eagle reference genome at six different genomic levels. Samples were collected in RNAlater in Albuquerque, NM during the summer of 2015. RNA was extracted and sequenced on the Illumina MiSeq then mapped to the golden eagle reference genome using HISAT2 and evaluated for sensitivity and precision using gffcompare.

Table 6.1: Average, median, and majority percent imperviousness values for Cooper's hawk nest territories in the Albuquerque, New Mexico area. Based on telemetry data, average nest territories are approximately $385 \mathrm{~m}$ apart (Millsap, unpublished data). Territories were established by making a 385 buffer around sampled nests in ArcMap 10.3.1 (ESRI, 2011). 
Values were extracted using the zonal statistics as table tool from an imperviousness environmental layer (NLCD, 2011).

Table 6.2: Information on Cooper's hawks sampled during the breeding season in 2015 in the Albuquerque, New Mexico area. Age, sex ( $\mathrm{F}=$ female, $\mathrm{M}=$ male), nest number (see Figure 6.1), RNA integrity number (RIN) from extracts (N/A = RIN value could not be detected by bioanalyzer $)$, and PCR results from Trichomonas screening $((+)=$ positive or $(-)=$ negative; protocol from Ecco et al. 2012) are included for each sample. One sample, E15, is not included due to bacterial contamination of RNA revealed by the quality analysis and subsequent removal from all further analyses.

Table 6.3: Total reads, aligned reads, and total percent (\%) alignment from RNA-seq on Cooper's hawk blood samples collected from Albuquerque, NM in 2015. For adult samples, the data from the Illumina HiSeq run are reported in addition to the data combining technical replicates from both a HiSeq and MiSeq run. Fledgling samples were only sequenced on the HiSeq platform

Table 6.4: Significant differentially expressed (DE) transcripts between urban and exurban fledgling and adult Cooper's hawks sampled in Albuquerque, NM, USA during the breeding season of 2015. Transcript names, fold change (Fc), p-values (pval), q-values (qval), and average fragments per kilobase per million reads (FPKM) are from Ballgown output after DE analysis. Fc values under 1 were more abundant in exurban environments, while more abundant transcripts in urban environments have Fc values greater than 1. The best match and species from a search using the Basic Local Alignment Search Tool (BLAST) for each transcript are reported. The best match was determined using the highest identity and e-values $\leq 10^{-5}$. Gene ontology terms are reported based on searches for the gene identified from the BLAST search and include molecular function (MF), biological processes (BP), or cellular components (CC). In addition, some common functions for each gene are listed based on information in Gene Ontology databases (e.g. Ensembl, GO_Central, and UniProt) and/or current literature.... 


\section{List of Figures}

Figure 2.1: Northern goshawk nest areas in New York State. In total, 109 known nest sites are included in these areas and each nest was occupied for at least one year between 2004 to 2015 . Exact locations were purposefully excluded due to the sensitive nature of this species. 36

Figure 2.2: Percent suitability results for the northern goshawk habitat suitability in New York State based on our MaxEnt model. We surveyed 16 sites for goshawk presence during the 2016 breeding season to test model results: eight of these were in the north (A), five in the central part of the state (B), and three in the south (C). Exact survey locations were purposefully excluded due to the sensitive nature of this species.

Figure 2.3: Output for the northern goshawks nest distribution MaxEnt model in New York State (A) Sensitivity and specificity for the training data, test data, and random model prediction AUC values. Since the test data AUC (blue line) is well above the random prediction line (black), this suggests this model is better than a random model. (B) Predicted, training, and test sample omissions. Since the test sample omission line (teal) is above the predicted omission line (black), this suggests the data layers are not spatially autocorrelated..... 38

Figure 2.4: Jackknife statistical testing of environmental predictor variables used in MaxEnt model of northern goshawk nest distribution in New York State. Graph shows model training gain for all variables, for each predictor variable alone, and for the model in the absence of each predictor variable. Note 'aspectclip' = aspect, 'hydrodistclip' = distance to water, 'nyelevclip' = elevation, 'nyhli' = heat load index, 'nysbawhclip' = basal area-weighted height, and 'nyslulc11' $=$ land cover.

Figure 3.1: Three-dimensional scan of my first prototype of the new mechanical owl design (right) with CAD model overlay on 3D scan illustrating foam body insert, hardware, and mechanical components and their location (left).

Figure 3.2: (A) Expected time to capture, in min., of northern goshawks using a live versus a mechanical lure owl. (B) Expected time to capture, in min., of the first and second goshawk captured at a single nest territory on the same day. Error bars represent $95 \%$ confidence intervals.

Figure 4.1: Sample collection locations for 98 northern goshawks in the northeastern United States during $2000-2017$.

Figure 4.2: Sample collection locations for Cooper's hawks in the northeastern United States. Total $\mathrm{n}=192$ and sampling years ranged from $2000-2017$.

Figure 5.1: Example graphical results from six BioAnalyzer reads. A = red-tailed hawk (RTHA) sample stored in RNAprotect ${ }^{\circledR}$ and never frozen (the only highly degraded sample depicted), B $=$ RTHA sample stored in RNAprotect ${ }^{\circledR}$ and never frozen, $\mathrm{C}=$ Cooper's hawk (COHA) sample stored in RNAlater ${ }^{\circledR}$ and frozen within 2-8 h (also used for Illumina MiSeq run, sample \#1) $\mathrm{D}=$ COHA sample stored in RNAlater® and frozen in 2-8 h (also used for Illumina MiSeq run, 
sample \#2) E = RTHA sample stored in RNAlater ${ }^{\circledR}$ and never frozen, F = RTHA samples stored

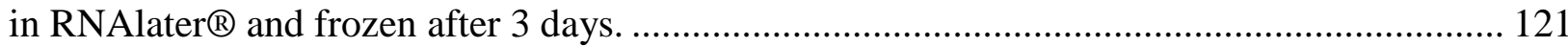

Figure 6.1: Nest locations of Cooper's hawks sampled in the greater Albuquerque, New Mexico area, USA. The basemap represents the percent imperviousness across the landscape (NLCD 2011). Nest territories (385m buffer around nest) were classified as either urban or exurban. In urban nest areas, the majority of cells had a positive percent imperviousness value, while exurban nests had a value of zero in the majority of cells. Nest numbers correspond to Table 6.1. 


\section{Chapter 1: Introduction}

Integrating human elements into ecological research is paramount (Alberti et al. 2003) because of the drastic impact humans have on the environment. Wildlife species around the globe are constantly challenged with environmental changes in an anthropogenically-driven world (Hunter, 2007). It is also becoming clear that there is a range of tolerance to humans and human activities among different species (Hunter, 2007, also see Harris et al., 2013). Understanding why certain species and individuals are able to adapt to anthropogenic disturbances while others succumb to these stressors is a pressing question in modern ecological research.

Due to the realized and potential impacts to biodiversity of the growing human population (Hunter, 2007), it is essential to develop models to better understand the differential response of wildlife species to humans. In North America, forest raptors of the genus Accipiter have the potential to be a good model for understanding how wild species adapt to humans and urbanization. This is because these species have been directly affected by anthropogenic activities, yet appear to have responded to human disturbance in different ways.

The three species in the genus Accipiter native to North America are the northern goshawk (Accipiter gentilis), the Cooper's hawk (A. cooperii), and the sharp-shinned hawk (A. striatus). Accipiters are a relatively widespread group of hawks that feed primarily on birds and mammals and two of these species have a continental distribution, while the third (the goshawk) is Holarctic in distribution. Like many other bird species, Accipiters experienced dramatic population declines during the mid-1900's, especially in the eastern United States (Farmer et al. 2008). Hawk migration count data show evidence of strong population declines of Cooper's hawks and sharp-shinned hawks, specifically in the northeast from the 1940's to 1970 (Snyder et al., 1973, Bednarz et al. 1990; Farmer et al. 2008). These declines were likely a result of multiple 
anthropogenic factors including direct persecution, habitat destruction, and the use of organochloride pesticides (Bildstein, 2001; Bildstein, 2008; Snyder et al. 1973).

Accipiters are a good model for understanding how anthropogenic processes have impacted wildlife because their populations have been heavily influenced by human activities. It is the goal of this research to understand how Accipiters are distributed in the highly disturbed eastern North American ecosystems, how their unique demographic histories have influenced their current population structure and genetic diversity, and to compare gene expression of Accipiters in heavily impacted (urban) settings with those in less impacted (exurban) settings. This dissertation has chapters describing each of these goals and also chapters describing the techniques I developed to aid my studies.

\section{Accipiter life history and conservation ecology}

Throughout the $18^{\text {th }}$ and $19^{\text {th }}$ centuries, raptors were considered vermin and they were not only unprotected, but many state game departments promoted and actively killed birds of prey (Bildstein, 2001; Bildstein, 2008). In the early-to-mid 1900's, some species were afforded legal protection but Accipiters were still considered "bad" hawks and blamed for killing poultry and game birds (Bildstein, 2008). As a result, Accipiters were actively targeted and in some cases, states even offered bounties for each bird killed. For example, up until 1951 in Pennsylvania, northern goshawks were worth $\$ 5$ each. The unfavorable reputation of these birds in conjunction with bounties led to significant increases in mortality rates (see Bildstein, 2008), which contributed to declines in population size.

Habitat loss was likely another major driver of historic Accipiter population declines. It is estimated that by 1920, deforestation associated with agricultural and lumbering practices 
reduced the original forest in the eastern United States to less than $10 \%$ of what originally comprised the landscape at first settlement by Europeans (Williams 1989). Deforestation made nesting habitat scarce for forest-reliant species, such as Accipiters. This loss of habitat was particularly problematic in conjunction with human persecution, which made human-populated areas unsafe for nesting (Bildstein, 2008).

The use of second-generation organochloride pesticides, especially dichlorodiphenyltrichloroethane (DDT), may have also contributed to population declines of Accipiters (Bildstein, 2008). DDT bioaccumulates in both aquatic and terrestrial food webs and therefore can be detrimental for high trophic-level predators (Gray, 2002). DDE (a metabolite of DDT) weakens the eggshells of raptors and this results in unsuccessful reproduction (Peakall, 1993). DDT is especially well known because spraying of this pesticide led to the major declines of the bald eagle (Haliaeetus leucocephalus) and the peregrine falcon (Falco peregrinus) (Ratcliffe, 1980; Grier, 1982). Other avian predators, such as Accipiters, were potentially affected by DDT, especially in the eastern United States. In fact, in one study, researchers found DDE levels were 20 times higher in eastern Cooper's hawk eggs compared to western Cooper's hawk eggs (Snyder et al., 1973). Similarly, DDE levels were found in higher concentrations in the tissues of eastern sharp-shinned hawks when compared to samples from the midwestern United States (Wood et al. 1996). However, to date, there is little research on the effects of DDT on raptors other than the bald eagle and peregrine falcon.

The conservation status of Accipiters has changed in recent years. These birds, as well as other raptors, were relieved from persecution-associated pressures because shooting raptors became less socially acceptable. This was, in part, because of the initiation of protection of these species with their addition to the Migratory Bird Treaty Act in 1972 (Bildstein, 2008). Also, 
since the early 1900's, agricultural abandonment, fire suppression, and reduced timber harvest rates have led to an increase in forest cover across the United States, especially in the east (Houghton and Lawrence, 1999; USDA, 2012). In general, the amount of forest cover in the United States has remained relatively consistent since the early 1970's (Capersen et al., 2000). In addition, DDT was banned from use in the United States in 1972. Because of these changes in human activity, Accipiter populations have had an opportunity to recover.

Each of the three North American Accipiter species have rebounded differently since the human-driven population declines in the 1900's. As of 2004, counts of Cooper's hawks had significantly increased at seven hawk migration count sites in the northeastern United States (Farmer et al., 2008). In contrast, sharp-shinned hawk counts increased in the late 1970's but negative trends began at count sites in the 1980's and continued into the 1990's (Farmer et al., 2008). Since the late 1970 's, counts of northern goshawks showed increasing trends in the Great Lakes region but trends were steady or negative at count sites further east (Farmer et al., 2008). Assuming these migration counts provide accurate representations of demographic trends, I would expect to see evidence of historic or current differences in genetic composition for each of the three species.

Even more interesting, the Accipiters have responded to and exploited urbanization in varying degrees. Traditionally, Accipiters were associated with intact forest habitats and all three were considered highly sensitive to human disturbance (Hennessy, 1978; Reynolds, 1983). More recently, however, Cooper's hawks and sharp-shinned hawks appear to have benefitted from life in densely population urban areas. Cooper's hawks, especially, have thrived in urban environments during the breeding season. Urban-breeding Cooper's hawks nest earlier, have larger clutches, deliver twice as much prey biomass to young, and have higher nesting success 
rates compared to rural-nesting pairs (Rosenfield et al., 1996; Boal and Mannan, 1999, Estes and Mannan, 2003).

While sharp-shinned hawks do not nest in quite as high densities in urban centers as Cooper's hawks, they are still commonly found nesting and wintering in urban environments (Powers, 1996, Coleman et al. 2002). Dunn and Tessaglia (1994) suggest that the success of the Cooper's hawk and sharp-shinned hawk in urban environments may be in part a result of the ability of individuals to exploit backyard bird feeders. Northern goshawks, on the other hand, still avoid urban habitats and in the United States, there are no known urban populations of this species (Bosakowski and Smith, 1997; Chace and Walsh, 2006). To date, northern goshawks remain the most elusive of the Accipiters, and habitat modeling is often used to better understand the distribution of this species (Reich et al. 2003, Miller et al. 2013).

\section{Conservation Genetics, Genomics, and Accipiters}

Genetic and genomic technologies provide a unique opportunity to understand how species respond to changes in the environment. As a result, conservation genetic and genomic studies are often used to understand how anthropogenic activities affect wild populations (e.g., habitat fragmentation, Keller and Largiader, 2014; introgression, Martinez et al., 2001; species invasions, Dlugosch and Parker, 2008). Accipiters provide a great model for understanding the responses of avian predators to human disturbance and urbanization because 1) there are three native species that are genetically and ecologically similar, 2) all three have experienced population declines as a result of human activities and each species has rebounded differently since the declines, and 3) the three species currently exhibit a different level of tolerance to humans and urbanization. 
It is important to study similar species to understand how genetic and molecular changes occur in natural populations (Simpson, 2002). The similar natural histories and ecological roles of the closely-related Accipiters can act as a control when examining the genetic consequences of the differential recovery of each species. In addition, studies of closely-related species on a short evolutionary timescale can be used to identify important phenotypic differences that may be correlated with various environmental stimuli (Simpson, 2002).

Major population declines, such as those seen in Accipiters, can have long-term genetic consequences as a result of genetic bottlenecks, which create a significant loss of genetic diversity within a population (Hamilton, 2009). This loss of genetic diversity can make it difficult for species to adapt to future changes in the environment (Hamilton, 2009). Understanding the genetic effects of historic declines of Accipiters may prove to be a good model for understanding genetic consequences of population fluctuation given that the three Accipiter species rebounded differently from observed declines. By investigating the contemporary genetic composition of these species, I can gain insights into how the declines affected each species and further how the unique recovery patterns have influenced genetic structuring and diversity. This research will add to the current knowledge on conservation genetic theory and its application to wild populations. In addition, understanding the current genetic status for each species can be useful for creating optimal management strategies for Accipiters in North America.

Microsatellites are a useful tool for exploring the genetic composition of wildlife populations. In the past few decades, microsatellites have become one of the most popular genetic markers for ecological studies (Selkoe and Toonen 2006). These markers consist of short tandem repeats (typically 1-6 base pairs) that are found throughout the genome of most species, 
and they mutate relatively rapidly providing high levels of variability for genetic studies (Selkoe and Toonen 2006). Due to their popularity, there is extensive knowledge about their function, distribution, and evolution across various taxa (Li et al. 2002; Ellegren 2004). Microsatellite primers have already been developed for numerous species, including the northern goshawk (Topinka and May 2004; Haughey et al. 2016). These markers are useful for assessing relatedness of individuals, estimating migration rates, determining fine-scale population differentiation, and investigating genetic bottlenecks (Selkoe and Toonen 2006; DeFaveri et al. 2013). In recent years, these methods have become highly cost effective and therefore, it is possible to analyze numerous individuals at multiple loci with minimal financial investment (Selkoe and Toonen 2006; DeFaveri et al. 2013).

Urbanization is increasing on a global scale and it is one of the most important emerging phenomena for contemporary ecological research (Alberti et al. 2003). There is a range of tolerance exhibited by wildlife to urban areas (Hunter, 2007). Cooper's hawks have successfully exploited urban environments, and this has led to observable phenotypic differences in urban versus exurban populations (Mannan and Boal 2000, Estes and Mannan 2003, Rosenfield et al. 1996, Boal and Mannan 1998). These changes are likely due to the novel environmental changes that accompany living in close proximity to humans.

Since Cooper's hawks colonized urban areas relatively recently, it is likely that gene expression is responsible for the phenotypic changes seen in these animals. Recent advances in transcriptomic technologies have allowed researchers to understand differences in gene expression patterns of populations exposed to different environments (see Hansen et al. 2006, Kohno et al. 2008, Harris et al. 2013). RNA-seq is a powerful tool for researching genome-wide gene expression. Traditional gene expression studies involved the use of hybridization-based 
microarrays; however, these types of methods require extensive effort to develop and therefore, are not available for many non-model organisms. In addition, microarrays only provide information on a limited amount of RNA molecules that could be present at any one time in an individual (Ozsolak and Milos 2011). RNA-seq, on the other hand, uses deep-sequencing technologies to profile the entire transcriptome, including precise measurements of transcripts and their isoforms (Wang et al. 2009). The basic concept behind this technique is that transcripts expressed in higher quantities are advantageous for an organism to function in its current environment. By comparing the relative number of each transcript in a species in two different environments (e.g. urban or exurban), it is possible to gain insights into which and how many genes differ in expression between the two groups. In addition, because transcripts are fully sequenced, the identity of each transcript can be investigated to provide a better understanding of their function and how they relate to a given environment.

While RNA-seq is a useful tool, it is a relatively novel methodology with some drawbacks that have not yet been resolved. First, it is an expensive technique and therefore, most studies using this methodology have relatively small sample sizes (Liu et al. 2014). In addition, RNA-sequencing generates a large amount of data and creates numerous informatic challenges including storage and processing of data and difficulty in dealing with errors (Wang et al. 2009). Finally, this method is subject to amplification biases that result in non-uniformity of transcriptome coverage (Levin et al. 2010; Ozsolak and Milos 2011). Thus, data should be interpreted carefully since these biases can result in a loss of data and Type I errors if analysis is not stringent enough.

Despite potential challenges, novel transcriptomic tools such as RNA-seq can be used to obtain useful information regarding gene expression patterns of species in various environments. 
Cooper's hawks, which have recently expanded into urban environments, may exhibit differential gene expression in urban and exurban environments. This research can provide insights into the selection processes responsible for organisms adapting to urbanization and highlight genes that may be important for urban wildlife in human-dominated environments.

\section{Research Objectives}

The goal of this research is to use conservation genetics and genomics to understand how anthropogenic processes have influenced the recovery, conservation biology, and ecology of highly mobile avian predator species. Given the unique history of Accipiter hawks in North America, I explored the genetic consequences of the largely human-driven population declines of Accipiters in the northeastern United States. In addition, I incorporated cutting-edge genomic (transcriptomic) technologies to begin to understand how one Accipiter species, the Cooper's hawk, is responding to life in densely populated urban environments. I also used spatial analysis to assist in locating suitable habitat for the most elusive of the Accipiter species, the northern goshawk. Finally, as part of my work, I developed two sets of tools, one field-based and one laboratory-based, that helped me carry out my work. These research objectives and tools are the subject of the subsequent five chapters of my dissertation.

The research objectives of this study were to:

1) Improve our ability to detect the most secretive and elusive Accipiter, the northern goshawk, using GIS technology to model suitable nesting habitat of this species (Chapter 2). 
2) Assess the current genetic diversity and population structure of North American Accipiters in the northeastern United States, and determine if there is evidence of genetic bottlenecks from historic population declines (Chapter 4).

3) Compare gene expression of urban and exurban nesting Cooper's hawks to better understand what genes are important for living in a human-dominated habitat (Chapter 6).

The tools I developed in support of this work were:

1) A new mechanical owl to increase success rates of capturing nesting raptors to maximize sample sizes for genetic research (Chapter 3).

2) A test of currently available RNA preservation reagents on blood collected from nesting raptors for the study of gene expression in wild avian populations (Chapter 5).

\section{Literature Cited}

Alberti, M., J.M. Marzluff, E. Shulenberger, G. Bradley, C. Ryan, and C. Zumbrunnen. 2003. Integrating humans into ecology: Opportunities and challenges for studying urban ecosystems. BioScience 53: 1169-1179.

Bednarz, J.C., D. Klem, Jr., L.J. Goodrich, and S.E. Senner. 1990. Migration counts of raptors at Hawk Mountain, Pennsylvania, as indicators of population trends, 1934-1986. Auk 107: 96-109.

Bildstein, K.L. 2001. Raptors as vermin: a history of human attitudes towards Pennsylvania's birds of prey. Endangered Species Update 18: 124-128.

Bildstein, K.L. 2008. A Brief History of Raptor Conservation in North America. Pp. 5-36 in K.L. Bildstein, J.P. Smith, E. Ruelas I., and R.R. Veit (eds). State of North America's Birds of Prey. Nuttall Ornithological Club and American Ornithologists. Union Series in Ornithology No. 3 Cambridge, Massachusetts and Washington, D.C.

Boal, C.W. and R.W. Mannan. 1998. Nest-site selection by Cooper's hawks in an urban environment. Journal of Wildlife Management 62: 864-871. 
Boal, C.W., and R.W. Mannan. 1999. Comparative breeding ecology of Cooper's hawks in urban and exurban areas of southeastern Arizona. Journal of Wildlife Management 63: $77-84$.

Bosakowski, T., and D.G. Smith. 1997. Distribution and species richness of a forest raptor community in relation to urbanization. Journal of Raptor Research 31: 26-33.

Caspersen, J.P., S.W. Pacala, J.C. Jenkins, G.C. Hurtt, P.R. Moorcroft, ad R.A. Birdsey. 2000. Contributions of land-use history to carbon accumulation in U.S. forests. Science 290: 1148-1151.

Chace, J.F., and J.J. Walsh. 2006. Urban effects on native avifauna: A review. Landscape and Urban Planning 74: 46-69.

Coleman, J.L., D.M. Bird, and E.A. Jacobs. 2002. Habitat use and productivity of sharp-shinned hawks nesting in an urban area. Wilson Bulletin 114: 467-473.

DeFaveri, J., H. Viitaniemi, E. Leder, and J. Merilä. 2013. Characterizing genic and non-genic molecular markers: comparison of microsatellites and SNPs. Molecular Ecology Resources: 377-392.

Dlugosch, K.M., and I.M. Parker. 20008. Founding events in species invasions: genetic variation, adaptive evolution, and the role of multiple introductions. Molecular Ecology 17: 431-449.

Dunn, E.H., and D.L. Tessaglia. 1994. Predation of birds at feeders in winter. Journal of Field Ornithology 65: 8-16.

Ellegren, H. 2004. Microsatellites: simple sequences with complex evolution. Nature Reviews Genetics 5: 435-445.

Estes, W.A., and R.W. Mannan. 2003. Feeding behaviors of Cooper's hawks at urban and rural nests in southeastern Arizona. The Condor 105: 107-116.

Farmer, C.J., J.P. Smith, S.H. Hoffman, G.S. Kaltenecker, K.Z. Woodruff, and P.J. Sherrington. 2008. Trends in autumn counts of migratory raptors in western North America. Pp. 217251 in K.L. Bildstein, J.P. Smith, E. Ruelas Inzunza, and R.R. Veit (eds.), State of North America's birds of prey. Nuttall Ornithological Club and American Ornithologists' Union, Cambridge, MA and Washington, D.C.

Gray, J.S. 2002. Biomagnification in marine systems: the perspective of an ecologist. Marine Pollution Bulletin 45: 46-52.

Grier, J.W. 1982. Ban of DDT and subsequent recovery of reproduction in bald eagles. Science 218: $1232-1235$.

Hamilton, M.B (ed). 2009. Population Genetics. Wiley-Blackwell, Chichester, West Sussex, UK.

Harris, E., J. Munshi-South, C. Obergfell, and R. O’Neill. 2013. Signatures of rapid evolution in urban and rural transcriptomes of white-footed mice (Peromyscus leucopus) in the New York metropolitan area. PLoS ONE 8: e74938. 
Hansen, B.H., S. Romma, O.A. Garmo, P.A. Olsvik, and R.A. Andersen. Antioxidative stress proteins and their gene expression in brown trout (Salmo trutta) from three rivers with different heavy metal levels. Comparative Biochemistry and Physiology Part C 143: 263274.

Haughey, C., G.K. Sage, G. Gegange, S.A. Sonsthagen, S. Talbot. 2016. Development of novel microsatellite markers for the northern goshawk (Accipiter gentilis) and their utility in cross-species amplification. Avian Biology Research 9: 195-199.

Hennessy, S.P. 1978. Ecological relationships of accipiters in northern Utah-with special emphasis on the effects of human disturbance. M.S. thesis, Utah State University, Logan, UT.

Houghton, R.A., J.L. Hackler, and K.T. Lawrence. 1999. The U.S. carbon budget: Contributions from land-use change. Science 285: 574-578.

Hunter, P. 2007. The human impact on biological diversity. European Molecular Biology Organization Reports 8: 316-318.

Keller, I., and C.R. Largiader. 2003. Recent habitat fragmentation caused by major roads leads to reduction in gene flow and loss of genetic variability in ground beetles. Proceedings of the Royal Society 270: 417-423.

Kohno, S., D.S. Bermudez, Y. Katsu, T. Iguchi, and L.J. Guillette Jr. 2008. Gene expression patterns in juvenile American alligators (Alligator mississippiensis) exposed to environmental contaminants. Aquatic Toxicology 88: 95-101.

Levin, J.Z., M. Yassour, X. Adiconis, C. Nusbaum, D.A. Thompson, N. Friedman, A. Gnirke, and A. Regev. 2010. Comprehensive comparative analysis of strand-specific RNA sequencing methods. Nature Methods 7: 709-715.

Li, Y.C., A.B. Korol, T. Fahima, A. Beiles, and E. Nevo. 2002. Microsatellites: genomic distribution, putative functions, and mutational mechanisms: a review. Molecular Ecology 11: 2453-2465.

Liu, Y., J. Zhou, and K.P. White. 2014. RNA-seq differential expression studies: more sequence of more replication? Bioinformatics 30: 301-304.

Mannan, R.W., and C.W. Boal. 2000. Home range characteristics of male Cooper's hawks in an urban environment. Wilson Bulletin 112: 21-27.

Martinez, J.L., J. Dumas, E. Beall, and E. Garcia-Vazquez. 2001. Assessing introgression of foreign strains in wild Atlantic salmon populations: variation in microsatellites assessed in historic scale collections. Freshwater Biology 46: 835-844.

Miller, R.A., J.D. Carlisle, M.J. Bechard, and D. Santini. 2013. Predicting nesting habitat of northern goshawks in mixed aspen-lodgepole pine forests in a high-elevation shrubsteppe dominated landscape. Open Journal of Ecology 3: 109-115.

Oswalt, S.N., and W.B. Smith. (Eds). 2014. U.S. Forest Resource Facts and Historical Trends. United States Department of Agriculture informational brochure. 
Ozsolak, F., and P.M. Milos. 2011. RNA sequencing: advances, challenges and opportunities. Nature Reviews Genetics 12: 87-98.

Peakall, D.B. 1993. DDE-induced eggshell thinning: an environmental detective story. Environmental Reviews 1: 13-20.

Powers, L.R. 1996. Wintering sharp-shinned hawks (Accipiter striatus) in an urban area of southwestern Idaho. Northwestern Naturalist 77: 9-13.

Ratcliffe, D.A. 1980. The Peregrine Falcon. T \& AD Poyser Ltd. London, UK.

Reich, R.M., S.M. Joy, and R.T. Reynolds. 2004. Predicting the location of northern goshawk nests: Modeling the spatial dependency between nest locations and forest structure. Ecological Modelling 176: 109-133.

Reynolds, R.T. 1983. Management of western coniferous forest habitat for nesting accipiters. General Technical Report RM-102. Forest Service, United States Department of Agriculture, Fort Collins, Colorado.

Rosenfield, R.N., J. Bielefeldt, J.L. Affeldt, and D.J. Beckmann. 1996. Urban nesting biology of Cooper's hawks in Wisconsin. In: Bird, D.M., D.E. Varian, and J.J. Negro (eds.), Raptors in Human Landscapes: Adaptation to Build and Cultivated Environments. Academic Press, New York, USA.

Selkoe, K.A., and R.J. Toonen. Microsatellites for ecologists: a practical guide to using and evaluating microsatellite markers. Ecology Letters 9: 615-629.

Simpson, P. 2002. Evolution of development in closely related species of flies and worms. Nature Reviews Genetics 3: 907-917.

Snyder, N.F.R, H.A. Snyder, J.L. Lincer, and R.T. Reynolds. 1973. Organochlorines, heavy metals, and the biology of North American accipiters. BioScience 23: 300-305.

Topinka J.R., and B. May. 2004. Development of polymorphic microsatellite loci in the northern goshawk (Accipiter gentilis) and cross-amplification in other raptor species. Conservation Genetics 5: 861-864.

Wang, Z., M. Gerstein, and M. Snyder. 2009. RNA-Seq: a revolutionary tool for transcriptomics. Nature Reviews Genetics 10: 57-63.

Williams, M. 1989. Americans and their forests: A historical Geography. Cambridge University Press, Cambridge, United Kingdom.

Wood, P.D., C. Viverette, L. Goodrich, M. Pokras, and C. Tibbott. 1996. Environemnetal contaminant levels in sharp-shinned hawks from the Eastern United States. Journal of Raptor Research 30: 136-144. 


\title{
Chapter 2: Northern goshawk nest site modeling in New York State using MaxEnt: Prediction and ground-truthing
}

\begin{abstract}
Species habitat modeling is an important tool in the current era of drastic human-driven environmental change. Habitat models are especially important for management and conservation of rare or sensitive species that may be affected by future landscape changes. I used Maximum Entropy, a presence-only modeling technique, to explore nesting habitat of an elusive avian predator in New York State. I used 109 known northern goshawk nest locations and publicly available environmental input layers of features identified in published literature on goshawk nesting habitat to develop the model. I then ground-truthed 16 locations identified as highly suitable by the model output. The MaxEnt model predicted goshawk nesting habitat with relatively high success $(\mathrm{AUC}=0.87$ ). The most important predictor variable in the model was land cover (67\% model contribution). Using the model output, I only located two previously unknown goshawk nest sites and multiple other large nests that were either unoccupied or used by other avian species. While the model may have overpredicted nesting habitat, it still provided valuable information about goshawk nest site selection in New York State. Also, ground-truthing efforts helped to highlight habitat features that would be helpful in future goshawk nest site models, such as more specific forest cover types and understory composition, should these data become available as environmental input layers.
\end{abstract}




\section{Introduction}

Species habitat modeling is an important application of Geographical Information System (GIS) technologies, especially in the current era of drastic environmental change, such as global climate change (Keith et al. 2008). These models are commonly used for assessing species distributions, estimating occupancy and abundance, determining habitat suitability, and even predicting the dispersion patterns of species facing abrupt land cover changes (Guisan and Zimmermann 2000, Store and Jokimäki 2003, Nielsen et al. 2010, Phillips 2017). The information gained is vital for improved management and conservation of many species. These models are particularly important for rare, sensitive, or specialist organisms that may be severely impacted by the rapidly changing environment.

Northern goshawks (Accipiter gentilis, hereafter "goshawks") are highly secretive, rare, avian predators that inhabit relatively large stands of mature forest (Hennessy 1978, Reynolds 1983, Mahon et al. 2008). In the last century, goshawks have experienced population declines throughout their range in the northern United States from a multitude of factors including persecution by humans, habitat loss, and fragmentation (Bildstein 2008). Population declines were especially pronounced in the eastern United States because of the landscape-scale timber harvesting that occurred throughout the 1800's as well as the ongoing expansion of urban areas (Bildstein 2008, Farmer et al. 2008). Many of the remaining populations in the east are small and goshawks are listed as a species of concern in several eastern states (NatureServe 2017). Further, climate change may have a drastic impact on this species in North America as a result of its intolerance to warmer climates (Kenward, 2010).

A potential stronghold for goshawks in the east lies in New York State. Approximately $63 \%$ of the state or about 7.6 million hectares is forested (Verschoor and Van Duyne 2012). The 
extensive, relatively unfragmented boreal forest of the Adirondack Park may be especially important since the goshawk is a northern-dwelling species that requires large expanses of forest for nesting (Wattel 1981, Reynolds 1992). However, despite the importance of this region for the eastern population, little is known about the nesting preferences of goshawks in New York.

Thus, I studied the utility of existing land cover datasets and topographic parameters to model suitable habitat for goshawks in New York State using Maximum Entropy methodology. The major goals of this work were to 1) determine the extent to which existing environmental maps can provide information on current northern goshawk nesting habitat preferences in New York State, 2) attempt to locate previously unknown areas suitable for northern goshawk nesting using the data that are currently available, and 3) identify alternate spatial data that could be used to improve future distribution models of this species in New York State.

\section{Methods}

\section{Species Habitat Associations}

I reviewed current literature to identify appropriate environmental layers to include in a habitat model for nesting northern goshawks. Given the highly sensitive nature and conservation status of goshawks, several studies have examined the habitat preferences of this highly elusive species to identify key areas necessary for its protection. Many of the studies on goshawk habitat were conducted in the western and mid-western United States. Multiple researchers identified late forest structure consisting of taller, larger, low-density trees to be important in goshawk nest areas (Squires and Ruggiero 1996, Daw and DeStefano 2001, Boal et al. 2005, Mahon et al. 2008). Nest sites also commonly had dense canopy cover and open or low understory composition (Squires and Ruggiero 1996, Daw and DeStefano 2001, Boal et al. 2005, Mahon et 
al. 2008, Miller et al. 2013). In general, goshawks prefer gradual or moderate slopes and aspect preference varies by study site (Squires and Ruggiero 1996, Mahon et al. 2008, Miller et al. 2013). For example, in Idaho, goshawks tended to nest on eastern-facing slopes while there was no aspect preference at nest sites in Wyoming (Squires and Ruggiero 1996, Miller et al. 2013). A preference for nests near water is sometimes seen in goshawk nest site selection (Reynolds et al. 1982). For example, in Oregon, nest sites were more strongly associated with nearby water, but water did not appear to be important for nest site selection in Idaho (Daw and DeStefano 2001, Miller et al. 2013).

Only a few studies have examined goshawk habitat preferences in the eastern United States. In northern New Jersey and southeastern New York, nest stands were predominantly in mixed forests with greater basal area, larger trees, and fewer saplings when compared to random sites (Speiser and Bosakowski 1987). In addition, nest sites were significantly further from human habitation, closer to swamps, and had more eastern hemlocks (Tsuga canadensis) and less oaks (Quercus spp.) (Speiser and Bosakowski 1987). These goshawks tended to avoid southern slopes and often nested near light duty roads or discernable trails (Speiser and Bosakowski 1987). A study in Pennsylvania found similar results with nest sites having greater basal area, higher canopy height, greater canopy cover, and less ground cover (Kimmel and Yahner 1994). In addition, they found that nest sites tended to be at higher elevations and were included in extensive mixed or sometimes coniferous forest, further from forest edges (Kimmel and Yahner 1994). Pennsylvania nest sites typically included more conifers (e.g. white pine Pinus strobus, eastern hemlock) and less oak species (Quercus spp.). However, nest tree selection was predominately red maple (Acer rubrum), American beech (Fagus grandifolia), or black cherry 
(Prunus serotina) (Kimmel and Yahner 1994, Brinker pers. comm.). Nests were found close to discernable trails; however, nests were further from light duty roads (Kimmel \& Yahner 1994).

\section{Field Data Collection}

Occupied goshawk nests were located in New York State from 2004-2015 (Figure 2.1). Most of the nest locations were located based on data and observations from natural resource professionals, recreational birders, outdoor enthusiasts, and landowners. Systematic nest searches were also performed in large tracts of public land. Nest occupancy was confirmed through observations of typical breeding behaviors such as territorial displays, egg incubating, and/or the presence of chicks or fledglings. I collected GPS points and noted the species of the nest tree at each occupied site. Nest sites used in the model were confirmed as an occupied goshawk nest at least once over the 11-year period.

\section{Available Environmental Layers}

I used ArcMap 10.3.1 (ESRI 2011) to prepare all of the environmental layers for use in the model (see Table 2.1). All raster data were converted to integer and projected into the Contiguous Albers Equal Area Conic projection. The extent of all layers was set to the boundary of New York State, and each had a 30m cell size.

To characterize forest patches, I used the most current National Landcover Dataset (NLCD 2011, Table 2.1) and a basal area-weighted height layer (NASA 2000, Table 2.1). I used the NLCD dataset from 2011 because it is the most representative of the wide range of sampling years because it is the closest to the median year. In addition, this dataset has a relatively high accuracy assessment (>80\%, Wickham et al. 2017), and because I wanted to use this model to 
locate new, contemporary nest areas and it is the most recent dataset available. While I

recognized the potential importance of canopy closure and understory cover in previous research on goshawk nesting habitat (Kimmel and Yahner 1994, Squires and Ruggiero 1996, Daw and DeStefano 2001, Boal et al. 2005, Mahon et al. 2008, Miller et al. 2013), these layers were not available for use in my model. Studies in the eastern United States have also identified elevation as a factor in nest site selection (Kimmel and Yahner 1994), so I included the National Map elevation layer for all of New York State (USGS 2011).

I incorporated additional layers that were important features in some regions of the goshawk's range across the United States. First, using data from the National Hydrology layer, I used the Euclidean distance tool to calculate distance from ness to water. The Euclidean distance tool determines $x \_$max and y_max and calculates the length of the hypotenuse created by these two values to determine the shortest straight-line distance between the point (nest) and the environmental feature (water body) (ESRI 2011). Second, I calculated aspect from the National Map elevation layer by determining the maximum rate of change between neighboring cells to determine the slope direction. The slope direction is a value ranging from $0-360^{\circ}$ with $0^{\circ}$ and $360^{\circ}$ as due north, $90^{\circ}$ as due east, $180^{\circ}$ as due south, and $270^{\circ}$ as due west (ESRI 2011). These values were then converted to linear aspect in ArcMap to be used as a continuous variable in the model. Lastly, I created a heat load index layer, also derived from the National Map elevation layer. The heat load index is a metric that accounts for slope direction as well as slope steepness to determine relative temperatures across a given area (McCune and Keon 2002). While all aspects have the same potential for radiation along a north-south axis, some aspects reach warmer temperatures (e.g. those that receive afternoon sun, McCune and Keon 2002). This metric accounts for this difference by "folding" the aspect so that SW slopes have the highest 
values and NE slopes have the lowest (McCune and Keon 2002). The heat load index layer is especially useful because it indirectly informs about tree community structure (Davis et al. 2010).

\section{Modeling Approach}

Two major categories of data are commonly used for species habitat modeling: presence-absence and presence-only data. Each has strengths and weaknesses and the two are often compared to determine which produces the most accurate results (e.g. Brotons et al. 2004). However, longterm datasets often lack absence data and even if absence data are available, they are not always reliable (Pearce and Boyce 2006, Elith et al. 2011). There is always uncertainty in absence data since species could be present but undetected by observers. For these reasons, there is growing interest in methodologies for modeling presence-only data.

Maximum Entropy (MaxEnt) has become increasingly popular for species habitat modeling because numerous studies have characterized it as superior to other presence-only methods (Elith et al. 2006, Hernandez et al. 2006, Hijmans and Graham 2006, Phillips et al. 2006, Pearson 2007). Elith et al. (2006) evaluated 16 presence-only models and found that MaxEnt outperformed other model types in predicting species distributions in six geographic regions. MaxEnt models use species occurrence data and a suite of environmental variables to predict a species distribution (Pearson 2007). This type of modeling uses machine learning to identify characteristics of input variables and the interactions between those input variables to define constraints on the "known" data points. Then, those constraints are applied to unexplored areas to identify areas of high occurrence probability (Phillips et al. 2006). The predicted distribution must fall under the defined constraints as MaxEnt models avoid making assumptions 
about anything that is not supported by the occurrence data (Jaynes 1957, Jaynes 1990). The resulting MaxEnt model will have the probability distribution of maximum entropy (closest to uniform) based on the constraints determined by the available environmental data (Pearson 2007).

There are other advantages to using MaxEnt modeling. MaxEnt only requires two types of input data: presence-only data points and environmental layers in raster format (Phillips et al. 2004, Phillips et al. 2006). In addition, input data can be both categorical or continuous and the user can determine how much of the data are used for training and testing the model (Phillips et al. 2006). The user can also directly examine the importance of predictor variables via jackknife analysis (Pearson 2007). One of the major advantages of MaxEnt modeling is the ability of these models to make accurate predictions of distributions when using small sample sizes (see Pearson et al. 2007, Kumar and Stohlgren 2009). The final output provides continuous values ranging from zero to one with greater values representing areas of greater suitability (Pearson 2007).

\section{Modeling}

I used MaxEnt Version 3.3.3 (Phillips et al. 2016) to model goshawk nesting habitat in New York State. The model was developed using 109 known nest locations (Figure 2.1). I used 75\% of the data points to train the model and the remaining $25 \%$ for model testing using the default MaxEnt settings. I validated the model by assessing the agreement between observed presence of nests to the predicted distribution using the area under the curve (AUC, Manel et al. 2001). In addition, I used jackknife tests to determine the relative importance of each environmental predictor variable. 


\section{Ground-Truthing the Model}

I created a map using the MaxEnt model to identify previously unknown areas suitable for goshawk nesting in New York. I used the 'raster calculator' tool in ArcMap 10.3.1 (ESRI 2011) to highlight areas with a $70 \%$ or greater suitability for goshawks based on the model results. I used 'region group' to group neighboring cells with the same probability classification and only included regions of at least $7.2 \mathrm{~km}^{2}(8 \times 30 \mathrm{~m}$ cells $)$ in the final map, thus eliminating spurious locations.

During the nesting season of 2016, I ground-truthed the model by surveying habitat identified as suitable by the model for goshawk presence. I created regional maps for three general areas of the state: north, central, and south (Figure 2.2). Because there is limited time during the summer breeding season to locate occupied goshawk nests, I searched multiple locations across the state as rapidly as possible. Thus, I focused on public land since it allows for immediate accessibility and targeted large patches with the highest possible suitability values in each of the three regions. I concentrated specifically on areas considered highly suitable (>70\%) in each tract of forest rather than surveying each parcel in its entirety. I surveyed 16 locations: eight in the northern region, five in the central part of the state, and three in the south. Surveys involved searching forest patches on foot with three or more researchers and the use of previously described goshawk callback surveys (Kimmel and Yahner 1990, Kennedy and Stahlecker 1993, USDA Forest Service 2000). 


\section{Results}

Nest sites

The majority of nest locations used in the model were located between 2009 and 2016 (80/109). The most common species used for nest trees was white pine (98/109). Other nest tree species included red pine (Pinus resinosa $\mathrm{n}=6$ ), European larch (Larix decidua $\mathrm{n}=4$ ), and quaking aspen (Populus tremuloides $\mathrm{n}=1$ ).

\section{Model Results}

The MaxEnt model predicted potential suitable northern goshawk habitat with relatively high success. The model outperformed a random model with a validation AUC of 0.87 (the test data line falls above the random prediction line, Figure 2.3). The model results also suggested that the input data were not spatially autocorrelated (the omission of test samples line falls above the predicted omission line, Figure 2.3). The internal MaxEnt jackknife statistical tests show that the most important predictor variable for the model was the land cover layer (model contribution $=$ $67 \%$, Table 2.2). The second and third most important variables were basal area-weighted height and elevation (model contribution $10.9 \%$ and $10.5 \%$; respectively, Table 2.2). All other variables contributed $<6 \%$ to the model (Table 2.2). The land cover layer provided the best training gain for the model, followed by basal area-weighted height and elevation (Figure 2.4). The majority of nest sites fell in the coniferous forest land classification (76\%), basal area-weighted height values were relatively high, and goshawks seemed to prefer elevation in the middle of that available in the state. 


\section{Ground-Truthing the Model}

The 16 forest parcels that I surveyed varied widely in size $\left(\sim 250-72,000 \mathrm{~km}^{2}\right)$ and composition (Table 2.3). Forest composition was typically dominated by coniferous species (white pine, eastern hemlock, red pine, scotch pine Pinus sylvestris, or black spruce Picea mariana) and in a few cases, was a mix of coniferous and deciduous species. The proportion of land in each parcel identified as suitable by the model was $<1-31 \%$, resulting in a range of $\sim 20$ to $4,500 \mathrm{~km}^{2}$ of suitable habitat (Table 2.3). All parcels had a maximum suitability value of $\geq 78$ (Table 2.3). At least one large stick nest was located in nine of the forest parcels surveyed and of those, two were confirmed as goshawk nests. One was currently occupied by a goshawk and one was occupied six years previously based on state records. Of the remaining nests (7/9), one was occupied by common ravens and six were unoccupied. However, two of the unoccupied nests were suspected raven nests. Each of these nests were lined with man-made items commonly used by ravens, such as string, plastic, and insulation. To my knowledge, raptors do not use this type of material in nest construction, but I have observed this type of material in multiple common raven nests in the region.

\section{Discussion}

The Model (Objective 1: Identifying characteristics)

I modeled northern goshawk habitat in New York State with moderate success. The in-program validation (AUC) of the MaxEnt model suggests that the model is a good fit for predicting goshawk nest sites in the state. However, based on ground-truthing efforts, I suspect that the model may be overfitting, which is a common issue seen in MaxEnt modeling (Radosavljevic 
and Anderson 2014). Overfitting occurs when a model is excessively complex in relation to the dataset and generally results in poor predictive performance (Merckx et al. 2011).

The model overfit is likely a result of sampling bias and non-independence of input data. Since this dataset did not originate from a systematic survey of the entire state, the data exhibit a strong geographic sampling bias (Fourcade et al. 2014). In addition, goshawk pairs are known to build multiple alternate nests in a single territory (Reynolds et al. 1992). Without a marked population, I had no way to confirm if adjacent nest locations were used by the same individuals in different years. Therefore, I could not remove non-independent data points and had to assume independence of all nest sites. Previous research has shown that AUC values can remain high even for models with strong sampling biases (Fourcade et al. 2014). I recognize this issue and therefore, recommend that the model results be interpreted cautiously.

Despite these issues, the model still provided valuable information about nest site selection by goshawks nesting in New York. I was able to determine general preferences for nest site characteristics in the state including land cover type, basal area-weighted height, and elevation. I was also able to establish that factors such as aspect, distance to water, and heat load may be less important in nest site selection in this region. Thus, MaxEnt is a useful tool even with suboptimal input data and I believe that it may be useful for future habitat modeling for this species.

Similar to previous research, I found that goshawks nesting in the state prefer larger, taller trees (higher basal area-weighted height). In contrast, the majority of nest sites were in coniferous forest, while previous studies on the east coast suggested that goshawks historically had a strong preference for mixed forests. In addition, previous research demonstrated that selected nest trees in NY and PA were typically deciduous species (Speiser and Bosakowski 
1987, Kimmel and Yahner 1994), but $90 \%$ of the nests located for this study were in white pines. This could suggest that coniferous forests, especially those containing white pines, are important for goshawks currently nesting in New York State. While this trend could be a result of sampling bias, it is still surprising given that coniferous forests make up a small fraction of the forest cover in the state. For example, white, red, or jack pine (Pinus banksiana) forests make up only $5 \%$ of the total 7.6 million hectares of forested land in New York (Verschoor and Van Duyne 2012). Further research is warranted to examine stands surrounding nest sites to better understand the tree species composition.

\section{Model Testing (Objective 2: Locating previously unknown nest sites)}

While the in-program validation of the MaxEnt model suggested a good fit, ground-truthing validation produced few new goshawk nest sites and often led us to nesting areas of non-target species. I only located two confirmed goshawk nests with two additional nests that I suspected may have been previously used by goshawks based on nest site characteristics. At best, this is only a $25 \%$ success rate. However, it is important to note that most of the located nests were unoccupied (7/9) and it is possible that some of these nests were previously used by goshawks. It is also possible that I failed to locate some goshawk nests during nest searching efforts, even in areas where I located other species. For example, ravens and goshawks have previously been found nesting in and defending the same territory (Martell and Dick 1996). Thus, the low success rate may not have been a result of poor model performance but various other factors such as failure to detect nests or lack of goshawk activity at located nests.

Another potential reason for the low success rate when ground-truthing is that I had a limited number of highly suitable areas to search. During field testing efforts, I focused on areas 
within state land parcels consisting of large contiguous patches with the highest suitability possible in each region. I had some difficulty finding areas that matched the search criteria in the northern region of the state, primarily because many of the highly suitable areas already had known nesting territories. In addition, the southern region of the state was problematic because there were relatively few high probability areas, suitability values tended to be low, and these areas were not as large in size compared to those in other parts of the state. Also, numerous large highly suitable privately-owned areas were left unsearched because time constraints restricted the surveys to public land.

Finally, the relatively low success rate could suggest that the model was not tailored specifically enough to goshawks. This may be because I lacked certain environmental data previously identified as important in goshawk nest site selection. For example, I found multiple common raven nests and there was generally more understory growth at these sites than what I expect at goshawk nesting sites. Future models could include more and/or improved (higher resolution) input data to increase model accuracy and reduce the chance of finding non-target species. This may be especially important given that land cover type was the most important contributor to the model and all other input data contributed little to the model output.

\section{Conclusions (Objective 3: Improving Future Models)}

MaxEnt appears to be a useful tool for modeling northern goshawk nesting habitat in New York State. I was able to obtain useful information about goshawk nesting habitat and locate two nest sites that were not used in the model input. However, I recognize that the model fit was likely inflated and therefore, it is clear that the model could be improved. Ideally, steps should be taken to reduce sampling bias and remove non-independent data points in future models. 
Also, I believe the data in this model may be too coarse for separating out suitable goshawk nesting habitat from other mature forest-nesting avian species. Most of the data layers that I used in the study contributed little to the final model (11\% or less). Therefore, the model could be improved with the addition of more useful data layers and/or finer grain data of existing data layers. Previous research has found canopy cover and understory composition to be important predictors of goshawk nest sites in multiple areas across the United States (Squires and Ruggiero 1996, Daw and DeStefano 2001, Boal et al. 2005, Mahon et al. 2008, Miller et al. 2013). I was unable to locate data layers to include this information in the model. The addition of these data to future models could potentially reduce the possibility of locating non-target species.

Another useful addition to the modeling parameters would be land cover data with more detailed forest classifications and higher resolution than the current NLCD. The land cover classification was the single most important factor in predicting suitable goshawk habitat in my model. I know from the existing dataset that goshawks tend to select stands of forest dominated by coniferous species, specifically with white pines for nest trees. However, the current NLCD dataset does not differentiate species or even groups of conifers. Therefore, more specific forest classification could potentially improve the model, provide useful information about dominant species in nest areas, and possibly result in locating more nest territories.

While my model provided new information about important habitat features specific to goshawks nesting in New York, the model did not result in a high success of unknown nest site discovery. Still, improvements can be made to increase the utility of MaxEnt models for locating new nest sites in New York State. First, future research could be used to reduce sampling bias and eliminate non-independent data points. In addition, expansion of nest searches to private 
lands across the state and/or the addition of other important environmental data layers identified in our study could increase the predictive potential of future models.

\section{Literature Cited}

Bildstein, K.L. (2008). A brief history of raptor conservation in North America. In: Bildstein, K.L., J.P. Smith, E. Ruelas I., and R.R. Veit, eds. State of North America's Birds of Prey. Nuttall Ornithological Club and American Ornithologists Union Series in Ornithology No. 3. Cambridge, Massachusetts, and Washington D.C., pp. 5-36

Boal, C.W., D.E. Andersen, and P.L. Kennedy. (2005). Foraging and nesting habitat of breeding male northern goshawks in the Laurentian mixed forest province, Minnesota. Journal of Wildlife Management, 69: 1516-1527.

Brotons, L., W. Thuiller, M.B. Araújo, and A.H. Hirzel. (2004). Presence-absence versus presence-only modelling methods for predicting bird habitat suitability. Ecography, 27: 437-448.

Davis, F.W., M. Borchert, R.K. Meentemeyer, A. Flint, and D.M. Rizzo. (2010). Pre-impact forest composition and ongoing tree mortality associated with sudden oak death in the Big Sur region; California. Forest Ecology and Management, 259: 2342-2354.

Daw, S.K., and S. DeStefano. (2001). Forest characteristics of northern goshawk nest stands and post-fledging areas in Oregon. Journal of Wildlife Management, 65: 59-65.

Elith, J., C.H. Graham, R.P. Anderson, M. Dudik, S. Ferrier, A. Guisan, R.J. Hijmans, F. Huettmann, J.R. Leathwick, A. Lehmann, J. Li, G. Lohmann, B.A. Loiselle, G. Manion, C. Moritz, M. Nakamura, Y. Nakazawa, J. McC. Overton, A.T. Peterson, S.J. Phillips, K. Richardson, R. Scachetti-Pereira, R.E. Schapire, J. Soberon, S. Williams, M.S. Wisz, and N.E. Zimmermann. (2006). Novel methods improve prediction of species' distributions from occurrence data. Ecography, 29: 129-151.

Elith, J., S.J. Phillips, T. Hastie, M. Dudik, Y.E. Chee, and C.J. Yates. (2011). A statistical explanation of MaxEnt for ecologists. Diversity and Distributions, 17: 43-57.

Environmental Systems Research Institute (ESRI). (2011). ArcGIS Desktop: Release 10.3.1 Redlands, CA.

Farmer, C.J., J.P. Smith, S.H. Hoffman, G.S. Kaltenecker, K.Z. Woodruff, and P.J. Sherrington. (2008). Trends in autumn counts of migratory raptors in western North America. In: Bildstein, K.L., J.P. Smith, E. Ruelas Inzunza, and R.R. Veit, eds. State of North America's birds of prey. Nuttall Ornithological Club and American Ornithologists' Union, Cambridge, MA and Washington, D.C., pp. 217-251.

Fourcade, Y., J.O. Engler, D. Rödder, and J. Secondi. (2014). Mapping species distributions with MAXENT using a geographically biased sample of presence data: A performance assessment of methods for correcting sampling bias. PLoS One, 9: e97122. 
Griesemer, S.J., T.K. Fuller, and R.M. Degraaf. (1998). Habitat use by porcupines (Erethizon dorsatum) in central Massachusetts: Effects of topography and forest composition. The American Midland Naturalist, 140: 271-279.

Guisan, A., and N.E. Zimmermann. (2000). Predictive habitat distribution models in ecology. Ecological Modelling, 135: 147-186.

Hennessy, S.P. (1978). Ecological relationships of accipiters in northern Utah-with special emphasis on the effects of human disturbance. M.S. thesis, Utah State University, Logan, UT.

Hernandez, P.A., C.H. Graham, L.L. Master, and D.L. Albert. (2006). The effect of sample size and species characteristics on performance of different species distribution modeling methods. Ecography, 29: 773-785.

Hijmans, R.J., and C.H. Graham. (2006). The ability of climate envelope models to predict the effect of climate change on species distributions. Global Change Biology, 12: 2272-2281.

Jaynes, E.T. 1957. Information theory and statistical mechanics. Physical Review, 106: 620-630.

Jaynes, E.T. 1990. Notes on present status and future prospects. In: Grandy Jr., W.T., and L.H. Schick, eds. Maximum entropy and Bayesian methods. Kluwer, Dordrecht, The Netherlands, pp. 1-13.

Keith, D.A., H.R. Akçakaya, W. Thuiller, G.F. Midgley, R.G. Pearson, S.J. Phillips, H.M. Regan, M.B. Araújo, and T.G. Rebelo. (2008). Predicting extinction risks under climate change: coupling stochastic population models with dynamic bioclimatic habitat models. Biology Letters, 4: 560-563.

Kennedy, P.L., and D.W. Stahlecker. (1993). Responsiveness of nesting northern goshawks to taped broadcasts of 3 conspecific calls. Journal of Wildlife Management, 57: 249-257.

Kenward, R. (2010). The Goshawk. Bloomsbury Publishing, London, UK.

Kimmel, J.T., and R.H. Yahner. (1990). Response of northern goshawks to taped conspecific and great horned owl calls. Journal of Raptor Research, 24: 107-112.

Kimmel, J.T., and R.H. Yahner. (1994). The northern goshawk in Pennsylvania: Habitat use, protocols, and status. Final Report. Pennsylvania State University.

Kumar, S., and T.J. Stohlgren. (2009). Maxent modeling for predicting suitable habitat for threatened and endangered tree Canacomyrica monticola in New Caledonia. Journal of Ecology and Natural Environment, 1: 94-98.

Lurz, P.W.W., P.J. Garson, and L.A. Wauters. (2000). Effects of temporal and spatial variations in food supply on the space and habitat use of red squirrels (Sciurus vulgaris L.). Journal of Zoology, 251: 167-178.

Mahon, T., E.L. McClaren, and F.I. Doyle. (2008). Parameterization of the northern goshawks (Accipiter gentilis laingi) habitat model for coastal British Columbia (Draft). Forest Investment Account (FIA), British Columbia, Canada. 
Manel, S., H.C. Williams, and S.J. Ormerod. (2001). Evaluating presence-absence models in ecology: the need to account for prevalence. Journal of Applied Ecology, 38: 921-931.

Marckx, B., M. Steyaert, A. Vanreusel, M. Vincx, and J. Vanaverbeke. (2011). Null models reveal preferential sampling, spatial autocorrelation and overfitting in habitat suitability modelling. Ecological Modelling, 222: 588-597.

Martell, M., and T. Dick. (1996). Nesting habitat characteristics of the northern goshawks (Accipiter gentilis) in Minnesota. Report submitted to Minnesota Department of Natural Resources Nongame Wildlife Program.

McCune, B., and D. Keon. (2002). Equations for potential annual direct incident radiation and heat load. Journal of Vegetation Science, 13: 603-606.

Miller, R.A., J.D. Carlisle, M.J. Bechard, and D. Santini. (2013). Predicting nesting habitat of northern goshawks in mixed aspen-lodgepole pine forests in a high-elevation shrubsteppe dominated landscape. Open Journal of Ecology, 3: 109-115.

NatureServe, 2017. NatureServe Explorer: An online encyclopedia of life (web application). Version 7.0. NatureServe, Arlington, VA, USA. Available online http://explorer.natureserve.org (Accessed Oct. 21, 2017).

Nielsen, S.E., G. McDermid, G.B. Stenhouse, and M.S. Boyce. (2010). Dynamic wildlife habitat models: Seasonal foods and mortality risk predict occupancy-abundance and habitat selection in grizzly bears. Biological Conservation, 143: 1623-1634.

Pearce, J.L., and M.S. Boyce. (2006). Modelling distribution and abundance with presence-only data. Journal of Applied Ecology, 43: 405-412.

Pearson, R.G. (2007). Species' Distribution Modeling for Conservation Educators and Practitioners. Synthesis. American Museum of Natural History. Available at http://ncep.amnh.org.

Pearson, R.G., C.J. Raxworthy, M. Nakamura, and A.T. Peterson. (2007). Predicting species' distributions from small numbers of occurrence records: A test case using cryptic geckos in Madagascar. Journal of Biogeography, 34: 102-117.

Phillips, A.J. (2017). Spatial models as powerful tools for climate change ecology. Ph.D. Dissertation, University of Washington, USA.

Phillips, S.J., R.P. Anderson, and R.E. Schapire. (2006). Maximum entropy modeling of species geographic distributions. Ecological Modeling, 190: 231-259.

Phillips, S.J., M. Dudík, and R.E. Schapire. (2004). A maximum entropy approach to species distribution modeling. In: Proceedings of the 21st International Conference on Machine Learning, ACM Press, New York, pp. 655-662.

Phillips, S.J., M. Dudik, and R.E. Schapire. (2016). Maxent software for modeling species niches and distributions (Version 3.3.3). Available from url: http://biodivers ityinformatics.amnh.org/open_source/maxent/ Accessed on 13 April 2016. 
Probst, J.R., D.M. Donner, C.I. Bocetti, and S. Sjogren. (2003). Population increase in Kirtland's warbler and summer range expansion to Wisconsin and Michigan's upper peninsula, USA. Oryx, 37: 365-373.

Radosavljevic, A., and R.P. Anderson. (2014). Making better MAXENT models of species distributions: complexity, overfitting and evaluation. Journal of Biogeography, 41: 629643.

Reynolds, R.T. (1983). Management of western coniferous forest habitat for nesting accipiters. General Technical Report RM-102. Forest Service, United States Department of Agriculture, Fort Collins, Colorado.

Reynolds, R.T., E.C. Meslow, and H.M. Wight. (1982). Nesting habitat of coexisting Accipiter in Oregon. Journal of Wildlife Management, 46: 124-138.

Reynolds, R.T., R.T. Graham, M.H. Reiser, R.L. Bassett, P.L. Kennedy, D.A. Boyce, Jr., G. Goodwin, R. Smith, and E.L. Fisher. (1992). Management recommendations for the northern goshawks in southwestern United States. USDA Forest Service General Technical Report RM-217.

Smart, L.S., J.J. Swenson, N.L. Christensen, and J.O. Sexton. (2012). Three-dimensional characterization of pine forest type and red-cockaded woodpecker habitat by smallfootprint, discrete-return lidar. Forest Ecology and Management, 281: 100-110.

Speiser, R., and T. Bosakowski. (1987). Nest site selection by northern goshawks in northern New Jersey and southeastern New York. The Condor, 89: 387-394.

Squires, J.R., and L.F. Ruggiero. (1996). Nest-site preference of northern goshawks in southcentral Wyoming. Journal of Wildlife Management, 60: 170-177.

Store, R., and J. Jokimäki. (2003). A GIS-based multi-scale approach to habitat suitability modeling. Ecological Modelling, 169: 1-15.

USDA Forest Service. (2000). Survey methodology for northern goshawks in the Pacific Southwest Region. Vallejo, CA.

Verschoor, K., and G. Van Duyne. (2012). Forestry and tree planting in New York State. Tree Planters' Notes, 55: 4-13.

Wattel, J. (1981). The goshawk and its relatives, some remarks on systematics and evolution. In: Kenward, R.E., and I. M. Lindsay, eds. Understanding the goshawk. Oxford Univ. Press, New York, pp. 6-28.

Wickham, J., S.V. Stehman, L. Gass, J. Dewitz, D.G. Sorenson, B.J. Granneman, R.V. Ross, and L.A. Baer. (2017). Thematic accuracy assessment of the 2011 National Land Cover Database (NLCD). Remote Sensing of Environment, 191: 328-341. 
Table 2.1: List of environmental variable layers, their associated code in a MaxEnt model, their source, year of publication, and internet URL. Each layer was used in a MaxEnt model to determine potential northern goshawk nesting habitat in New York State. Two layers (heat load index and aspect) were created in ArcMap from the elevation layer, so these layers do not have a URL.

\begin{tabular}{|c|c|c|c|c|}
\hline $\begin{array}{c}\text { Environmental } \\
\text { Variable }\end{array}$ & $\begin{array}{c}\text { MaxEnt } \\
\text { Layer Code }\end{array}$ & Source & Year & URL \\
\hline Land cover & Nyslulc & $\begin{array}{c}\text { National Land Cover } \\
\text { Database via National Map }\end{array}$ & 2011 & http://viewer.nationalmap.gov/basic/ \\
\hline $\begin{array}{c}\text { Basal Area- } \\
\text { Weighted Height }\end{array}$ & nysbawhclip & NASA Earth Data & 2000 & http://daac.ornl.gov/cgi-bin/dsviewer.pl?ds_id=1161 \\
\hline Elevation & nyelevclip & National Map & 2013 & http://viewer.nationalmap.gov/basic/ \\
\hline Aspect & aspectclip & $\begin{array}{l}\text { Based on elevation dataset } \\
\text { from National Map }\end{array}$ & 2013 & N/A \\
\hline Heat Load Index & Nyhli & $\begin{array}{l}\text { Based on elevation dataset } \\
\text { from National Map }\end{array}$ & 2013 & N/A \\
\hline Distance to water & hydrodistclip & $\begin{array}{c}\text { National Hydrology Dataset } \\
\text { via National Map }\end{array}$ & 2016 & http://viewer.nationalmap.gov/basic/ \\
\hline
\end{tabular}


Table 2.2: Percent contribution of all environmental layers to the MaxEnt model used for northern goshawk nest distribution modeling in New York State.

\begin{tabular}{cc}
\hline Variable & Percent Contribution \\
\hline \hline Land cover & 67.4 \\
Basal area-weighted canopy height & 10.9 \\
Elevation & 10.5 \\
Distance to water & 5.7 \\
Heat Load Index & 3.0 \\
Aspect & 2.5 \\
\hline
\end{tabular}


Table 2.3: Description of each forest parcel surveyed for goshawks during the 2016 breeding season. Locations were chosen based on the MaxEnt model results.

\begin{tabular}{ccccccc}
\hline $\begin{array}{c}\text { General } \\
\text { Location }\end{array}$ & $\begin{array}{c}\text { Total Area } \\
\text { Parcel } \\
\left(\mathbf{K m}^{2}\right)\end{array}$ & $\begin{array}{c}\text { Proportion } \\
\text { of parcel } \\
\text { suitable }\end{array}$ & $\begin{array}{c}\text { Max } \\
\text { Suitability } \\
\text { Value }\end{array}$ & $\begin{array}{c}\text { Dominant Tree } \\
\text { Species }\end{array}$ & $\begin{array}{c}\text { Nest } \\
\text { located }\end{array}$ & Occupied \\
\hline Central & 3638 & 11.1 & 96 & White pine & Yes & No \\
Central & 37355 & 11.8 & 100 & White pine & Yes & No \\
Central & 16433 & 4.5 & 99 & White pine & Yes & No \\
Central & 19479 & 11.5 & 100 & White pine & Yes* & Yes \\
Central & 23286 & 6.5 & 100 & Mixed & No & - \\
North & 2230 & 9.9 & 99 & Eastern hemlock & Yes & No \\
North & 71876 & 0.5 & 87 & Scotch pine & Yes & No \\
North & 256 & 31.3 & 95 & White pine & Yes & Yes \\
North & 3343 & 7.0 & 96 & Mixed & No & - \\
North & 22333 & 5.0 & 99 & White pine & Yes* & No \\
North & 13948 & 2.8 & 98 & Mixed conifers & No & - \\
North & 7897 & 2.1 & 96 & Red pine & No & - \\
North & 30281 & 0.2 & 78 & White pine & No & - \\
South & 2134 & 1.0 & 90 & Black spruce & No & - \\
South & 7426 & 0.8 & 85 & Black spruce & No & - \\
South & 2979 & 8.0 & 98 & Red pine & Yes & No \\
\hline
\end{tabular}

* Denotes nests that were confirmed as goshawk nests. 


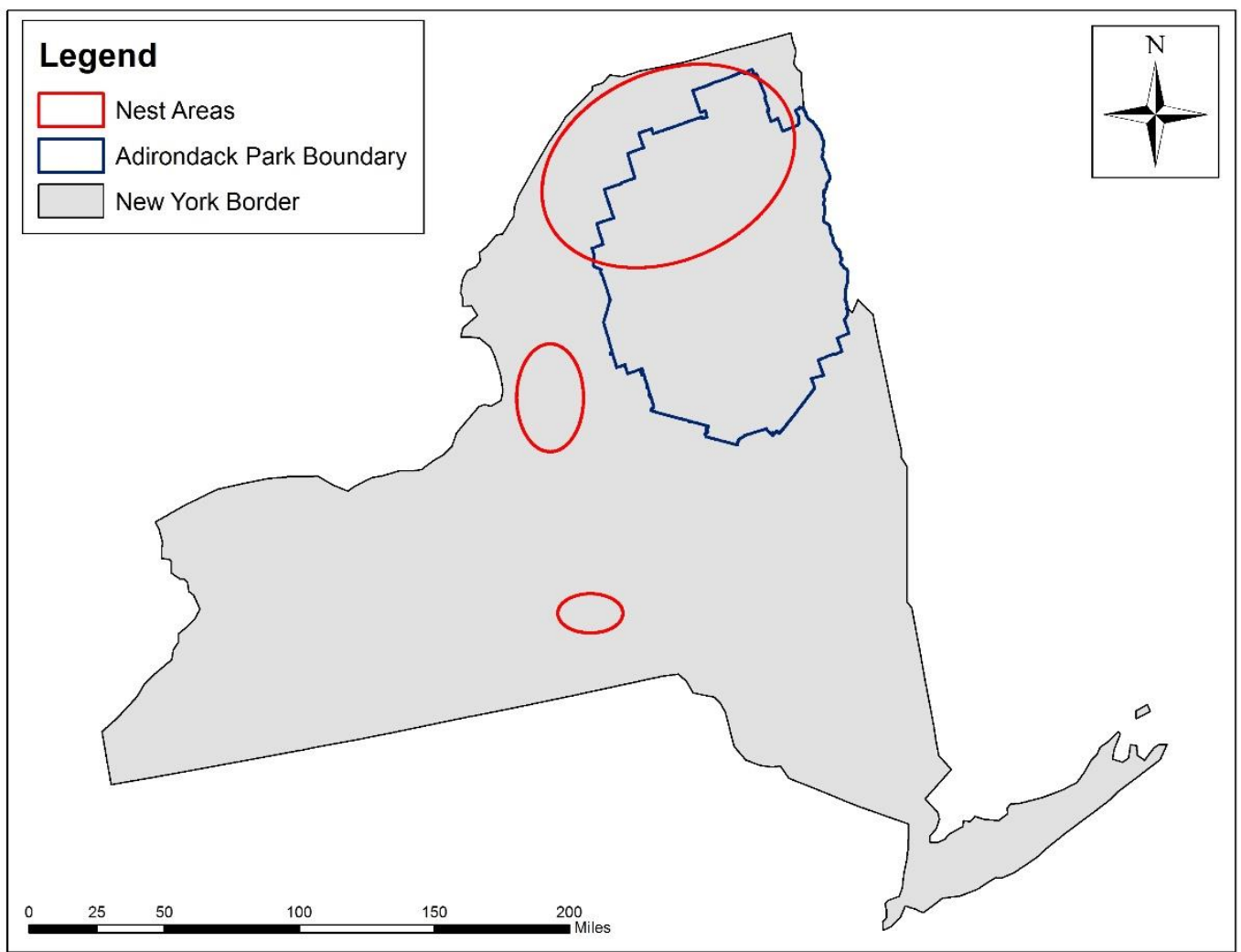

Figure 2.1: Northern goshawk nest areas in New York State. In total, 109 known nest sites are included in these areas and each nest was occupied for at least one year between 2004 to 2015. Exact locations were purposefully excluded due to the sensitive nature of this species. 

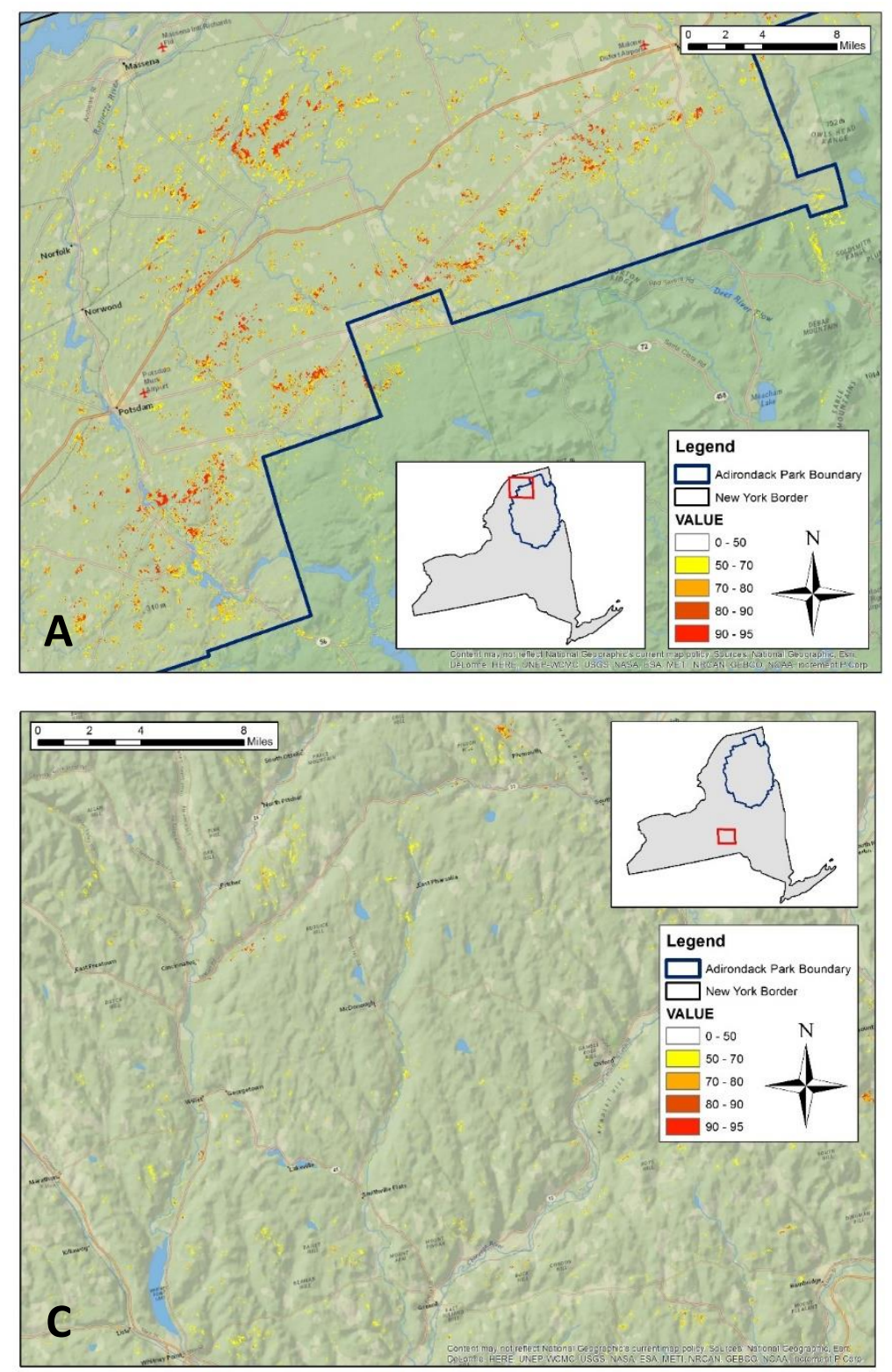

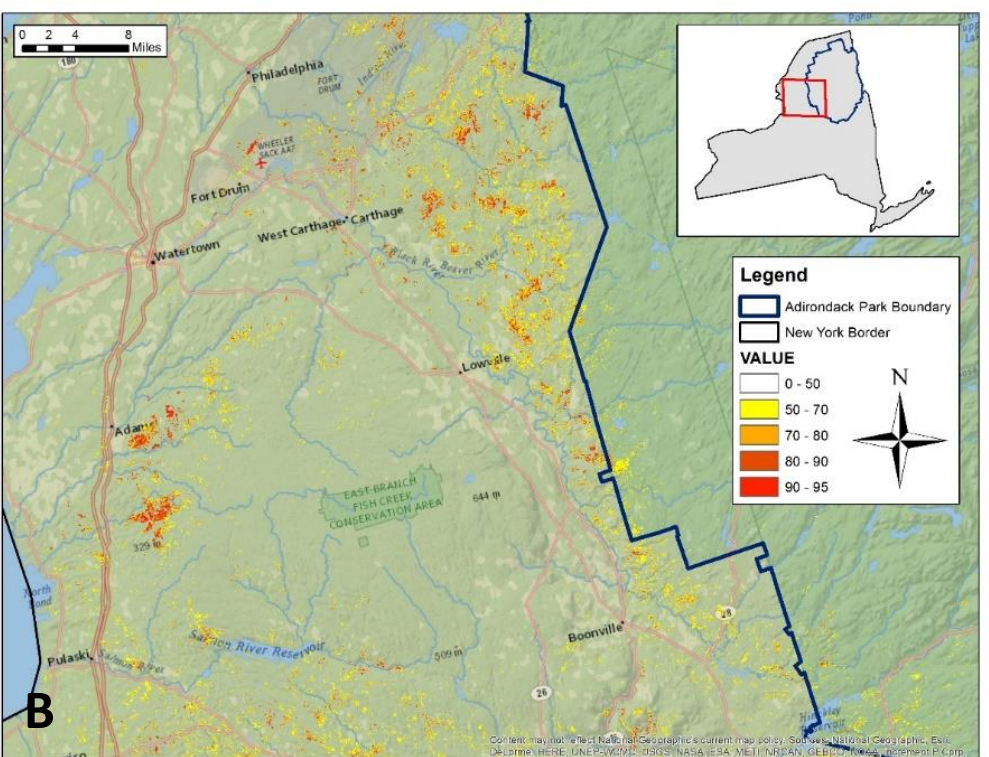

Figure 2.2: Percent suitability results for the northern goshawk habitat suitability in New York State based on our MaxEnt model. We surveyed 16 sites for goshawk presence during the 2016 breeding season to test model results: eight of these were in the north (A), five in the central part of the state (B), and three in the south $(\mathrm{C})$. Exact survey locations were purposefully excluded due to the sensitive nature of this species. 

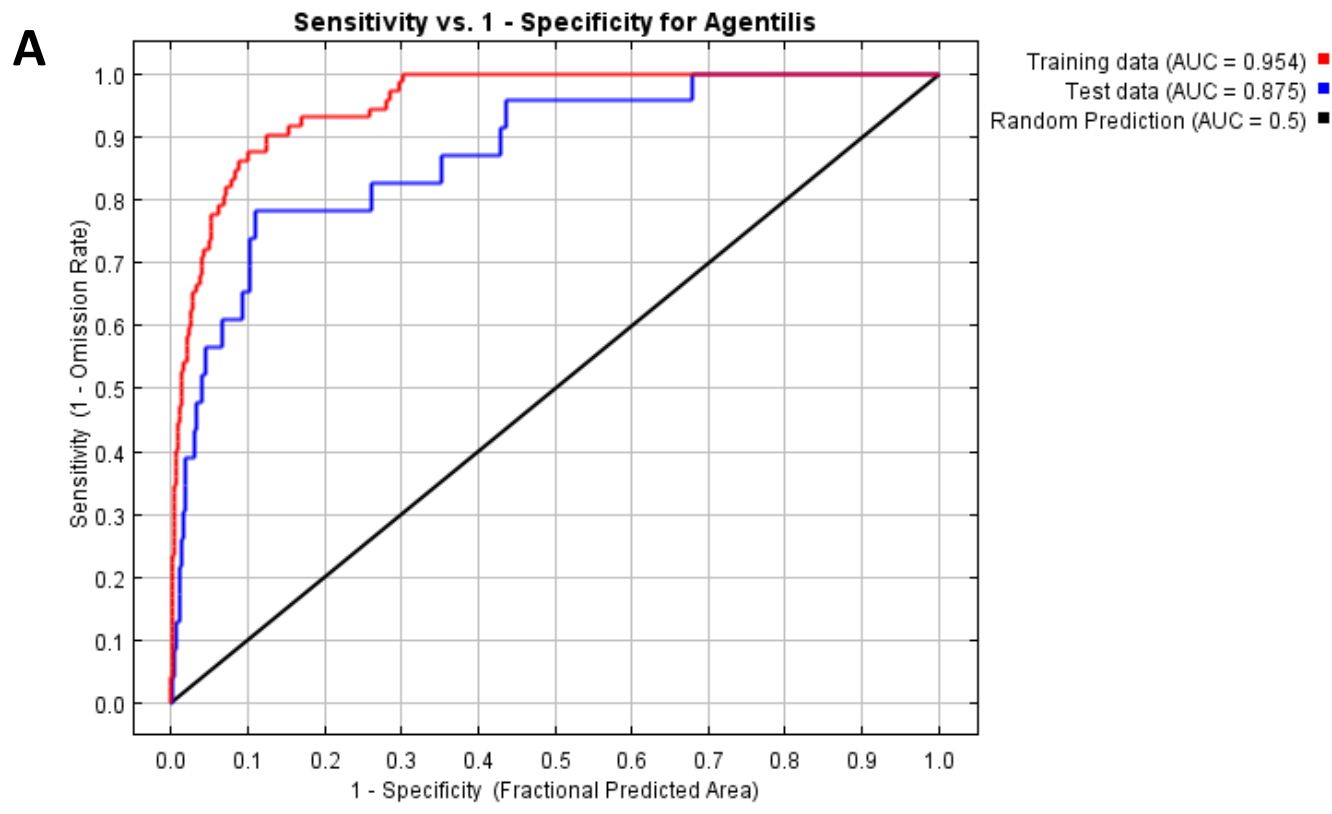

B

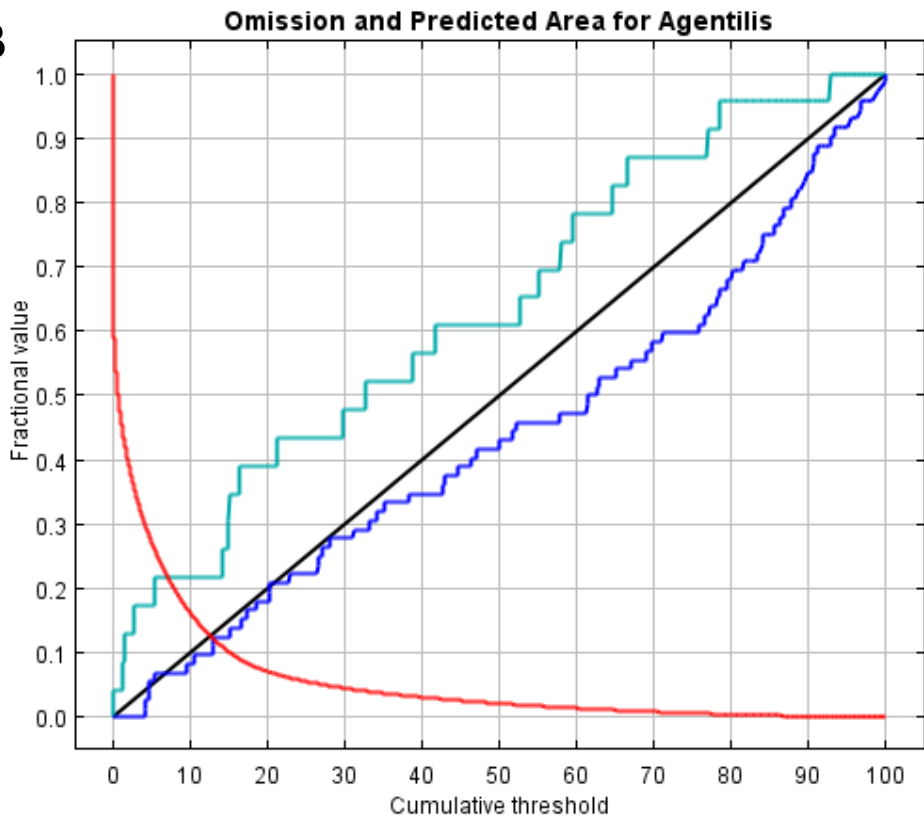

Fraction of background predicted Omission on training samples Omission on test samples Predicted omission $\mathbf{~}$

Figure 2.3: Output for the northern goshawks nest distribution MaxEnt model in New York State (A) Sensitivity and specificity for the training data, test data, and random model prediction AUC values. Since the test data AUC (blue line) is well above the random prediction line (black), this suggests this model is better than a random model. (B) Predicted, training, and test sample omissions. Since the test sample omission line (teal) is above the predicted omission line (black), this suggests the data layers are not spatially autocorrelated. 


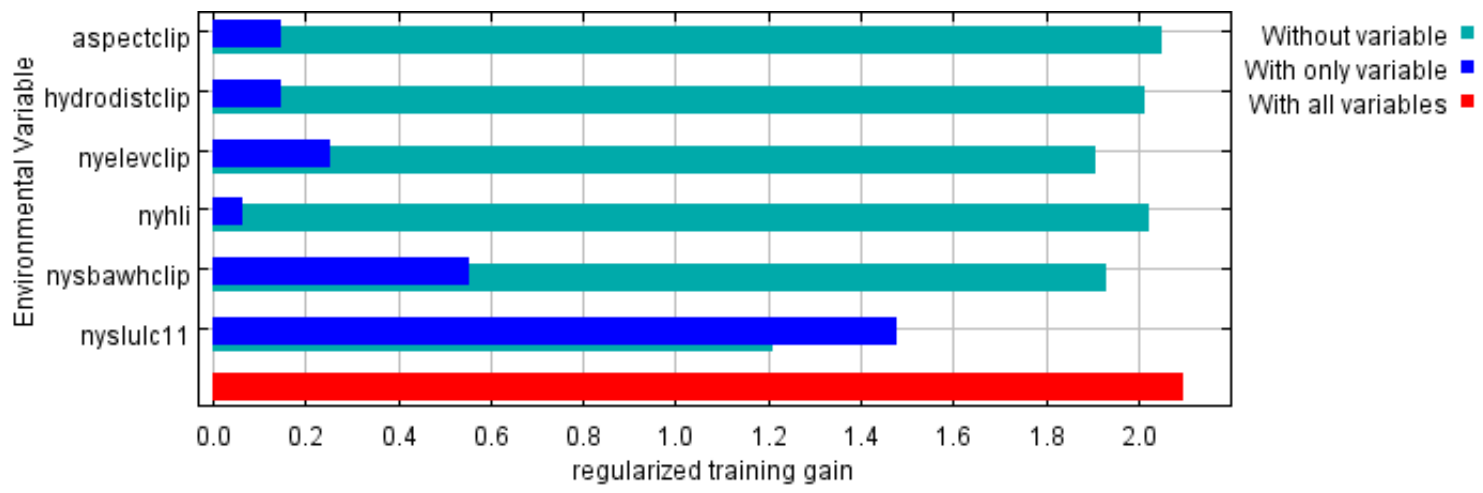

Figure 2.4: Jackknife statistical testing of environmental predictor variables used in MaxEnt model of northern goshawk nest distribution in New York State. Graph shows model training gain for all variables, for each predictor variable alone, and for the model in the absence of each predictor variable. Note 'aspectclip' = aspect, 'hydrodistclip' = distance to water, 'nyelevclip' = elevation, 'nyhli' = heat load index, 'nysbawhclip' = basal area-weighted height, and 'nyslulc11' $=$ land cover. 


\title{
Chapter 3: An improved mechanical owl for efficient capture of nesting raptors.
}

\begin{abstract}
Scientific study of raptors often requires the use of a lure to capture individuals for marking or collecting various data and samples. Live lure owls in the genus Bubo are commonly used in conjunction with mist nets or dho-ghazas to trap nesting raptors, but the use of these lures presents many ethical, logistical, and financial challenges. While taxidermized and mechanical owls have been used previously, the success of these types of lures varies widely. I created a more realistic mechanical owl with a greater range of motion, then tested the owl on six raptor species in a variety of habitats. Capture rates using the mechanical owl were similar or slightly higher than studies using live lure owls or previously designed mechanical owls for all but one species. Time to capture of northern goshawks (Accipiter gentilis) was on average eight min. faster when using the mechanical owl versus the live owl. Cost analysis revealed that the initial expense and long-term maintenance of a mechanical owl are both less than that of a live lure owl. Mechanical owls can be a useful tool for trapping raptors. While there are still some drawbacks to using a mechanical owl, my results suggest that they are comparable to live lure owls in many scenarios and I believe the benefits of using a mechanical owl may often outweigh the costs.
\end{abstract}




\section{Introduction}

Wild animals, including raptors, frequently must be captured and handled for scientific research (Schemnitz 2009). In the case of raptors, direct capture of individuals allows for banding and marking, collection of accurate sex, age, and morphometric data, radio-telemetry outfitting, and tissue sampling for genetics, toxicology, and disease testing (Bloom et al. 2007). Capturing birds of prey often requires the use of live animal lures (Bloom et al. 2007). However, use of lures can be challenging because of ethical, financial, and logistical considerations (Bloom et al. 2007, Millsap et al. 2007).

The use of live lure owls in the genus Bubo in conjunction with mist nests or dho-ghazas is one of the most widespread and effective methods for trapping nesting birds of prey (Hamerstrom 1963, Bloom et al. 1992, Steenhof et al. 1994, Jacobs 1996, McCloskey and Dewey 1999, Jacobs and Proudfoot 2002). However, the use of live lure owls comes with a host of challenges including the building and maintenance of housing for the owl, cost of feeding and equipment, difficulty of transport to nest sites, stress on the owl during handling, ethical considerations, the need for Animal Care and Use Committee approval, and the potential danger during trapping to either the lure owl or wild raptors (Jacobs, 1996; McCloskey and Dewey 1999; Bloom et al. 2007). As a result of these challenges, taxidermist-prepared owls have been used for trapping nesting raptors with varying success (Guard et al. 1989, McCloskey and Dewey 1999). The most effective of these have been owls fitted with mechanical components to allow the head to rotate and the body to swivel (Jacobs 1996, Jacobs \& Proudfoot 2002).

To my knowledge, there have been no attempts to improve upon the engineering of the first mechanical owl prototypes or to test the effectiveness of mechanical owls more broadly. This is despite mechanical owls being a relatively cheap and easy solution to the challenges 
faced when using a live lure owl. Given the benefits of using a mechanical owl, I conducted research to further development of mechanical owl prototypes. The specific objectives of my research were to 1) construct a more mobile and realistic-appearing mechanical owl than is currently available, 2) test the efficacy of the new owl on multiple nesting raptor species in various habitats and compare capture rates to those of studies using live owls and previous mechanical owls, and 3) determine if there are differences in the amount of time to capture when using a live owl compared to the mechanical owl.

\section{Methods}

\section{Owl Construction}

I obtained great-horned owl (Bubo virginianus) carcasses from local rehabilitation centers under salvage permits from state agencies and from the U.S. Fish and Wildlife Service (USFWS), and I used these carcasses for constructing mechanical lure birds. The starting point for my design was based on the first published plan for a mechanical owl (Jacobs 1996). Similar to that design, I used a two-channel remote control unit consisting of a Futaba ${ }^{\circledR}$ transmitter, receiver, battery pack, and two servos.

During construction, the body, head, and wings were separated and prepared following standard taxidermy procedures by licensed taxidermists. The core of the body consisted of a polyurethane foam taxidermy insert specifically designed for great-horned owls (Van Dyke's Taxidermy) or custom made by the taxidermist, while the intact, empty, skull was filled manually with either a hard or soft epoxy. Appropriately sized and colored glass eyes were inserted into the eye sockets at the same time so that the eyes were held in the skull permanently 
once the epoxy dried. Both wings were removed from the body leaving the top portion of the humerus bone exposed and all other bones were left intact inside the wings.

Engineering of the owl was carried out in collaboration with Shanti Hamburg of the West Virginia University Aerospace Engineering Department. We carved out a section from the top of the body insert and used silicon adhesive to mount a servo (Head Actuation Servo in Figure 3.1) into the top of the body insert. We drilled four holes into the circular plate at the top of the servo and epoxied a small magnet into each of the holes. We created a matching plywood disc, containing four magnets spaced to match those on the body servo, and attached the disk to the bottom of the owl head. This magnetic attachment allows for the head to fall off the body if it is struck by attacking raptors.

We sawed off the end of each humerus bone in the owl's wing and inserted a 2-inch long threaded rod covered in epoxy into the hollow center. We left the end of the rod exposed and a small washer and a Nyloc nut were placed on the end of the rod. We then inserted a small piece of $1 / 16 "(1.59 \mathrm{~mm})$ aluminum into the foam body of the owl. We cut an L-shaped slot in the side of the aluminum and fed the threaded rod through that slot and loosely tightened a Nyloc nut onto the bolt. The nut held the bolt firmly in place in the L-shaped slot but still allowed it spin freely.

Once the wings were attached, we used two different approaches to attach them to the servo. In one case, we attached a control horn to the wrist of the wing and used a push-rod to connect the horn to a servo between the bird's legs (Wing Actuation Servo in Figure 3.1). In the other case, the servo was placed in the interior of the foam core and then threaded a push rod through the foam core to connect the servo to the threaded rod in the humerus. In general, we 
found the push-rod between the legs moved the wings more but was more prone to damage than the push-rod within the foam core.

Finally, we permanently attached the completed owl to either a wooden log or a plastic "rock" perch. The wire from the servos were run to the receiver and power supply under the owl's feathers or through the core itself. The receiver and power supply were hidden either behind the legs of the owl or under the perch to conceal them from view. A basic list of necessary equipment and parts for the construction of a mechanical owl based on this design can be found in Appendix 3.1 and 3.2, respectively.

\section{Field Testing}

During the summers of 2015-2017, I tested the efficacy of my mechanical owl as a lure for trapping six raptor species (Cooper's hawks Accipiter cooperii, northern goshawks A. gentilis, sharp-shinned hawks A. striatus, red-shouldered hawks Buteo lineatus, ferruginous hawks Buteo regalis, and merlins Falco columbarius) in five states across the United States. In these tests, three different mechanical owls prepared by two different taxidermists were used. Each owl was prepared according to the above protocols, although the design of each was slightly different as improvements were identified and implemented.

When trapping, the mechanical owl was set next to a mist net or dho-ghaza near occupied raptor nests, following the protocol previously described for live lure owls (Bloom et al. 2007). I placed the mechanical owl on a slightly elevated perch $(\sim 0.5-1 \mathrm{~m})$ when trapping in forest, marsh, and urban habitats, and placed the owl directly on the ground in grassland habitats. I broadcasted conspecific alarm calls and great-horned owl vocalizations using a FoxPro predator call to attract the attention of target birds. Because different species responded differently to 
these calls, vocalizations were played in a context-specific manner. For example, Accipiter spp. responded to both owl and conspecific calls, but ferruginous hawks did not respond well to owl calls so only conspecific calls were used for this species. While vocalizations were being played, researchers moved the owl using the dials on the transmitter, while remaining hidden from view in a habitat-appropriate blind, until target birds were captured.

\section{Data Preparation}

I recorded the total number of territories where I attempted to capture raptors using the new mechanical owl. If a territory was visited more than once in a given year, it was counted as a single territory. However, if a single territory was visited in subsequent years, it was counted as multiple territories. I recorded the number of individuals that were successfully captured for each species and the order in which the male and female adult birds were caught at each territory (first or second). A few individuals were caught in the net but escaped due to net malfunction or handler error. These were not included as successful captures so that the data could be directly compared with previously reported capture rates using live lure owls.

When possible, I determined both the "territory capture rate" and the "individual capture rate" for each species trapped. I defined the territory capture rate as the number of individuals caught divided by the total available to be captured, assuming two adults per territory. I defined the individual capture rate as the number caught divided by the number of territorial birds that likely saw the owl. I estimated the number of birds that likely saw the owl from observation in the field. Neither of these estimators is a perfect indication of trapping success. For example, territory capture rates likely underestimate capture success, since some territorial birds do not see the owl and thus are not available to be caught. In contrast, individual capture rates may 
overestimate success, since there are likely to be birds that see the owl and are not detected by the researchers. I only report an individual capture rate for ferruginous hawks because only one adult was targeted per territory and all trapping efforts were stopped if and when the first adult was captured.

For all northern goshawks captured in New York in 2016 and 2017 and in Pennsylvania in 2017, I used the mechanical owl and I recorded time, rounded to the nearest min., of net set and capture. I defined net set as the time when researchers were concealed in the blind and additional researchers had vacated the nest area. I defined capture as the time the target bird was successfully caught in the net. I used these data to estimate, for each individual caught, a metric that I called "time to capture" that was defined as the difference between the time the bird was captured and the time the net was set. I then compared these data to those from a similar dataset collected when trapping northern goshawks using a live lure owl in Pennsylvania from 2005 2016 (Brinker, unpublished data).

I also determined the capture history for each goshawk that I successfully trapped. I assumed that all un-banded adults were first time-captures. If a captured individual had a USFWS leg band, I verified from previous records that it was previously trapped using the owl and mist net trap set. In no instance did I capture a bird previously banded by a researcher that was not associated with the project.

\section{Data Analysis: Capture rates}

I compared species-specific capture rates from trapping efforts from this study with published and unpublished data on capture rates using a live lure owl. I also compared the capture rates using the new mechanical owl with those from the first published mechanical owl description 
(Jacobs 1996). The first published mechanical owl was used in both a ground and an elevated trap set (Jacobs 1996, Jacobs and Proudfoot, 2002). I compared each of these capture rates to my rates with the new mechanical owl using a ground trap set as I did not have time to test my owl in an elevated trap set.

\section{Data Analysis: Time to capture}

I evaluated the difference in mean time to capture of northern goshawks when using the mechanical versus a live lure owl (raw data included in Appendix 3.3). Because I always used the broadcast caller with my mechanical owl, but only $50 \%$ of the live owl trapping sessions used such a caller, I used an exponential model to test if there was a difference in time to capture using the live lure owl with and without accompanying vocalizations. I did not detect a difference between the two (slope coefficient $=-0.06$, Wald test statistic $=-0.18, p=0.86$ ) and therefore, I combined all live owl data together in subsequent statistical tests.

I modelled time to capture (the response variable) as an exponential random variable within a generalized linear model framework (McCullagh and Nelder, 1989). I modelled the expected capture time as a function of owl type (mechanical or live), capture history (first time caught or recapture), and order caught (first or second of the day at a single territory). I included capture history as a covariate because I expected that having been captured in a prior year may have influenced the probability of being captured in the current year. Likewise, order caught was included as a covariate in the model. This covariate was mostly included as a correction factor since the second bird caught in a given day will always take longer than the first bird, as the consequence of the way I calculated time to capture (using net set as the start time). This is because upon catching the first adult, I would remove it from the net and secure it before 
returning to the blind to continue the trapping attempt for the remaining adult. I used the net set time as the start time for both the first and second bird caught for comparison to the dataset using the live lure owl which was collected previously and calculated in this manner. I used a Wald test to determine significance $(\mathrm{p}<0.05)$ of each covariate in the model.

I fit a total of eight models, describing all possible combinations of the three covariates and a null model, with custom code in program R version 3.3.1 (code available upon request). I compared the models using Akaike Information Criterion (AIC) model selection procedures. I ranked the models based on AIC score and models with a $\triangle \mathrm{AIC}$ of $\leq 2$ were considered equally well supported by the data (Burnham and Anderson, 2002).

\section{Cost Comparison}

Finally, I estimated the total costs associated with a mechanical owl (based on my design) and a live lure owl. These estimates included the initial cost as well as annual maintenance costs. For the mechanical owl, I included amounts I paid, rounded to the nearest $\$ 5$, for construction, taxidermy, a transport box, batteries, and annual upkeep (e.g. replacement batteries or parts, super glue and epoxy, etc.). I consulted a local avian rehabilitation center and veterinary hospital to estimate approximate costs, rounded to the nearest $\$ 5$, for housing, food, falconry equipment (leather jesses, ankles, glove, leash), and veterinary care for a live great-horned owl. Estimates

for the housing and carriers (mechanical or live) included only the material costs; labor and tool costs were not included. Materials needed for the housing and carrier were estimated based on the minimum federally-mandated size requirements for a flighted great-horned owl kept in captivity (Arent, 2007). I excluded permit costs since these may vary based on the location of trapping efforts. Since my original mechanical owl has been used successfully for three 
consecutive trapping seasons, I calculated the 3-year cost for each owl type for comparison of long-term use.

\section{Results}

\section{Capture Rates}

I used my mechanical lure owl to attempt to capture 114 of 144 adult raptors at 72 occupied territories. As expected, individual capture rates were slightly higher than territory capture rates for 5 of 6 species (Table 3.1). The only exception was merlins, where individual and territory capture rates were equal (Table 3.1) but sample size was very low. For 5 of 6 species, the territory capture rates were similar or higher when using the mechanical owl compared to a live lure owl (Table 3.1). The exception was red-shouldered hawks; I captured $42 \%$ with a mechanical owl but $75 \%$ were reported captured with the live lure owl. I was only able to compare data on individual capture rates for one species, the northern goshawk. Capture rates for this species were nearly identical with the mechanical owl (92\%) as compared to the live lure owl (94\%, Table 3.1).

My mechanical owl performed better than did the first described mechanical owl in capture of both Cooper's hawks and sharp-shinned hawks (Jacobs 1996; Table 3.2). This was true regardless of whether I considered their elevated or non-elevated trap set (Table 3.2). In contrast, the original owl appeared to more frequently capture red-shouldered hawks $(65 \%)$ when using the elevated trap set than did my owl (53\%) on the ground (Table 3.2). 


\section{Time to Capture}

I collected time to capture data on a total of 66 adult northern goshawks (live lure owl $n=34$, mechanical lure owl $n=32$ ). The best model to explain the time to capture data included owl type and order caught (Table 3.3). When using the mechanical owl to capture northern goshawks, the mean expected capture time was approximately eight min. shorter than when using the live lure owl (slope coefficient $=-0.68$, Wald test statistic $=-2.75, p=0.006$, Figure 3.2). As expected, the first bird captured in a given day was caught an average of 13 min. earlier than the second bird (slope coefficient $=-0.93$, Wald test statistic $=-3.43, \mathrm{p}$ value $=0.0006$, Figure 3.2). I had one other competing model with a $\triangle \mathrm{AIC}$ of 2 , and this model included all three covariates. However, because this model only has one more parameter than the best model, and that additional parameter (capture history) is not significant based on the Wald test (slope coefficient $=-0.004$, Wald test statistic $=-0.01, \mathrm{p}=0.99)$, this parameter is likely a "pretending variable" and should not be interpreted as having an effect (Anderson, 2008; Arnold, 2010). Therefore, I found no evidence to suggest that capture history had a strong effect on time to capture.

\section{Cost Comparison}

The initial annual cost of constructing a mechanical owl was approximately $\$ 775$, including parts, taxidermy, a box for transport, and eight rechargeable batteries with a charger (Table 3.4). For the first year, housing, a box for transport, food, and proper equipment for handling a live owl costs approximately $\$ 2,230$ (Table 3.4). Subsequent annual maintenance costs are greater for a live owl; approximately $\$ 1,325$ compared to only $\$ 75$ for a mechanical owl (Table 3.4). 
Assuming the mechanical owl lasts for three years, a mechanical owl costs far less than a live owl (mechanical: \$925; live: \$4,880; Table 3.4).

\section{Discussion}

Mechanical Owls for Raptor Trapping

My work showed that not only are mechanical owls suitable for trapping wild raptors, but with appropriate design considerations, mechanical owls may, in certain situations, perform even better than a live owl. The mechanical owls deployed were effective when trapping six different raptor species in habitat types ranging from forest, to marsh, to grassland. For most target species, capture rates were comparable or better than the published and unpublished results of capture rates with a live lure owl.

This study was the first to directly compare capture times using a mechanical versus a live lure owl. Although I was only able to make this comparison for northern goshawks in the eastern United States, I captured goshawks significantly faster with the mechanical owl than I did with the live owl. This is important from a number of ethical and logistical perspectives. From an animal welfare perspective, quicker capture times presumably reduces the amount of stress on the target bird (this is certainly the case with faster handling times; Matson et al. 2006, Romero and Romero 2001) and reduces the total time the adults are kept away from the chicks in the nest. In addition, reduced trapping time decreases the probability that potential predators will locate the nest. Likewise, from a logistical perspective, the faster I capture birds in the field, the more opportunity I have to capture other birds during the short nesting season. As researchers, our ultimate goal is to collect sound data as efficiently as possible with minimal impact on wildlife. The use of a mechanical lure owl may be an important step to get us closer to this goal. 
One potential reason for the high success of the mechanical owl is that trappers have complete control over the timing, type, and amount of movement exhibited by the mechanical owl. A live owl, especially one that has experienced being used for raptor trapping in the past, is aware of the threat from territorial raptors and sometimes remains relatively still or attempts to hide. As a result, it may take longer for the target birds to notice the live owl and the response a terrified live owl elicits may be weaker than from a mechanical owl that appears unperturbed by attacking territorial birds. Finally, the ability to move the mechanical lure owl immediately when an adult raptor is near the lure may make it more visible and result in a faster stoop by the target bird.

As expected, the first adult bird captured at each nest was captured more quickly than the second. However, this was mainly due to the manner in which the time to capture variable was defined based on the data available. If possible, it may be beneficial in future studies to have a second "start time" for when the second bird arrives near the trap set, rather than using the net set time for both individuals. Also, I had expected that capture history would influence time to capture, since previously captured birds may be more hesitant to attack the owl. However, I found that there was no evidence to support this hypothesis, suggesting that previously captured birds may not remember trap sets or being captured in prior seasons.

Obtaining any owl, live or mechanical, requires some level of investment. A live owl requires permits, housing, food, and veterinary care. A mechanical owl requires permits, mechanical parts, taxidermy, replacement batteries, occasional repairs, and a dry box for storage and protection. All these requirements incur costs of time and money by researchers. That said, the costs of a mechanical owl are far cheaper than maintaining a live owl, especially for multiple trapping seasons. 
There are also substantial ethical benefits to using a mechanical owl over a live owl. Although IACUC regulations generally allow use of a live owl, an educated observer of the behavior of a live lure owl can usually see the stress and fear the bird displays when put at a trap site. Likewise, live owls can be injured when trapping and use of a live bird is unacceptable to some members of the general public. Therefore, the benefits of using a mechanical owl - higher capture rates, lower costs, fewer ethical concerns - likely outweigh their costs. I expect that future design improvements to the mechanical owl and to its application may result in even higher success rates and a greater value to their use as compared to the use of a live lure bird.

\section{Design Considerations}

I made several design improvements over previously described versions of the mechanical owl (Jacobs, 1996). The most notable of these was the addition of a wing flapping movement. Previously designed mechanical owls included two servos to allow the head and entire body of the owl to spin independently (Jacobs, 1996). While the head movement may have mimicked a live owl, the entire body turning on a swivel is not especially natural-looking.

I believe (but did not test empirically) that the addition of the realistic wing movements improved the chances of target birds seeing the mechanical lure. I designed these movements specifically to mimic those of a young great-horned owl flapping its wings in quick short bursts. This, in conjunction with the use of small, young owl carcasses for the mechanical owl, may have contributed to my success rates by making the owl look less intimidating than would an adult owl.

Another design improvement was the magnetic attachment for the head. This allowed the head to come off easily, thus reducing the possibility of permanent damage to the mount from 
impact by especially aggressive raptors. On numerous occasions, raptors of all species knocked the head off the mechanical owl, but otherwise the owl remained intact. I was even able to capture some target birds (especially northern goshawks) with the headless owl. I do, however, recommend that when using this method, a lightweight filler is used in the skull of the owl to reduce the chance of damage from impact with the ground.

Finally, my owl design allows for the body, head, and wings to be separated for ease of transport and storage. Because of the time required for setup, I rarely used this feature. That said, the feature was useful in several space-limited situations. Future designs could improve upon this concept and include parts that allow for quick break-down and reconstruction of the owl. This way the owl could be placed in a backpack or other compact unit for easy and safe transport to nest sites. Another useful addition would be waterproofing of all mechanical parts.

\section{Approaches to Comparing Capture Rates}

It was not trivial to compare capture rates among different published studies and among different species. It was necessary to determine territory capture rates because those were the only capture rate data previous researchers using live owls typically reported. However, in some cases territory capture rates do not accurately reflect success of trapping because some territorial individuals may not be present at the nest area during trapping attempts. Therefore, individual capture rates may be more informative. For example, home ranges of northern goshawks during the breeding season can be as large as 25 square kilometers and males may range far from the nest area to find food (Reynolds et al. 1992). In this study, it was not uncommon for us to only see one territorial individual during a trapping effort. As such, reporting a territory capture rate would indicate that the trap set using the lure owl failed to catch a second individual that never 
saw the trap. In contrast, an individual capture rate would accurately reflect that I never had the opportunity to trap that individual.

Another complication with territory capture rates is that they assume that there are only two territorial adults in a territory. However, it is not unusual for raptors to form nesting trios (Santana et al. 1986, Kimball et al. 2003). When trapping red-shouldered hawks during the study, I often observed two adults and one second year bird, all of which showed aggression and defensive behavior towards the owl. Therefore, a territory capture rate does not accurately reflect the trapping success in these scenarios since there are actually three individuals that could be captured at some territories.

As a consequence of our inadequacy at assessing both number of territorial birds present and availability of those birds to be trapped, both these metrics are imperfect indicators of true capture rate. In fact, it is likely that the true capture rate may lie somewhere between the individual capture rate and the territory capture rate. As such, I believe that it is useful to report both rates when trapping nesting raptors with a live or mechanical lure owl in future research.

\section{Future Directions}

I take several lessons from my trials with mechanical owls as lures for trapping wild raptors. The most important of the findings is that for most species, mechanical owls are at least as effective, and sometimes more effective, than live lure owls. In fact, it is my belief that trapping success was far more likely to be influenced by external factors than by the type of lure I used.

For example, vegetative cover may have influenced trapping success. In particular, the thick marshy habitat of red-shouldered hawks often lacked openings near the nest to place the owl and consequently, I suspect that only some of the adult birds saw the lure owl in these areas. 
This could explain why using a mechanical owl in an elevated net set may result in greater capture success for red-shouldered hawks nesting in complex habitat (Jacobs and Proudfoot, 2002). In a similar vein, trapping in open grassland at ferruginous hawk nests also presented a great challenge. Because of the flat ground and low vegetation, the mist net (set as a dho-gaza) was typically highly visible. As a consequence, there would be numerous observed stoops at the owl but low overall capture rates.

It would also be useful to compare success rates when trapping urban or suburban nesting hawks compared to those nesting in more "natural" settings. Anecdotally, urban and suburban hawks seemed less timid and easier to capture, possibly from human habituation which made these individuals less sensitive to researcher presence. In addition, the presence of non-target species may have also influenced my ability to trap resident raptors. In some territories, vocalizations attracted numerous American crows (Crovus brachyrhynchos) or non-target raptor species (e.g. prairie falcons, Falco mexicanus; northern harriers, Circus cyaneus). This only occurred on a few occasions, but I noted that I was never able to catch target birds in the presence of non-target species. Therefore, future studies could be used to determine how vegetative cover, net visibility, human habituation, and the presence of non-target species affect trapping success.

Finally, while I did not detect a difference in capture time based on the use of vocalizations in the live owl dataset, vocalizations may be important when using a mechanical owl. Previous research has shown that vocalizations used in conjunction with a taxidermized owl increased success rates (McCloskey and Dewey, 1999). Thus, I always used vocalizations when trapping with the mechanical lure owl, although each trapping team used different strategies for 
the specific species that was targeted. Future research could test the difference in success rates and time to capture when using the mechanical owl with and without vocalizations.

\section{Conclusions}

In the cases I evaluated, the use of mechanical owls as a lure to trap wild raptors presents a suite of advantages over use of live lure owls. Beyond their equal or superior performance in the field, they cost less, are easier to transport, require fewer permits, are ethically superior (for the lure and the wild bird), and are likely to be perceived more positively by the public. Use of mechanical owls though, is not without its own set of challenges that are distinct from those associated with use of a live owl. In particular, live owls do not require batteries to operate (batteries which can sometimes die at extremely inconvenient times), live owls are far more waterproof than a taxidermy mount, and live owls are much better at ducking (and therefore, do not require repairs). Although mechanical owls may not perform as well as a live owl in every setting, this study suggests that the use of a mechanical lure owl is applicable in a wide variety of situations.

\section{Literature Cited}

ANDERSON, D.R. 2008. Model-based inference in the life sciences, a primer on evidence. Springer, New York, NY, USA.

ARENT, L.R. 2007. Raptors in Captivity: Guidelines for Care and Management. Hancock House Publishers, Blaine, WA, USA.

ARNOLD, T.W. 2010. Uninformative parameters and model selection using Akaike's Information Criterion. Journal of Wildlife Management 74:1175-1179.

BloOM, P.H., J.L. HencKel, E.H. Henckel, J.K. SCHMUtZ, B.WoOdBRIDGE, J.R. BRYAN, R.L. Anderson, P.J. Detrich, T.L. Maechtle, J.O. McKinley, M.D. MCCRARy, K. Titus, ANd P.F. 
SCHEMPF. 1992. The dho-gaza with great horned owl lure: An analysis of its effectiveness in capturing raptors. Journal of Raptor Research 26:167-178.

Bloom, P.H., W.S. Clark, AND J.W. KIDD. 2007. Capture techniques. Pages 193 - 219 in D.M. Bird, and K.L. Bildstein [Eds.], Raptor Research and Management Techniques. Hancock House Publishers, Blaine, WA, USA.

BURNHAM, K.P. AND ANDERSON, D.R. 2002. Model selection and multimodel inference: a practical information-theoretic approach. Springer, New York, NY, USA.

HAMERSTROM, F. 1963. The use of great horned owls in catching marsh hawks. Proceedings of the XIII International Ornithological Congress 13:866-869.

JACOBS, E.A. 1996. A mechanical owl as a trapping lure for raptors. Journal of Raptor Research 30:31-32.

JACOBS, E.A, AND G.A. ProudfoOt. 2002. An elevated net assembly to capture nesting raptors. Journal of Raptor Research 36:320-323.

Kimball, R.T., P.G. PARKER, AND J.C. BeDnARZ. 2003. Occurrence and evolution of cooperative breeding among the diurnal raptors (Accipitridae and Falconidae). The Auk 120:717-729.

Matson, K.D., B.I. TiElEman, AND K.C. KLASING. 2006. Capture stress and the bactericidal competence of blood and plasma in five species of tropical birds. Physiological and Biochemical

Zoology 79:556-564.

MCCloskey, J.T., AND S.R. DEWEY. 1999. Improving the success of a mounted great horned owl lure for trapping northern goshawks. Journal of Raptor Research 33:168-169.

McCullagh, P., AND J.A. Nelder. 1989. Generalized Linear Models, Second Edition. Chapman and Hall/CRC, New York, NY, USA.

MillsAP, B.A. 2007. Legal considerations. Pages 437 - 449 in D.M. Bird, and K.L. Bildstein [Eds.], Raptor Research and Management Techniques. Hancock House Publishers, Blaine, WA, USA.

Reynolds, R.T., R.T. Graham, M.H. Reiser, R.L. BASSETt, P.L. Kennedy, D.A. BoyCE, JR., G. GoOdwIN, R. SMITH, AND E.L. FISHER. 1992. Management recommendations for the northern goshawk in the southwestern United States. Forest Service General Technical Report, USDA, Fort Collins, CO, USA.

Romero, M., AND R.C. RoMERO. 2002. Corticosterone responses in wild birds: The importance of rapid initial sampling. The Condor 104:129-135. 
Santana, E. R.L. KNight, And S.A. Temple. 1986. Parental care at a red-tailed hawk nest tended by three adults. The Condor 88:109-110.

Schemnitz, S.D., G.R. BAtcheller, M.J. Lovallo, H.B. White, AND M.W. FAll. 2009. Capturing and handling wild animals. Pages 64 - 117 in N.J. Silvy [Eds.], The Wildlife Techniques Manual. John Hopkins University Press, Baltimore, MD, USA.

STEENHOF, K., G.P. CARPENTER, AND J.C. BEDNARZ. 1994. Use of mist nets and a live great horned owl to capture breeding American kestrels. Journal of Raptor Research 28:194196. 
Table 3.1: Territory and individual capture rates for six species of raptors using mechanical or live owl lures. All mechanical owl capture rates come from my new design with head and wing movement. Location includes states in the USA where trapping attempts occurred with the mechanical lure owl. Live lure owl data are from previous studies with locations of trapping efforts shown in parentheses. Species include Cooper's hawk (COHA), ferruginous hawk (FEHA), merlin (MERL), northern goshawk (NOGO), redshouldered hawk (RSHA), and sharp-shinned hawk (SSHA). Individual capture rates were not reported in most published studies.

\begin{tabular}{cccccc} 
& & \multicolumn{2}{c}{ Territory Capture Rates } & \multicolumn{2}{c}{ Individual Capture Rates } \\
\hline Species & Location & Mechanical Owl & Live Owl & Mechanical Owl & Live owl \\
\hline \hline COHA & NY, PA & $72 \%(13 / 18)$ & $52 \%(32 / 62)(\mathrm{CA}, \mathrm{USA})^{1}$ & $76 \%(13 / 17)$ & N/A \\
FEHA & ID & N/A & $19 \%(66 / 354)(\mathrm{AB}, \mathrm{CA})^{1}$ & $55 \%(6 / 11)$ & N/A \\
MERL & NY & $100 \%(2 / 2)$ & $90 \%(77 / 86)(\mathrm{AK}, \mathrm{USA})^{1}$ & $100 \%(2 / 2)$ & N/A \\
NOGO & NY, PA & $77 \%(34 / 44)$ & $74 \%(46 / 62)(\mathrm{PA}, \mathrm{USA})^{2}$ & $92 \%(34 / 37)$ & $94 \%(46 / 62)(\mathrm{PA}, \mathrm{USA})^{2}$ \\
& & $76 \%(41 / 54)(\mathrm{CA}, \mathrm{USA})^{1}$ & & \\
& & $54 \%(27 / 50)(\mathrm{CA}, \mathrm{USA})^{1}$ & & \\
& & & & \\
RSHA & NY, WV, VA & $42 \%(21 / 50)$ & $75 \%(199 / 264)(\mathrm{CA}, \mathrm{USA})^{1}$ & $53 \%(21 / 40)$ & N/A \\
SSHA & NY, PA & $75 \%(6 / 8)$ & $53 \%(18 / 34)(\text { Spain })^{3,4}$ & $86 \%(6 / 7)$ & $(\mathrm{CA}, \mathrm{USA})^{1}$ \\
\hline
\end{tabular}

${ }^{1}=$ Bloom et al. 1992, ${ }^{2}=$ Brinker (unpublished data), ${ }^{3}=$ Zuberogoitia et al. 2008. 4 No data are available for sharp-shinned hawks, reported capture rate is from Eurasian sparrowhawks (Accipiter nisus). 
Table 3.2: Individual capture rates of my mechanical owl compared to those from previous mechanical owl datasets. Species include red-shouldered hawks (RSHA), Cooper's hawks (COHA), and sharp-shinned hawks (SSHA). Previous mechanical owl design included head and full body swiveling movement and this design was used both on the ground and in an elevated trap set. My owl included both head and wing movement and was only using with a trap set on the ground. 1 = Jacobs, 1996, Wisconsin, USA, 2 = Jacobs and Proudfoot, 2002, Wisconsin, USA.

\begin{tabular}{cccc}
\hline Species & $\begin{array}{c}\text { Original mechanical owl } \\
\text { on ground }^{1}\end{array}$ & $\begin{array}{c}\text { Original mechanical owl } \\
\text { elevated trap set }^{2}\end{array}$ & $\begin{array}{c}\text { My owl on } \\
\text { ground }\end{array}$ \\
\hline \hline RSHA & $54 \%(15 / 28)$ & $65 \%(30 / 46)$ & $53 \%(21 / 40)$ \\
COHA & $60 \%(3 / 5)$ & $67 \%(2 / 3)$ & $76 \%(13 / 17)$ \\
SSHA & $77 \%(48 / 62)$ & $81 \%(34 / 42)$ & $86 \%(6 / 7)$ \\
\hline
\end{tabular}


Table 3.3: Akaike's Information Criterion (AIC), the change in AIC ( $\triangle$ AIC), and model weight results for time to capture of northern goshawks based on owl type (mechanical vs. live), capture history (first capture vs. recapture), and order caught (first of the day vs. second of the day at a single territory).

\begin{tabular}{lccc}
\hline \multicolumn{1}{c}{ Model Parameters } & AIC & $\boldsymbol{\Delta}$ AIC & Model Weight \\
\hline Owl type + Order caught & 502.9 & 0.0 & 0.681 \\
Owl type + Capture history + Order caught & 504.9 & 2.0 & 0.251 \\
Order caught & 508.3 & 5.4 & 0.046 \\
Capture history + Order caught & 510.2 & 7.2 & 0.019 \\
Owl type & 513.8 & 10.9 & 0.003 \\
Owl type + Capture history & 515.6 & 12.7 & 0.001 \\
Intercept only & 522.2 & 19.3 & 0.000 \\
Capture history & 524.2 & 21.2 & 0.000 \\
\hline
\end{tabular}


Table 3.4: Initial and annual cost estimates for a mechanical versus a live lure owl.

\begin{tabular}{|c|c|c|c|c|}
\hline & \multicolumn{2}{|c|}{ Mechanical Owl } & \multicolumn{2}{|l|}{ Live Owl } \\
\hline & Item & Cost & Item & Cost \\
\hline \multirow{5}{*}{ Initial costs } & Parts & $\$ 150$ & Housing & $\$ 700$ \\
\hline & Taxidermy & $\$ 500$ & Falconry Equipment & $\$ 80$ \\
\hline & Transport box & $\$ 100$ & Transport box & $\$ 150$ \\
\hline & Batteries/Charger & $\$ 25$ & Veterinary fees & $\$ 100$ \\
\hline & & & Food & $\$ 1,200$ \\
\hline Total Cost (1 year) & & $\$ 775$ & & $\$ 2,230$ \\
\hline \multirow{3}{*}{ Annual costs } & & & Replacement falconry Equipment & $\$ 25$ \\
\hline & Misc. for upkeep & $\$ 75$ & Veterinary fees & $\$ 100$ \\
\hline & & & Food & $\$ 1,200$ \\
\hline Total Cost ( 3 years) & & $\$ 925$ & & $\$ 4,880$ \\
\hline
\end{tabular}




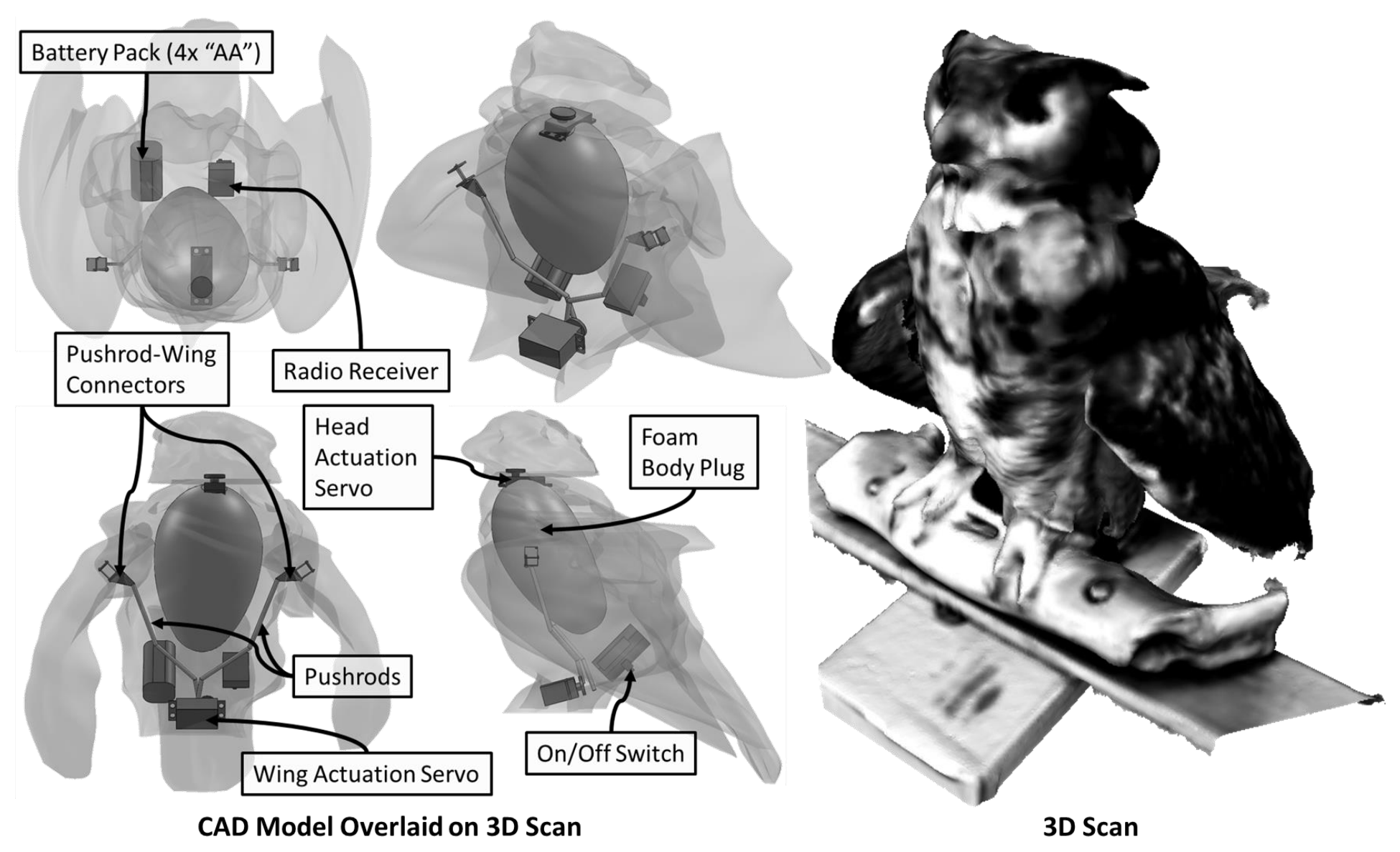

Figure 3.1: Three-dimensional scan of my first prototype of the new mechanical owl design (right) with CAD model overlay on 3D scan illustrating foam body insert, hardware, and mechanical components and their location (left). 


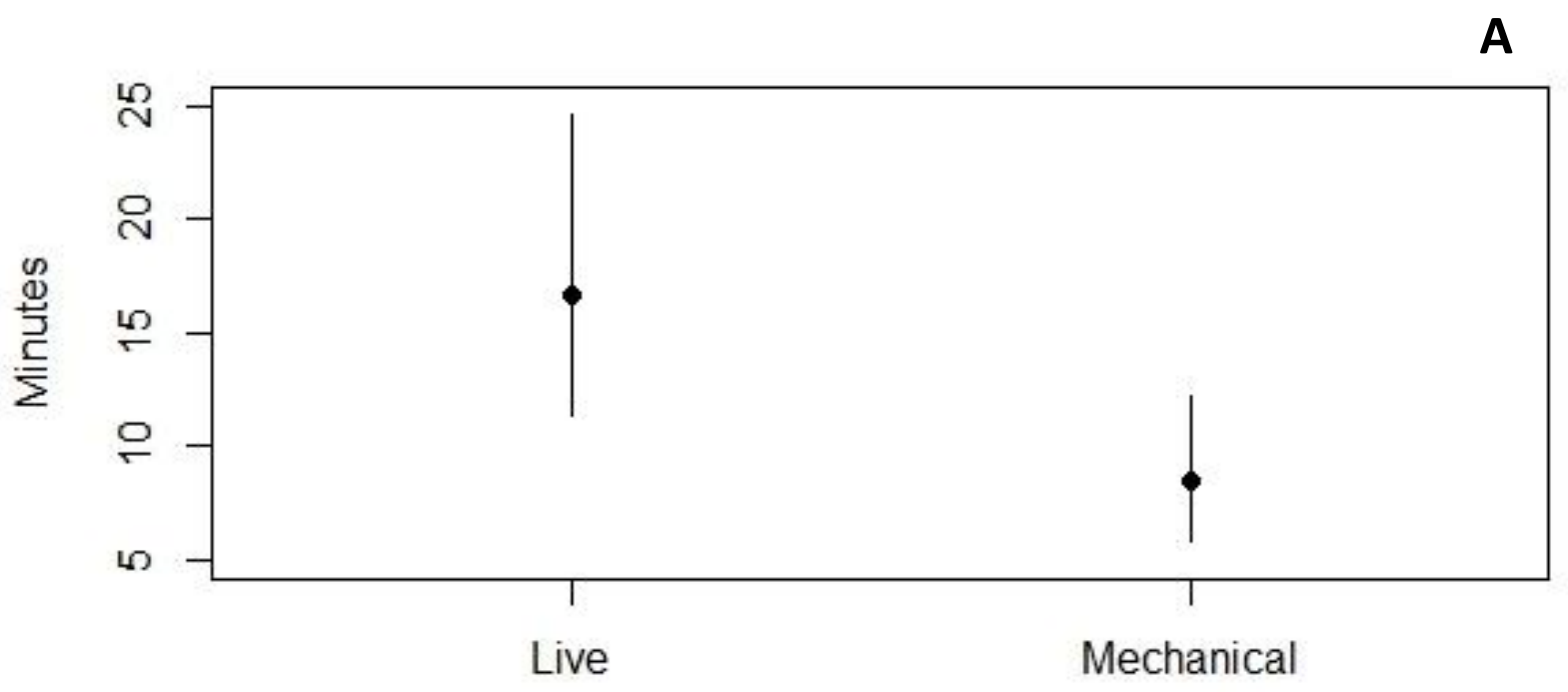

Owl Type

B

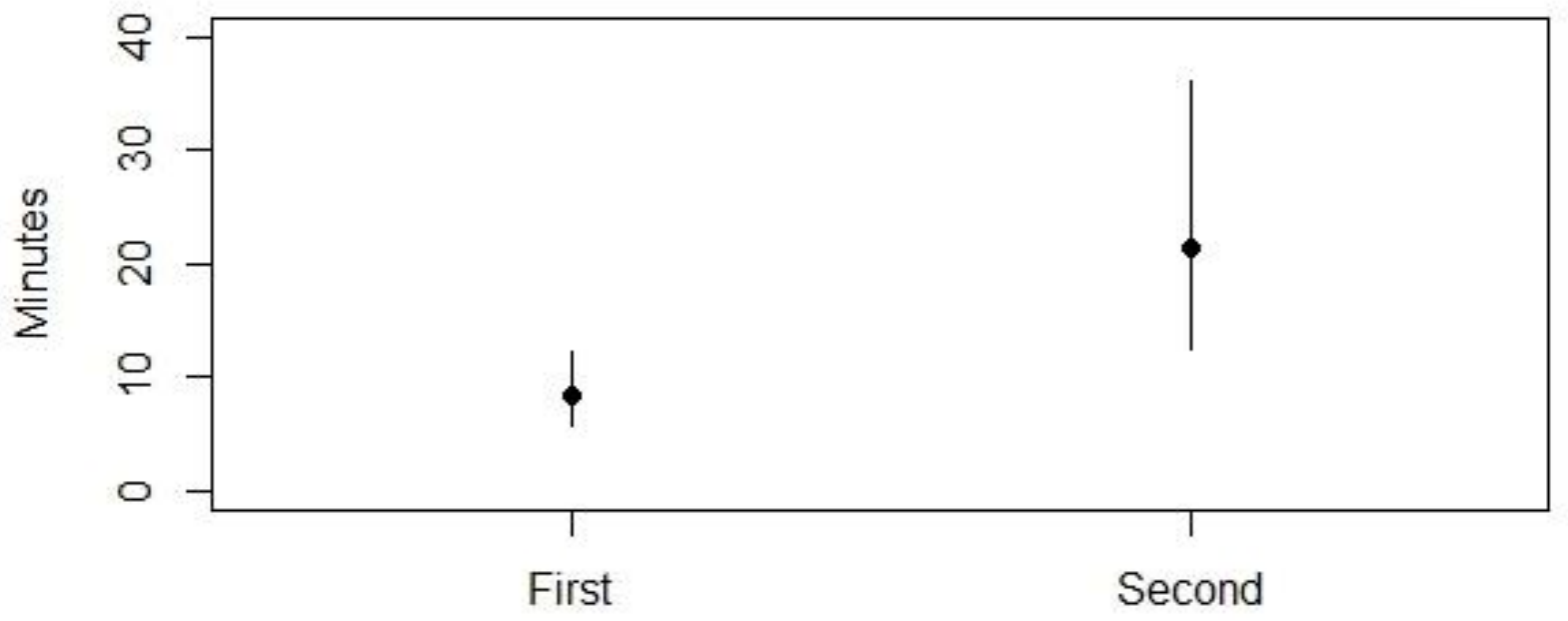

Order Caught

Figure 3.2: (A) Expected time to capture, in min., of northern goshawks using a live versus a mechanical lure owl. (B) Expected time to capture, in min., of the first and second goshawk captured at a single nest territory on the same day. Error bars represent $95 \%$ confidence intervals. 
Appendix 3.1: Minimum tool list necessary for assembly of mechanical owl.

- Hobby Knife

- Snap-blade Razor Knife

- Cordless Drill \& bits

- Scroll Saw /w metal \& wood blades

- Rotary Tool /w cutoff wheels \& sanding discs

- Small mixing cups \& sticks

- Hand Tools: pliers, screwdrivers,

- Safety: Nitrile gloves, paper face masks, safety glasses 
Appendix 3.2: Suggested hardware and materials for assembly of mechanical lure owl.

\section{$\underline{\text { Item }}$}

- Radio Transmitter

- Radio Receiver

- $\operatorname{Servo}(2 \mathrm{x})$

- Switch

- Battery

- Pushrods

- Pushrod-Wing Connectors

- Pushrod-Servo Connector

- Magnets

- 5-minute Epoxy

- Silicone Adhesive

- Microfiber Filler

- Aluminum Sheet

- Threaded Rod

- Nuts \& Washers

\section{$\underline{\text { Name }}$}

Futaba 3PRKA 3-channel ground transmitter Futaba R203GF 3-channel ground receiver

Futaba S3003 Standard Servo

Futaba SWH12

Futaba NR4QB

Great Planes 4-40 thread 12" /w clevis

Great Planes Large Nylon Control horn

Great Planes screw-lock connector

$1 / 4$ " diameter, $1 / 16 "$ thick rare earth magnet $(8 \mathrm{x})$

Loctite Heavy Duty 5 minute epoxy

Loctite Clear Silicone Waterproof Sealant

West System 403 Microfiber Adhesive Filler

$1 / 16$ " thick 6061 aluminum sheet

8-32 Threaded Rod (any)

8-32 Nyloc nuts \& flat washers

\section{Purpose}

Sends control signals from operator to system Receives control signals and distributes to servo actuators

Servomotor actuators, one for each independent motion Power toggle for system

Rechargeable system battery (can substitute 4x AA battery holder)

Transmits movement from wing drive servo to wings Connects Pushrod to Wing

Connects servo to wing pushrod

Removable connection between head and actuation servo

High-strength adhesive for permanent connections

Long-term removable bonds - servo mounting

Fiberglass filler to thicken and strengthen epoxy

Body-side wing mounts

Wing-side wing mounts

Body-wing fastening 
Appendix 3.3: Time to capture raw data from trapping attempts on northern goshawks in NY and PA during the $2005-2017$ breeding seasons.

\begin{tabular}{|c|c|c|c|c|c|c|c|}
\hline Year & $\begin{array}{c}\mathrm{Se} \\
\mathbf{x}\end{array}$ & State & Owl Type & $\begin{array}{c}\text { Vocalization } \\
\text { s used? } \\
\end{array}$ & $\begin{array}{l}\text { Capture } \\
\text { History } \\
\end{array}$ & $\begin{array}{c}\text { Order } \\
\text { Caught } \\
\end{array}$ & $\begin{array}{l}\text { Time to } \\
\text { Capture } \\
\end{array}$ \\
\hline 2016 & $\mathrm{~F}$ & NY & Live & $\mathrm{Y}$ & First & 1 & 9 \\
\hline 2005 & $\mathrm{~F}$ & PA & Live & $\mathrm{N}$ & First & 1 & 10 \\
\hline 2005 & M & PA & Live & $\mathrm{N}$ & First & 2 & 61 \\
\hline 2010 & $\mathrm{~F}$ & PA & Live & $\mathrm{N}$ & First & 1 & 15 \\
\hline 2010 & $\mathrm{~F}$ & PA & Live & $\mathrm{N}$ & First & 1 & 40 \\
\hline 2010 & $\mathrm{~F}$ & PA & Live & $\mathrm{N}$ & Recap & 1 & 15 \\
\hline 2011 & $\mathrm{~F}$ & PA & Live & $\mathrm{N}$ & First & 1 & 5 \\
\hline 2011 & $\mathrm{~F}$ & PA & Live & $\mathrm{N}$ & First & 1 & 10 \\
\hline 2012 & M & PA & Live & $\mathrm{N}$ & First & 1 & 10 \\
\hline 2012 & $\mathrm{~F}$ & PA & Live & $\mathrm{N}$ & Recap & 1 & 5 \\
\hline 2012 & $\mathrm{~F}$ & PA & Live & $\mathrm{N}$ & Recap & 1 & 10 \\
\hline 2012 & M & PA & Live & $\mathrm{N}$ & First & 2 & 5 \\
\hline 2012 & $\mathrm{~F}$ & PA & Live & $\mathrm{N}$ & First & 2 & 180 \\
\hline 2013 & $\mathrm{~F}$ & PA & Live & $\mathrm{N}$ & First & 1 & 25 \\
\hline 2013 & M & PA & Live & $\mathrm{N}$ & First & 1 & 6 \\
\hline 2013 & $\mathrm{~F}$ & PA & Live & $\mathrm{N}$ & First & 1 & 4 \\
\hline 2013 & $\mathrm{~F}$ & PA & Live & $\mathrm{N}$ & Recap & 1 & 30 \\
\hline 2013 & M & PA & Live & $\mathrm{Y}$ & First & 2 & 68 \\
\hline 2013 & $\mathrm{~F}$ & PA & Live & $\mathrm{N}$ & Recap & 2 & 23 \\
\hline 2014 & $\mathrm{~F}$ & PA & Live & $\mathrm{Y}$ & First & 1 & 1 \\
\hline 2014 & $\mathrm{~F}$ & PA & Live & $\mathrm{Y}$ & First & 1 & 55 \\
\hline 2014 & $\mathrm{~F}$ & PA & Live & $\mathrm{Y}$ & Recap & 1 & 38 \\
\hline 2014 & $\mathrm{~F}$ & PA & Live & $\mathrm{Y}$ & Recap & 1 & 3 \\
\hline 2014 & M & PA & Live & $\mathrm{Y}$ & Recap & 2 & 3 \\
\hline 2015 & M & PA & Live & $\mathrm{Y}$ & First & 1 & 12 \\
\hline 2015 & M & PA & Live & $\mathrm{Y}$ & Recap & 1 & 13 \\
\hline 2015 & $\mathrm{~F}$ & PA & Live & Y & First & 2 & 94 \\
\hline 2015 & $\mathrm{~F}$ & PA & Live & $\mathrm{Y}$ & Recap & 2 & 51 \\
\hline 2016 & $\mathrm{~F}$ & PA & Live & $\mathrm{Y}$ & First & 1 & 5 \\
\hline 2016 & $\mathrm{~F}$ & PA & Live & $\mathrm{Y}$ & First & 1 & 14 \\
\hline 2016 & $\mathrm{~F}$ & PA & Live & Y & First & 1 & 9 \\
\hline 2016 & M & PA & Live & $\mathrm{Y}$ & First & 1 & 18 \\
\hline 2016 & M & PA & Live & $\mathrm{Y}$ & First & 2 & 15 \\
\hline 2016 & $\mathrm{~F}$ & PA & Live & $\mathrm{Y}$ & First & 2 & 19 \\
\hline 2015 & M & NY & Mechanical & $\mathrm{Y}$ & First & 1 & 30 \\
\hline 2015 & $\mathrm{~F}$ & NY & Mechanical & $\mathrm{Y}$ & First & 1 & 10 \\
\hline 2015 & F & NY & Mechanical & Y & First & 1 & 10 \\
\hline 2015 & $\mathrm{~F}$ & NY & Mechanical & Y & First & 1 & 10 \\
\hline 2015 & $\mathrm{~F}$ & NY & Mechanical & Y & First & 1 & 5 \\
\hline
\end{tabular}




\begin{tabular}{cccccccc}
2015 & M & NY & Mechanical & Y & First & 1 & 30 \\
2015 & M & NY & Mechanical & Y & First & 2 & 30 \\
2015 & M & NY & Mechanical & Y & First & 2 & 10 \\
2016 & F & NY & Mechanical & Y & First & 1 & 10 \\
2016 & F & NY & Mechanical & Y & First & 1 & 10 \\
2016 & M & NY & Mechanical & Y & First & 1 & 2 \\
2016 & F & NY & Mechanical & Y & First & 1 & 4 \\
2016 & M & NY & Mechanical & Y & First & 1 & 1 \\
2016 & F & NY & Mechanical & Y & First & 1 & 2 \\
2016 & F & NY & Mechanical & Y & First & 1 & 1 \\
2016 & M & NY & Mechanical & Y & Recap & 1 & 9 \\
2016 & F & NY & Mechanical & Y & Recap & 1 & 1 \\
2016 & M & NY & Mechanical & Y & First & 2 & 15 \\
2016 & F & NY & Mechanical & Y & First & 2 & 25 \\
2017 & F & NY & Mechanical & Y & First & 1 & 11 \\
2017 & F & NY & Mechanical & Y & First & 1 & 6 \\
2017 & F & NY & Mechanical & Y & First & 1 & 8 \\
2017 & M & NY & Mechanical & Y & First & 1 & 3 \\
2017 & M & NY & Mechanical & Y & Recap & 1 & 26 \\
2017 & M & NY & Mechanical & Y & First & 2 & 3 \\
2017 & M & NY & Mechanical & Y & First & 2 & 23 \\
2017 & M & NY & Mechanical & Y & First & 2 & 8 \\
2017 & F & NY & Mechanical & Y & Recap & 2 & 24 \\
2017 & M & PA & Mechanical & Y & First & 1 & 7 \\
2017 & F & PA & Mechanical & Y & First & 1 & 9 \\
2017 & F & PA & Mechanical & Y & First & 2 & 21 \\
2017 & M & PA & Mechanical & Y & First & 2 & 5 \\
\hline & & & & & & & \\
\end{tabular}




\title{
Chapter 4: Interpreting genetic bottlenecks: The utility of examining multiple closely related species to understand demographic history
}

\begin{abstract}
Understanding the genetic consequences of demographic declines is an important component of conservation research. Currently, there are two methods for investigating genetic bottleneck occurrence based on contemporary genetic data: the heterozygosity excess method, and the $M$ ratio method. Previous research suggests that each of the methods has strengths and weaknesses for accurately detecting bottlenecks, and therefore, a useful approach is using both tests in conjunction with one another. A major limitation of these tests, however, is the reliance on mutation model parameters that are seldom available for non-model species. Therefore, I propose a novel method of comparing the results of both bottleneck tests on multiple closely-related species to understand the relative impact of demographic declines. I tested for genetic bottlenecks in two closely-related raptor species that experienced historic declines in the eastern United States as a result of multiple anthropogenic disturbances. I found that there was some evidence to suggest a genetic bottleneck in northern goshawks (Accipiter gentilis) and Cooper's hawks (A. cooperii) using the heterozygosity excess and $M$ ratio method, respectively. However, as previously suggested, the results were strongly influenced by mutation model parameters used in the simulations. Despite this, I was able to use the results from each species to inform the relative impact of demographic declines. For example, the $M$ ratio test may indicate that declines were much more severe in the Cooper's hawk population, while the heterozygosity excess test in conjunction with allelic richness may suggest that goshawk populations may have bottlenecked then remained small for a long time. This study is the first to show the utility of comparing bottleneck tests for two closely-related species with similar demographic histories.
\end{abstract}




\section{Introduction}

An important component of conservation biology involves identifying demographic bottlenecks and understanding their effect on genetic variation in a population (Cornuet and Luikart 1996). Numerous species are experiencing severe reductions in population size from a variety of anthropogenic disturbances, such as habitat loss and fragmentation (Luikart et al. 1998; Blomqvist 2010). Often, such major declines in populations can have long-term genetic consequences as a result of bottlenecks, which create a significant loss of genetic diversity within a population (Hamilton 2009). Loss of genetic diversity can lead to increased inbreeding, fixation of deleterious alleles, reduced population viability, and ultimately make it difficult for species to adapt to future changes in the environment (Frankham 1995; Allendorf and Leary 1996; Newman and Pilson 1997; Hamilton, 2009). In general, it is broadly accepted by conservation biologists that bottlenecks are a concern, especially for less common species, since these issues can potentially increase the probability of extinction (Frankel and Soulé 1981; Hendrick and Miller 1992; Frankham 1995; Cornuet and Luikart 1996; Spencer et al. 2000).

Ideally, when investigating a reduced population, it is best to compare historical and contemporary genetic data to identify the presence and severity of a genetic bottleneck (Schwartz et al. 2007; Bonebrake et al. 2010). However, this is often not possible since historic samples or data may not be available for these types of comparisons (Bonebrake et al. 2010). While there are efforts to collect long-term data and archive museum specimens for genetic samples (Wandeler et al. 2007; Leonard 2008), it is difficult to predict which species will experience future demographic declines, and when or where these declines will occur.

To solve this problem, researchers have developed a number of alternative techniques that examine current genetic data to determine the likelihood of past genetic bottlenecks. Two of 
the most widely used genetic methods for detecting bottlenecks are the heterozygosity excess method (Cornuet and Luikart 1996) and the $M$ ratio method (Garza and Williamson 2001). Several studies have evaluated the utility and accuracy of these methods using both empirical and simulated datasets (Spencer et al. 2000; Garza and Williamson 2001; Williamson-Natesan 2005; Busch et al. 2007; Peery et al. 2012). In general, the heterozygosity excess test is better at detecting more recent or less severe bottlenecks, especially when pre-bottleneck populations are small or when mutation rates are low. In contrast, the $M$ ratio method is more reliable at detecting long-lasting, severe, bottlenecks when pre-bottleneck populations are large and mutation rates are high, even when the population has made a demographic recovery (Williamson-Natesan 2005). Therefore, the use of both methods in conjunction with one another may be the best approach when investigating the possibility of genetic bottlenecks in at-risk populations.

Unfortunately, both the heterozygosity excess and $M$ ratio method come with a variety of challenges. In particular, both methods are prone to Type I (detecting a bottleneck in an equilibrium population) and Type II (failing to detect a bottleneck when it exists) errors (Williamson-Natesan 2005). These tests are heavily reliant on assumptions about how mutations occur and estimates of effective population size. For example, the rate at which errors occur is influenced by the assumed mutation model (e.g., infinite alleles model, IAM; step-wise mutation model, SMM; or the two-phase mutation model, TPM). Williamson-Natesan (2005) found that in general, both methods were less subject to errors under the TPM. However, when using the TPM, additional parameters must be set by the user including the average size of multistep mutations, the proportion of mutations that are multistep, and in the case of $M$ ratio, an estimate of $\theta$, which requires an accurate estimate of both mutation rate $(\mu)$ and effective population size 
$\left(N_{e}\right)$. Studies have shown that incorrect estimations of these parameters can strongly influence the probability of error (see Williamson-Natesan 2005, Peery et al. 2012; Putman and Carbone 2014). This is further complicated by the fact that the value of each parameter is generally unknown for species of interest (Peery et al. 2012). Therefore, interpreting the results of bottleneck tests is difficult given that there is substantial uncertainty in input parameters for wild populations.

One potential approach for reducing the uncertainty in bottleneck testing could be to examine the same markers in multiple closely-related species inhabiting the same geographic area at the same time. This is because microsatellite mutation patterns are likely conserved across closely-related organisms (e.g. mutation rates; see Schlötterer, 1998). In addition, this could be especially useful if each species experienced similar threats that resulted in demographic declines. By using this approach, researchers can use the results of bottleneck tests to compare genetic effects in a relative sense rather than relying on arbitrary cut-off values from tests of significance that are strongly influenced by unknown genetic parameters. For example, if a range of reasonable mutation parameters are used and the bottleneck tests are significant or close to significant for one species in some cases, but this is never the case for the other species, it may suggest that the first species experienced more dramatic genetic effects from demographic declines.

To demonstrate the utility of this method, I analyzed genetic data from two closely related raptor species, the northern goshawk (Accipiter gentilis) and the Cooper's hawk (A. cooperii). These widely distributed, forest-dwelling predators both faced multiple threats throughout the early to mid-1900's including habitat loss and fragmentation, direct human persecution, and the widespread use of organochloride pesticides such as DDT (Snyder et al. 
1973; Bildstein 2001; Bildstein 2008). There is evidence to suggest that these factors led to population declines in both species, and that the declines were especially pronounced in the eastern United States (Snyder et al. 1973; Bednarz et al. 1990; Farmer et al. 2008; Breeding Bird Atlas data). Further, the Cooper's hawk population seems to have made a full recovery, while the status of the goshawk is less clear, and it is currently a species of concern in many states across the northeast (Farmer et al. 2008; NatureServe 2017).

The goals of my research were to 1) examine the current genetic diversity and structure of northern goshawk and Cooper's hawk populations in the northeastern U.S., 2) determine if there is any evidence of a genetic bottleneck in either species, and 3) explore the utility of comparing the results to inform conclusions about the relative impacts of declines. This approach may help to better understand the consequences of the demographic declines in these species to inform conservation and management efforts, especially for the goshawk. In addition, this case study may show the utility of this type of analysis for future genetic bottleneck studies of poorly understood wild populations.

\section{Materials and Methods}

\section{Sample Collection}

I collected tissue samples (blood, feather, muscle) from Accipiter hawks from multiple locations across the northeastern United States. Samples were collected both in the field and at wildlife rehabilitation centers (Figure 4.1 and Figure 4.2). Breeding adult hawks were captured using standard techniques described in the Raptor Research and Management Techniques manual (Bloom et al. 2007). Trapping efforts were primarily in New York, Pennsylvania, and West Virginia. Blood samples were taken from the jugular or brachial vein of all healthy individuals 
captured, then transferred to either an Whatman ${ }^{\circledR}$ FTA card or placed in a liquid cell lysis buffer or ethanol (Wink 2007). Feather samples were collected and stored in paper envelopes at room temperature. Volunteers from wildlife rehabilitation centers collected muscle tissue from dead specimens and buccal swabs from live birds undergoing rehabilitation. The date of admission was recorded for all individuals sampled at wildlife centers, and these dates were used to separate out probable residents admitted during the breeding season (April - August) from the larger pool of residents and migrants (hereafter potential migrants; admitted September March). Finally, to reduce the chance of falsely detecting inbreeding based on sampling bias, I included only one member of each known family group in the final analysis.

\section{Laboratory Processing}

I extracted DNA from all samples using the Qiagen DNAeasy ${ }^{\mathrm{TM}}$ Blood \& Tissue Kit following the manufacturer's tissue-appropriate protocol. DNA quantity and quality were determined using a Thermo Scientific NanoDrop ${ }^{\mathrm{TM}}$ Lite Spectrophotometer. I selected 15 previously described polymorphic microsatellite markers developed for northern goshawks for genetic analysis that also cross-amplify in Cooper's hawks (Topinka and May 2004; Haughey et al. 2016). These included Age 2, Age 4, Age 5, Age 6, Age 7, Age 8, Age 9, and Age 11 (Topinka and May 2004), and Age 1302, Age 1305, Age 1308, Age 1311, Age 1314, and Age 1316 (Haughey et al. 2016). I used the Qiagen Multiplex PCR kit following the manufacturer's recommendations and ran the markers in sets of three for a total of five multiplex reactions. I followed the thermocycler protocol developed by the original authors for each of the respective markers (see Topinka and May 2004; Haughey et al. 2016). The forward primer of each primer set was fluorescently labeled for detection of alleles on a Beckman GeXP Genetic Analyzer. Ten percent of all 
samples were run in duplicate, and negative controls were included on all capillary electrophoresis runs.

\section{Quality Control}

All markers were tested for departure from Hardy-Weinburg Equlibrium (HWE) and for linkage disequilibrium using GENEPOP on the Web (Raymond and Rousset 1995; Rousset, 2008). In both cases, a sequential Bonferroni correction (Rice 1989) was applied to account for multiple comparisons. Program MiCROCHECKER (Version 2.2.3, Van Oosterhout et al. 2004) was used to determine if null alleles or scoring errors were present in any of the markers.

\section{Evaluation of Genetic Structure}

I used a Bayesian-clustering approach to infer the occurrence of population structuring in each species (STRUCTURE Version 2.3.4, Pritchard et al. 2000; Fauch et al. 2003, 2007; Hubisz et al. 2009) assuming an admixture model with correlated allele frequencies. I ran the program both with and without the a priori sampling location information (parameters: 100,000 burn-in period and 100,000 Markov chain Monte Carlo iterations, repeated 10 times). For each species, I tested a range of possible number of clusters $(K)$ and this range was set to $2+$ the number of sampling

locations. I determined the optimum $K$ using the Evanno et al. (2005) method in STRUCTURE HARVESTER (Earl and vonHoldt, 2012). For the Cooper's hawk samples, specifically, I tested for population structure first using only the known resident samples, then repeated the test using all samples including residents and potential migrants. 


\section{Estimating genetic diversity and Ne}

Standard measures of genetic diversity were calculated for both species. I calculated Wright's inbreeding coefficient ( $\left.F_{I S}\right)$ in program GENALEX to determine if there was evidence of inbreeding in either population. I determined the observed $\left(H_{o}\right)$ and expected $\left(H_{e}\right)$ heterozygosities using GenAleX (Version6.502, Peakall and Smouse 2006; 2012). Allelic richness by locus was calculated for each species using HP-RARE (Version June-6-2006, Kalinowski 2005). To compare allelic richness between the two species, I first determined a rarified allelic richness which corrects for differences in sample size. This metric was calculated using the smallest sample size and lowest number of microsatellite loci in the respective datasets (n samples $=98$, loci $=11$ ). For both observed heterozygosity and rarified allelic richness, I tested the distribution of the differences for normality using a Shapiro-Wilk test (Zar, 2010). I then used a paired t-test in R ( $\mathrm{R}$ Core Team 2013) to determine if the allelic richness or observed heterozygosity was significantly different between the two species.

Estimating effective population size $\left(N_{e}\right)$ is often difficult yet highly important for detecting population bottlenecks, so I used multiple methods to estimate this metric. These included the heterozygote-excess method (Zhdanova and Pudovkin 2008), an updated linkage disequilibrium method (LD, Waples and Do 2008), and a molecular coancestry method (Nomura 2008). Programs NeEstimator (Version 2.01, Do et al. 2014) and LDNe (Version 1.32, Waples and Do 2008) were used to determine these estimates, assuming random mating and using a minimum allele frequency of 0.02 as recommended by Waples and Do (2009) for sample sizes $>25$. 


\section{Detecting Genetic Bottlenecks}

An important assumption when testing for genetic bottlenecks is that there is no genetic substructure within the population being tested (Busch et al. 2007). Therefore, I used the results from STRUCTURE to inform the datasets used for each species when testing for genetic bottlenecks. Two methods were used to determine if there was evidence of a genetic bottleneck in the population of each study species: 1) the heterozygosity excess test and 2) the $M$ ratio test. A bottlenecked population will typically lose more rare alleles than common ones, and therefore, will have higher levels of heterozygosity than expected post-bottleneck (Cornuet and Luikart 1996). In addition, the mean ratio, $M$, of number of alleles $(k)$ to the allele size range $(r)$ will increase in a bottlenecked population because lost alleles will always reduce $k$, but will only reduce $r$ if the largest or smallest allele in the range is lost (Garza and Williamson 2001).

I used the Wilcoxon signed-rank test in BotTLENECK (Version 1.2.02, Cornuet and Luikart 1996) to test for heterozygosity excess in both the goshawk and Cooper's hawk populations. This non-parametric test compares the expected heterozygosity under mutation drift-equilibrium to the expected heterozygosity under HWE across all loci. This is the most robust test for heterozygosity excess when using a small number of markers $(<20$, Cornuet and Luikart 1996). In a non-bottlenecked population, there is an equal chance for each locus to have either heterozygosity excess or deficiency. In contrast, a bottlenecked population will deviate from this and significantly greater than $50 \%$ of markers will have a heterozygosity excess.

Because mutation patterns of most microsatellite markers do not follow a strict infinitealleles or stepwise- mutation model (IAM and SMM, respectively), I performed the heterozygosity excess test using the two-phase mutation model (TPM, Di Rienzo et al. 1994). The BOTTLENECK program allows for two parameters to be changed under the TPM model: 
proportion of mutations that are single-step $\left(1-p_{g}\right)$, and the variance in the geometric distribution of multi-step mutations. Peery et al. (1999) suggest setting these parameters to $95 \%$ and 12 , respectively. However, some research suggests that these parameters differ in various organisms. For example, $p_{g}$ in avian microsatellite markers has been shown to be higher than in other taxa, and typically ranges from 20-40\% (Beck et al. 2003; Ortego et al. 2008). More specifically, Ortego et al. (2008) found that non-single-step mutations occurred $40 \%$ of the time for another raptor species, the lesser kestrel (Falco naumanni). In addition, the variance of multistep mutations is not constant among avian species (average size of multi-step mutations $=2.2-$ 4.0, see Peery et al. 2012). Thus, I ran multiple simulations in BOTTLENECK using both the recommended parameters and parameters based on avian microsatellite research, which included: 1 ) the generic recommendations (Peery et al. 1999; $1-p_{g}=95 \%$, variance $=12$ ), 2) unrelated raptor parameters $\left(1-p_{g}=60 \%\right.$, variance $\left.\left.=6\right), 3\right)$ relaxed avian parameters $\left(1-p_{g}=\right.$ $80 \%$, variance $=5), 4)$ average avian parameters $\left(1-p_{g}=70 \%\right.$, variance $\left.=10\right)$, and 5) conservative avian parameters $\left(1-p_{g}=60 \%\right.$, variance $\left.=16\right)$.

The $M$ ratio method was also used to test for evidence of a genetic bottleneck (Garza and Williamson 2001). The $M$ ratio software consists of two programs; the first (M_P_VAL) calculates the average $M$ for the empirical dataset, while the second (CRITICAL_M) determines the critical $M$ value $\left(M_{c}\right)$, for which $95 \%$ of values from stable populations will fall above this threshold. Both programs require three user-specified parameters: $\theta\left(4 N_{e} \mu\right.$, where $N_{e}=$ effective population size and $\mu=$ average mutation rate per site per generation), $p_{g}$ (proportion of mutations that are not one step), and the average size of mutations that are greater than one-step $\left(\Delta_{g}\right)$. In general, a higher $\theta$, $p_{g}$, or $\Delta_{g}$ results in a lower $M_{c}$ and a more conservative estimation of bottlenecking since the bottleneck has to be more severe to drop below the critical threshold (Busch et al. 2007). 
Garza and Williamson (2001) suggest that for most microsatellites, $\mu=5 \times 10^{-4}, p_{g}=0.1$, and $\Delta_{g}=3.5$. However, as previously mentioned, $p_{g}$ has been found to be higher $(20-40 \%)$ in avian species, specifically (Beck et al. 2003; Ortego et al. 2008). In addition, avian markers tend to have faster mutation rates than those of other taxa (Beck et al. 2003; Ortego et al. 2008; Masters et al. 2011; Brohede et al. 2012; see Peery et al. 2012). In the lesser kestrel, the mutation rate was found to be as high as $2 \times 10^{-3}$ per site per generation (Ortego et al., 2008). Also, empirical datasets suggest a lower $\Delta_{g}$ in wild populations, so I calculated the average size of multi-step mutations using available literature on avian microsatellites (Primmer et al. 1996; Garza and Williamson 2001; Ortego et al. 2008; see Peery et al. 2012). Based on these data, I ran multiple simulations in the $M$ ratio program to determine if there was evidence of a bottleneck under a variety of generic and taxa-specific parameters. First, I used the generic parameters recommended by Garza and Williamson (2001). All other models consisted of parameters based on avian microsatellite studies. I used values based on research on lesser kestrels, an unrelated raptor (Ortego et al. 2008; $\mu=2 \times 10^{-3}, \Delta_{g}=2.5, p_{g}=0.4$ ), relaxed avian parameters (see Peery et al. $2012 ; \mu=1 \times 10^{-3}, \Delta_{g}=2.2, p_{g}=0.2$ ), averaged avian parameters (see Peery et al. $2012 ; \mu=$ $6 \times 10^{-3}, \Delta_{g}=3.1, p_{g}=0.3$ ), and the most conservative avian parameters (see Peery et al. $2012 ; \mu=$ $\left.8 \times 10^{-3}, \Delta_{g}=4, p_{g}=0.4\right)$

Finally, I ran each of the simulations with two different $\theta$ values, first using an average estimated $N_{e}$ to calculate $\theta$, then a larger $N_{e}$ estimate (using the upper limit of the confidence interval) to calculate a highly conservative $\theta$. Whenever possible, I used $N_{e}$ estimates based on the LD method since this method has been shown to be the most robust, especially when the true $N_{e}$ is small (Waples and Do 2008). In cases where $N_{e}$ is large, however, the LD method will provide a "infinite" result for the upper bound of the confidence interval. In these instances, I 
used the coancestry method to determine a conservative $N_{e}$ estimate. However, I applied a correction to these values since the coancestry model is known to underestimate $N_{e}$ by as much as $60 \%$ when using microsatellite loci (Do et al. 2014).

\section{Results}

\section{Sample Collection}

I collected tissue samples from 98 goshawks from four states in the northeastern United States, (Figure 4.1) and all of these samples were collected from breeding individuals. I obtained samples from a total of 192 Cooper's hawks from 14 states in the northeastern USA (Figure 4.2). Of these, 87 were residents and the remaining 105 were potential migrants. I also collected samples from sharp-shinned hawks, but I was unable to obtain a large enough sample size to include this species in the analysis. All samples were collected between $2000-2017$.

\section{Quality Control}

Three of the 15 microsatellite loci deviated from HWE. Two of these, Age 4 and Age 1305, only deviated in the Cooper's hawk population, while the third, Age 6, deviated from HWE in both species. All of these markers had either null alleles or scoring errors and were removed from further analyses. One additional marker, Age 2, was removed from the analysis of the Cooper's hawk population because amplicons did not match the expected repeat pattern and thus could not be scored reliably. There was no evidence of linkage disequilibrium in any of the remaining locus pairs, after sequential Bonferroni correction. 


\section{Evaluation of Genetic Structure}

There was no evidence of significant structure within populations of either species, as the most likely number of genetic clusters $(K)$ was one in all simulations run in program STRUCTURE. This was even the case when I included migrants with the resident Cooper's hawk samples. Thus, for all bottleneck analyses, I used the entire dataset available for each species.

\section{Estimating genetic diversity and Ne}

Inbreeding coefficients were generally low, at -0.019 and 0.016 for goshawks and Cooper's hawks, respectively (Table 4.1). Observed and expected heterozygosities were similar between the two species $(t=-0.08, d f=10, p=0.93$; Table 4.1). The number of observed alleles per locus ranged from 2-22 in goshawks and 3-26 in Cooper's hawks (Table 4.1). Cooper's hawks had significantly higher rarified allelic richness when compared to goshawks $(\mathrm{t}=-2.28, \mathrm{df}=10, \mathrm{p}=$

0.04; Table 4.1). As expected, estimates of effective population size were consistently higher for Cooper's hawks than for goshawks. The heterozygote-excess method estimated both populations to have a maximum effective population size of infinity (Table 4.2). The LD method estimated $N_{e}$ as approximately 250 for goshawks and 1,750 for Cooper's hawks, while the coancestry model estimated lower values for both species (60 for goshawks, 1,550 for Cooper's hawks; Table 4.2).

\section{Detecting Genetic Bottlenecks}

None of the three tests for heterozygosity excess detected evidence of a genetic bottleneck in the Cooper's hawk population (Table 4.3). There was some evidence of a genetic bottleneck in the goshawk population; the heterozygosity excess test suggested a bottleneck when unrelated raptor 
parameters were used $(\mathrm{p}=0.015)$, but not when using the generic or avian parameters (Table 4.3). In contrast, the opposite trend was observed when implementing the $M$ ratio method. There was no evidence of a bottleneck in the goshawk population, but some evidence to suggest a bottleneck in the Cooper's hawk population. Specifically, when using the relaxed avian parameters, a bottleneck was detected using $\theta$ based on either the average estimated $N_{e}$ or a large estimate of $N_{e}$. Also, in the test assuming the unrelated raptor parameters with the average $N_{e}$ estimate used to calculate $\theta$, the average $M$ was below $M_{c}$, suggesting a bottleneck. However, there was no evidence of a bottleneck when using the unrelated raptor parameters and a highly conservative $N_{e}$ to calculate $\theta$. None of the remaining tests showed evidence of a bottleneck, regardless of the $\theta$ estimate (generic parameters, average avian parameters, conservative avian parameters; see Table 4.4).

\section{Discussion}

A major conclusion from this study is that current tools for investigating genetic bottlenecks with contemporary data are highly sensitive to mutation model parameters, that often are not available for non-model species. However, by examining the possibility of a genetic bottleneck in two closely-related species simultaneously, I was able to draw conclusions about the relative impacts of the species' declines that I wouldn't have been able to otherwise. Finally, I was also able to obtain useful baseline genetic information on both of these ecologically important avian predators. 


\section{Bottleneck analysis}

This study corroborates previous findings that the two common methods for detecting bottlenecks, heterozygosity excess and $M$ ratio, are heavily influenced by user-specified parameters related to marker mutations (Guinand and Scribner, 2003). While I informed my tests using data from current published literature, the results of the bottleneck tests were highly variable and strongly dependent on input values. This is because there is a great deal of uncertainty in selecting accurate parameters when dealing with wild populations. There are few studies on avian microsatellite mutation patterns, and the results from these studies show that these features are highly variable even within the taxon (see Peery et al. 2012). Further, because of the rare nature of mutations, all of the studies are based on small sample sizes, typically consisting of an analysis of only a few mutations in known family lines (see Primmer et al. 1996; Ortego et al. 2008). As a result, it is difficult to determine which simulation parameters are the most reliable and thus species-specific research on mutation patterns may be required for accurate bottleneck testing when implementing these methods.

Based on previous simulation studies, I was able to meet the criteria recommended to detect genetic bottlenecks in goshawks and Cooper's hawks ( $\geq 8$ microsatellite markers; sample size $\geq 100$, Spencer et al. 2000; Peery et al. 2012). There is some evidence to suggest that one or both species experienced a genetic bottleneck. However, in neither case was there evidence of a bottleneck using both methods, nor was the signal unanimous across all tests for one method for either species. Depending on which parameters are used, there are three possible scenarios to explain the outcomes of these tests.

The first possible scenario would be that both populations did, in fact, experience a bottleneck. Based on the strengths of the two tests, the results match what I would expect: 
evidence of a bottleneck in the goshawk population using the heterozygosity excess test and in Cooper's hawk populations using the $M$ ratio test. This is because the heterozygosity excess method is usually more sensitive to detection when pre-bottleneck populations are small, while $M$ ratio performs better when pre-bottleneck populations are large. The natural history of these species would indicate that goshawk populations will generally be smaller than those of Cooper's hawks, since Cooper's hawks require smaller territories and breed in much higher densities, especially in urban areas (Rosenfield et al. 1996; Boal and Mannan 1998; Chiang et al. 2012). Further, the $M$ ratio test is better at detecting bottlenecks when a population has recovered compared to the heterozygosity excess test. It is apparent that Cooper's hawk populations have made a demographic recovery, while recovery is less clear in goshawk populations (Farmer et al. 2008).

Another potential conclusion is that neither population experienced a genetic bottleneck. Type I errors have been demonstrated in both methods (Williamson-Natesan 2005) and additionally, the majority of the simulations did not indicate a genetic bottleneck based on significance cut-offs. This could be the case if the demographic declines recorded in these species were not real. An important assumption when using migration count data is that the trends seen at migratory stations are directly correlated with the true population size. Also, breeding bird surveys are largely conducted by volunteers and therefore, there is substantial variation in the skills of observers identifying species. These weaknesses in trend data could potentially lead to incorrect interpretations of demographic patterns. A more likely explanation could be that the demographic declines recorded in these species were real, but not significant enough to cause a genetic bottleneck. Indeed, Garza and Williamson (2001) suggest an average $M$ of 0.68 as a general cut-off for bottlenecked populations. However, this threshold was based 
primarily on known bottlenecked mammalian populations and may not be applicable to avian species.

Finally, a third possibility it that one species experienced a bottleneck while the other did not. Since these two Accipiters are closely related, I would assume that the mutation rates and patterns are similar between the two organisms. Therefore, if species-specific mutation data were available, I would expect that the mutation rate, proportion of multi-step mutations, and average size of multi-step mutations would be the same for both species. Yet, significance values suggested a bottleneck in the goshawk population when using the conservative avian-parameters but only detected a bottleneck for Cooper's hawks using more relaxed avian parameters. Therefore, if the true values are similar to either the conservative or the relaxed parameters, then there would only be evidence for a bottleneck in one of the two species.

Clearly, there are three reasonable conclusions that can be drawn from the results of this study and each of these can be backed up by natural history information or knowledge of the strengths and weaknesses of available bottleneck tests. Unfortunately, without a more accurate understanding of the species-specific microsatellite markers, it is impossible to know with certainty which species experienced a bottleneck based on current methods. This suggests that relying on current bottleneck tests with arbitrary significance cut-off values may be problematic when investigating the effects of demographic declines of wild populations. Thus, under these circumstances, it may be most useful to compare the results for each species to better understand the impact of historic declines. 


\section{Comparing the Species}

Despite the uncertainty associated with current bottleneck testing methods, I believe that useful information can be gained if the results from both species are examined simultaneously. For example, these tests allow me to determine the relative impact of recent demographic declines by comparing test results of the two species. The average $M$ was much lower and always closer to $M_{c}$ in Cooper's hawks than in goshawks when using the $M$ ratio test. This could suggest that the observed demographic declines were much more severe in Cooper's hawks than in goshawks. Several natural history traits may support this explanation. If Cooper's hawk populations were in fact larger prior to the bottleneck, then it would stand to reason that there were more individuals to be lost from potential threats. Before these birds were protected, they were actively hunted by humans. If there were large numbers of this species, it is likely that hunters encountered and shot them more often than goshawks. This would also be the case if Cooper's hawks were more tolerant of humans as compared to goshawks. Goshawks are currently known to avoid humans and breed far from forest edges, while Cooper's hawks are known to exploit urban habitats (Kimmel and Yahner 1994, Rosenfield et al. 1996; Boal and Mannan 1998, 1999; Chiang et al. 2012). If Cooper's hawks were more prone to visiting human-dominated areas to find prey, they would have been more likely to be shot and more exposed to pesticides. Indeed, Snyder et al. (1973) found relatively high concentrations of DDE, a metabolite of DDT, in eastern Cooper's hawk eggs. Therefore, the results from the goshawk $M$ ratio test provided a useful reference when examining the Cooper's hawk data.

Likewise, information from the Cooper's hawk population can be used to inform the trends observed in the goshawk population. The heterozygosity excess test showed evidence of a bottleneck in the goshawk population in one simulation and was nearly significant in two others. 
However, one common problem of some bottleneck tests, including the heterozygosity excess test, is that they cannot distinguish between populations that have been small for a long time (and are at equilibrium) from those that have recently experienced a bottleneck. The $M$ ratio test is one of the only tests that can be used to differentiate between these two scenarios. Garza and Williamson (2001) demonstrated that after a reduction, $M$ will recover in small equilibrium populations, but allelic diversity will continue to decline. The allelic richness was significantly lower in goshawks when compared to Cooper's hawks, even though I would expect it to be higher since the markers were specifically selected for high polymorphism in goshawks (see Contemporary Genetic Measures section). Therefore, goshawk populations may have been reduced a long time ago, presumably from early major timber-harvesting efforts in the eastern United States (Bildstein 2008), and returned to equilibrium and remained small ever since.

\section{Contemporary Genetic Measures}

The results of this study provide useful baseline information about the current genetic composition of two ecologically important avian predators in the eastern United States. There was no indication of significant structuring in either population. This suggests that there is gene flow across the region and that in general, the northeastern United States can be treated as one management unit for both species. In the case of the Cooper's hawk, this single management unit may be even larger than the 14-state area that I sampled since migrants could have come from outside the sampling region.

In addition, there is no evidence of inbreeding in either population and heterozygosity levels are similar between the two species. However, the reduced allelic richness in goshawks indicates low genetic diversity. Allelic richness has been shown to be a more informative metric 
than heterozygosity for estimating genome-wide diversity (Fischer et al. 2017), and this indicates that diversity may be reduced in goshawks compared to Cooper's hawks. Further, there is typically an ascertainment bias when developing microsatellite markers; polymorphism is highest in the species for which the markers were created and is lower when used for crossspecies amplification (Ellegren et al. 1995). Therefore, because the markers were developed for goshawks, I would expect fewer alleles per locus in Cooper's hawks, further validating low diversity in goshawks.

This research also provided estimates of effective population size for both Accipiter species in the northeastern United States. While it is difficult to determine an exact $N_{e}$, approximations can be helpful for understanding the relative size of populations for the purposes of management. The LD method of estimating $N_{e}$ is most powerful when used for small populations, and as such the estimate for the goshawk population is likely more reliable than that of the Cooper's hawk. The Cooper's hawk population is possibly quite large in this area based on the $N_{e}$ estimates. These results are concordant with the biology of the species; Cooper's hawks typically use smaller home ranges as compared to goshawks (Cooper's hawks: 140 - 437 hectares, Chiang et al. 2012; goshawks: 215 - 2500 hectares, Reynolds et al. 1992), and have recently been able to exploit urban and suburban areas for nesting (Rosenfield et al. 1996; Boal and Mannan 1998, 1999; Estes and Mannan 2003). This has allowed the Cooper's hawk population to expand in the last few decades and the Avian Conservation Assessment Database suggests that there could be as many as 700,000 breeding individuals in North America (Partners in Flight 2017). 


\section{Conclusions}

The ability to detect genetic bottlenecks is an important tool for management and conservation of wildlife populations. However, the results of this study corroborate previous findings that the currently available methods for detecting bottlenecks are somewhat unreliable for poorly studied species (Williamson-Natesan 2005; Peery et al. 2012). Despite this, I believe that by investigating the genetics of multiple populations or species concurrently, we can gain a better understanding of the effects and severity of demographic declines.

It is clear from the $M$ ratio tests that Cooper's hawks likely suffered more severely from historical declines as compared to northern goshawks. Likewise, the results from both bottleneck tests in conjunction with an examination of allelic diversity suggest that goshawk populations may have been small for a long time rather than recently bottlenecked. Thus, by comparing these results and simultaneously drawing from the species' natural histories, I can make general, relative conclusions about the impacts of historic population declines.

In addition, this study provides useful genetic information for a reference in future investigations of these species. Inbreeding is not apparent in either species and gene flow is likely high for the northeastern United States. Further, if the Cooper's hawk population did experience a bottleneck, the population seems to be thriving despite this. Finally, I believe that the species of concern, the northern goshawk, likely has not experienced a recent severe bottleneck, but has likely been a small equilibrium population for a long time. The genetic data from this study should be used in future monitoring efforts for this species, especially since effective population size estimates suggest it is a small population. Therefore, it is imperative that future bottlenecks are avoided since small populations can be more vulnerable to negative genetic effects. 


\section{Literature Cited}

Allendorf FW, Leary RF (1996) Heterozygosity and fitness in natural populations of animals. In: Soulé ME (ed) Conservation biology: the science of scarcity and diversity, pp. 57-76. Sinauer Associates Inc. Sunderland, Massachusetts

Beck NR, Double MC, Cockburn A (2003) Microsatellite evolution at two hypervariable loci revealed by extensive avian pedigrees. Mol Biol Evol 20:54-61

Bednarz JC, Klem D Jr, Goodrich LJ, Senner SE (1990). Migration counts of raptors at Hawk Mountain, Pennsylvania, as indicators of population trends, 1934-1986. Auk 107:96-109

Bildstein KL (2001) Raptors as vermin: a history of human attitudes towards Pennsylvania's birds of prey. Endangered Species Update 18: 124-128

Bildstein KL (2008) A brief history of raptor conservation in North America. In: Bildstein KL, Smith JP, Inzunza ER, Veit RR (eds) State of North America's birds of prey pp. 5-36. Nuttall Ornithological Club and American Ornithologists. Union Series in Ornithology No. 3 Cambridge, Massachusetts and Washington, D.C.

Blomqvist D, Pauliny A, Larsson M, Flodin L (2010) Trapped in the extinction vortex? Strong genetic effects in a declining vertebrate population. BMC Evol Biol 10:33. doi:10.1186/1471-2148-10-33

Bloom PH, Clark WS, Kidd JW (2007) Capture Techniques. In: Bird DM, Bildstein KL (eds). Raptor research and management techniques. Hancock House Publishers, Surrey, British Columbia

Boal CW, Mannan RW (1998) Nest-site selection by Cooper's hawks in an urban environment. J Wildl Manag 62:864-871

Bonebrake TC, Christensen J, Boggs CL, Ehrlich PR (2010) Population decline assessment, historical baselines, and conservation. Conserv Lett 3:371-378

Brohede J, Møller AP, Ellegren H (2004) Individual variation in microsatellite mutation rate in barn swallows. Mutat Res 545:73-80

Busch JD, Waser PM, DeWoody JA (2007) Recent demographic bottlenecks are not accompanied by a genetic signature in banner-tailed kangaroo rats (Dipodomys spectabilits). Mol Ecol. doi: 10.1111/j.1365-294X.2007.03283.x

Chiang SN, Bloom PH, Bartuszevige AM, Thomas SE (2012) Home range and habitat use of Cooper's hawks in urban and natural areas. Online (www.ucpress.edu/go/sab) in Lepczyk CA, Warren PS (eds) Urban bird ecology and conservation. Studies in Avian Biology (no. 45), University of California Press, Berkeley

Cornuet JM, Luikart G (1997) Description and power analysis of two tests for detecting recent population bottlenecks from allele frequency data. Genetics 144:2001-2014. 
Di Rienzo A, Peterson AC, Garza JC, Valdes AM, Slatkin M, Freimer NB (1994) Mutational processes of simple-sequence repeat loci in human populations. Proc Natl Acad Sci 91:3166-3170

Do C, Waples RS, Peel D, MacBeth GM, Tillett BJ, Ovenden JR (2013) NeEstiMATOR v2: reimplementation of software for the estimation of contemporary effective population size $\left(N_{e}\right)$ from genetic data. Mol Ecol Resour 14:209-214

Earl DA, vonHoldt BM (2012) STRUCTURE HARVESTER: a website and program for visualizing STRUCTURE output and implementing the Evanno method. Conservation Genet Resour 4:359-361

Ellegren H, Primmer CR, Sheldon BC (1995) Microsatellite evolution - directionality or bias. Nature Genet 11:360-362

Estes WA, Mannan RW (2003) Feeding behaviors of Cooper's hawks at urban and rural nests in southeastern Arizona. Condor 105:107-116

Evanno G, Regnaut S, Goudet J (2005) Detecting the number of clusters of individuals using the software STRUCTURE: a simulation study. Mol Ecol 14:2611-2620

Farmer CJ, Smith JP, Hoffman SH, Kaltenecker GS, Woodruff KZ, Sherrington PJ (2008) Trends in autumn counts of migratory raptors in western North America. In: Bildstein KL, Smith JP, Inzunza ER, Veit RR (eds) State of North America's birds of prey pp. 217251. Nuttall Ornithological Club and American Ornithologists' Union, Cambridge, MA and Washington, D.C

Falush D, Stephens M, Pritchard JK (2003) Inference of population structure using multilocus genotype data: linked loci and correlated allele frequencies. Genet Society America 164:1567-1587

Falush D, Stephens M, Pritchard JK (2007) Inference of population structure using multilocus genotype data: dominant markers and null alleles. Mol Ecol Notes. doi:10.1111/j.14718286.2007.01758.x

Fischer MC, Rellstab C, Leuzinger M, Roumet M, Gugerli F, Shimizu KK, Holderegger R, Widmer A (2017) Estimating genomic diversity and population differentiation - an empirical comparison of microsatellite and SNP variation in Arabidopsis halleri. BMC Genomics 18:69. doi:10.1186/s12864-016-3459-7

Frankel OH, Soulé ME (1981) Conservation and evolution. Cambridge University Press, Cambridge

Frankham R (1995) Conservation Genetics. Annu Rev Genetics 29:305-327

Garza JC, Williamson EG (2001) Detection of reduction in population size using data from microsatellite loci. Mol Ecol 10:305-318 
Guinand B, Scribner KT (2003) Evaluation of methodology for detection of genetic bottlenecks: inferences from temporarily replicated lake trout populations. C R Biologies 326:S61S67

Hamilton MB (ed) (2009) Population genetics. Wiley-Blackwell, Chichester, West Sussex, UK

Haughey C, Sage GK, Gegange G, Sonsthagen SA, Talbot S (2016) Development of novel microsatellite markers for the northern goshawk (Accipiter gentilis) and their utility in cross-species amplification. Avian Biol Res 9:195-199

Hedrick PW, Miller PS (1992) Conservation genetics: techniques and fundamentals. Ecol Applic 2:30-46

Hubisz MJ, Falush D, Stephens M, Pritchard JK (2009) Inferring weak population structure with the assistance of sample group information. Mol Ecol Resour 9:1322-1332

Kalinowski ST (2005) HP-RARE: a computer program for performing rarefaction on measures of allelic diversity. Mol Ecol Notes 5:187-189

Kimmel JT, Yahner RH (1994) The northern goshawk in Pennsylvania: habitat use, protocols, and status. Final Report. Pennsylvania State University

Leonard JA (2008) Ancient DNA applications for wildlife conservation. Mol Ecol 17:4186-4196

Luikart G, Sherwin WB, Steele BM, Allendorf FW (1998) Usefulness of molecular markers for detecting population bottlenecks via monitoring genetic change. Mol Ecol 7:963-974

Masters BS, Johnson LS, Johnson BGO, Brubaker JL, Sakaluk SK, Thompson CF (2011) Evidence for heterozygotes instability in microsatellite loci in house wrens. Biol Lett $7: 127-130$

NatureServe (2017) NatureServe Explorer: An online encyclopedia of life (web application). Version 7.0. NatureServe, Arlington, VA, USA. Available online http://explorer.natureserve.org (Accessed Oct. 21, 2017)

Newman D, Pilson D (1997) Increased probability of extinction due to decreased effective population size: experimental populations of Clarkia pulchella. Evolution 51:354-362

Nomura T (2008) Estimation of effective number of breeders from molecular coancestry of single cohort sample. Evol App. doi:10.1111/j.1752-4571.2008.00015.x

Ortego J, Aparicio JM, Cordero PJ, Calabuig G (2008) Characteristics of loci and individuals are associated with germline microsatellite mutation rates in lesser kestrels (Falco naumanni). Mutat Res 648:82-86

Partners in Flight (2017) Avian conservation assessment database version 2017. Available at http://pif.birdconservancy.org/ACAD. Accessed on 9/29/2017

Peakall R, Smouse PE (2006) GENALEX 6: genetic analysis in Excel. Population genetic software for teaching and research. Mol Ecol Notes 6:288-295 
Peakall R, Smouse PE (2012) GenAlEx 6.5: genetic analysis in Excel. Population genetic software for teaching and research-an update. Bioinformatics 28:2537-2539

Peery MZ, Kirby R, Reid BN, Stoelting R, Doucet-Bëer E, Robinson S, Vásquez-Carrillo, Pauli JN, Palsbøll PJ (2012) Reliability of genetic bottleneck tests for detecting recent population declines. Mol Ecol 21:3403-3418

Primmer CR, Ellegren H, Saino N, Møller AP (1996) Directional evolution in germline microsatellite mutations. Nature Genet 13:391-393

Pritchard JK, Stephens M, Donnelly P (2000) Inference of population structure using multilocus genotype data. Genetics 155:945-959

Putman AI, Carbone I (2014) Challenges in analysis and interpretation of microsatellite data for population genetic studies. Ecol Evol 4:4399-4428. doi: 10.1002/ece3/1305

R Core Team (2013) R: a language and environment for statistical computing. R foundation for Statistical Computing, Vienna, Austria URL http://www.R-project.org/

Raymond M, Rousset F (1995) GENEPOP (version 1.2): population genetics software for exact tests and ecumenicism. J Heredity 86:248-249

Reynolds RT, Graham RT, Reiser MH et al. (1992) Management recommendations for the northern goshawk in the southwestern United States. General Technical Report RM-217. Forest Service, United States Department of Agriculture, Fort Collins, Colorado

Rice WR (1989) Analyzing table of statistical tests. Evol 43:223-225

Rosenfield RN, Bielefeldt J, Affeldt JL, Beckman DJ (1996) Urban nesting biology of Cooper's hawks in Wisconsin. In: Bird DM, Varian DE, Negro JJ (eds) Raptors in human landscapes: adaptation to build and cultivated environments. Academic Press, New York

Rousset F (2008) GENEPOP'007: a complete reimplementation of the GENEPOP software for Windows and Linux. Mol Ecol Resour 8:103-106

Schlötterer, C (1998) Genome evolution: are microsatellites really simply sequences? Curr Biol 8:R132-R134

Schwartz MK, Luikart G, Waples RS (2007) Genetic monitoring as a promising tool for conservation and management. Trends Ecol Evolut 22:25-33

Snyder NFR, Snyder HA, Lincer JL, Reynolds RT (1973) Organochlorines, heavy metals, and the biology of North American accipiters. BioScience 23: 300-305

Spencer CC, Neigel JE, Leberg PL (2000) Experimental evaluation of the usefulness of microsatellite DNA for detecting demographic bottlenecks. Mol Ecol 9:1517-1528

Topinka JR, May B (2004) Development of polymorphic microsatellite loci in the northern goshawk (Accipiter gentilis) and cross-amplification in other raptor species. Conserv Genet 5:861-864 
Van Oosterhout C, Hutchinson WF, Wills DPM, Shipley P (2004) MICRO-CHECKER: software for identifying and correcting genotyping errors in microsatellite data. Mol Ecol Notes 4:535-538

Wandeler P, Hoeck PEA, Keller LF (2007) Back to the future: museum specimens in population genetics. Trends Ecol Evolut 22:634-642

Waples RS, Do C (2008) LDNE: a program for estimating effective population size from data on linkage disequilibrium. Mol Ecol Resour 8:753-756

Waples RS, Do C (2009) Linkage disequilibrium estimates of contemporary Ne using highly variable genetic markers: a largely untapped resource for applied conservation and evolution. Evol Appl. doi:10.1111/j.1752-4571.2009.00104.x

Williamson-Natesan, EG (2005) Comparison of methods for detecting bottlenecks from microsatellite loci. Conserv Genet 6:551-562

Wink M (2007) Systematics. In: Bird DM, Bildstein KL (eds) Raptor Research and Management Techniques. Hancock House Publishers, Surrey, British Columbia

Wright S (1978) Evolution and the genetics of populations: variability within and among natural populations. University of Chicago Press, Chicago

Zar JH (2010) Biostatisical analysis $5^{\text {th }}$ Ed. Prentice Hall Inc. Upper Saddle River, New Jersey

Zhdanova O, Pudovkin AI (2008) Nb_HetEx: a program to estimate the effective number of breeders. J Heredity 99:694-695 
Table 4.1: Inbreeding coefficient $\left(\mathrm{F}_{\mathrm{IS}}\right)$, observed heterozygosity $\left(\mathrm{H}_{\mathrm{o}}\right)$, expected heterozygosity $\left(\mathrm{H}_{\mathrm{e}}\right)$, allelic richness, and rarified allelic richness across all loci for northern goshawk (NOGO, $\mathrm{n}=98)$ and Cooper's hawk $(\mathrm{COHA}, \mathrm{n}=192)$ populations in the northeastern United States. Markers without values were dropped from the analysis because they deviated from Hardy-Weinberg Equilibrium as a result of null alleles or scoring errors.

\begin{tabular}{|c|c|c|c|c|c|c|c|c|c|c|}
\hline \multirow[b]{2}{*}{ Marker Name } & \multicolumn{2}{|c|}{$\mathrm{F}_{\mathrm{IS}}$} & \multicolumn{2}{|c|}{$H_{e}$} & \multicolumn{2}{|c|}{$H_{o}$} & \multicolumn{2}{|c|}{ No. alleles (observed) } & \multicolumn{2}{|c|}{ No. alleles (rarified) } \\
\hline & NOGO & COHA & NOGO & $\mathrm{COHA}$ & NOGO & COHA & NOGO & COHA & NOGO & COHA \\
\hline Age 2 & -0.050 & - & 0.873 & - & $0.906^{\mathrm{a}}$ & - & 12 & - & $11.62^{\mathrm{a}}$ & - \\
\hline Age 4 & 0.026 & - & 0.838 & - & $0.811^{\mathrm{a}}$ & - & 11 & - & $10.99^{\mathrm{a}}$ & - \\
\hline Age 5 & 0.112 & -0.066 & 0.466 & 0.629 & 0.398 & 0.644 & 5 & 7 & 5 & 6.6 \\
\hline Age 7 & -0.054 & 0.010 & 0.918 & 0.928 & 0.946 & 0.920 & 22 & 26 & 21.24 & 23.7 \\
\hline Age 8 & -0.058 & 0.078 & 0.253 & 0.842 & 0.260 & 0.775 & 5 & 9 & 4.65 & 8.63 \\
\hline Age 9 & -0.104 & 0.040 & 0.741 & 0.610 & 0.806 & 0.584 & 5 & 5 & 5 & 4.8 \\
\hline Age 10 & -0.059 & 0.027 & 0.801 & 0.650 & 0.832 & 0.633 & 9 & 9 & 8.83 & 7.73 \\
\hline Age 11 & 0.068 & 0.012 & 0.579 & 0.747 & 0.544 & 0.740 & 6 & 8 & 6 & 7.44 \\
\hline Age 1302 & -0.008 & 0.017 & 0.470 & 0.628 & 0.469 & 0.637 & 2 & 7 & 2 & 6.79 \\
\hline Age 1305 & 0.078 & - & 0.732 & - & $0.660^{\mathrm{a}}$ & - & 7 & - & $6.99^{a}$ & - \\
\hline Age 1308 & -0.053 & -0.064 & 0.667 & 0.469 & 0.663 & 0.503 & 4 & 3 & 4 & 3 \\
\hline Age 1311 & -0.108 & -0.058 & 0.630 & 0.533 & 0.695 & 0.574 & 5 & 6 & 4.83 & 5.54 \\
\hline Age 1314 & -0.009 & 0.026 & 0.597 & 0.692 & 0.588 & 0.661 & 4 & 9 & 4 & 8.11 \\
\hline Age 1316 & -0.046 & 0.155 & 0.551 & 0.206 & 0.581 & 0.183 & 4 & 4 & 4 & 3.42 \\
\hline Average & -0.019 & 0.016 & 0.651 & 0.630 & 0.617 & 0.623 & 7.21 & 8.45 & $6.32 *$ & 7.8* \\
\hline
\end{tabular}

${ }^{\mathrm{a}}=$ Markers not included in average $\mathrm{Ho}$ or rarified allelic richness calculation to ensure result is comparable to COHA dataset for paired t-test

*denotes a significant difference between NOGOs and COHAs 
Table 4.2: Effective population size $\left(N_{e}\right)$ estimates for northern goshawk (NOGO) and Cooper's hawk (COHA) populations in the northeastern United States. Three different methods were used to estimate $N_{e}$ : heterozygote-excess (Zhdanova and Pudovkin, 2008), linkage disequilibrium (Waples and Do, 2008), and molecular coancestry (Nomura, 2008). Values in parentheses are estimated ranges based on $95 \%$ confidence intervals.

\begin{tabular}{lccc}
\cline { 2 - 4 } & Heterozygote-excess & Linkage disequilibrium & Coancestry method \\
\hline \hline NOGO & N/A $(20-$ Infinite $)$ & $247(149-601)$ & $61(1-225)$ \\
COHA & N/A $(630-$ Infinite $)$ & $1755(295-$ Infinite $)$ & $1553(1-7800)$ \\
\hline
\end{tabular}


Table 4.3: Results of statistical tests (p-values) for heterozygosity excess from Wilcoxon signedrank tests on northern goshawk (NOGO) and Cooper's hawk (COHA) genetic datasets in program BOTTLENECK (Cornuet and Luikart 1996). Tests were run assuming the two-phase mutation model $(\mathrm{TPM})$. Var $=$ in the geographic distribution of the TPM, $p_{\mathrm{g}}=$ proportion of mutations that are not one-step and $*$ denotes a significant p-value when $\alpha=0.05$.

\begin{tabular}{lcc}
\hline \multicolumn{1}{c}{ Simulation (Parameters) } & NOGO & COHA \\
\hline \hline Generic $^{1}\left(\operatorname{var}=12, p_{g}=0.05\right)$ & 0.38 & 0.99 \\
Unrelated raptor $^{2}\left(\operatorname{var}=6, p_{g}=0.4\right)$ & 0.07 & 0.71 \\
Relaxed $\operatorname{avian}^{3}\left(\operatorname{var}=5, p_{g}=0.2\right)$ & 0.16 & 0.92 \\
Average $\operatorname{avian}^{3}\left(\operatorname{var}=10, p_{g}=0.3\right)$ & 0.06 & 0.74 \\
Conservative avian $\left(\operatorname{var}=16, p_{g}=0.4\right)$ & $0.02^{*}$ & 0.38 \\
\hline
\end{tabular}

$1=$ Garza and Williamson $(2001),{ }^{2}=$ Ortego et al. $2008,{ }^{3}=$ see review by Peery et al. 2012 
Table 4.4: Results from $M$ ratio tests for genetic bottlenecks in the northern goshawk (NOGO) and Cooper's hawk (COHA) populations in the northeastern United States. Tests were run using various parameters estimated from published literature $(\mu=$ mutation rate, $\Delta_{\mathrm{g}}=$ average size of a mutation that is larger than one-step, $p_{g}=$ proportion of mutations that are larger than one-step). Average $M$ is the mean ratio of number of alleles $(k)$ to the allele size range (r), while $M_{c}$ is the critical $M$ value (95\% of values will fall above this threshold). Tests indicating a genetic bottleneck (where $M_{c}$ was higher than the average $M$ ) for the empirical datasets are shown in bold and italic. Relaxed $\theta$ values were calculated using average $N_{e}$ values $(\mathrm{NOGO}=250, \mathrm{COHA}=1750)$, while conservative $\theta$ was calculated using high $\mathrm{N}_{\mathrm{e}}$ estimates $(\mathrm{NOGO}=600, \mathrm{COHA}=13,000)$.

\begin{tabular}{|c|c|c|c|c|}
\hline Species & Simulation (parameters) & $M c$ (Average $\theta)$ & $M c$ (Conservative $\theta)$ & Average $M$ \\
\hline \multirow{5}{*}{ NOGO } & $\operatorname{Generic}^{1}\left(\mu=5 \times 10^{-4}, \Delta_{g}=3.5, p_{g}=0.1\right)$ & 0.827 & 0.877 & \multirow{5}{*}{0.922} \\
\hline & 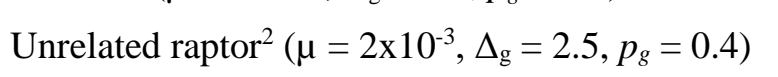 & 0.748 & 0.760 & \\
\hline & 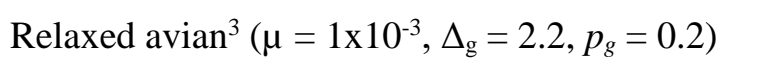 & 0.850 & 0.852 & \\
\hline & Averaged $\operatorname{avian}^{3}\left(\mu=6 \times 10^{-3}, \Delta_{g}=3.1, p_{g}=0.3\right)$ & 0.698 & 0.707 & \\
\hline & Conservative $\operatorname{avian}^{3}\left(\mu=8 \times 10^{-3}, \Delta_{g}=4, p_{g}=0.4\right)$ & 0.576 & 0.593 & \\
\hline \multirow{5}{*}{ COHA } & $\operatorname{Generic}^{1}\left(\mu=5 \times 10^{-4}, \Delta_{g}=3.5, p g=0.1\right)$ & 0.752 & 0.751 & \multirow{5}{*}{0.781} \\
\hline & 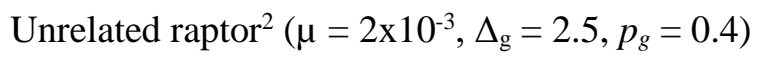 & 0.782 & 0.755 & \\
\hline & 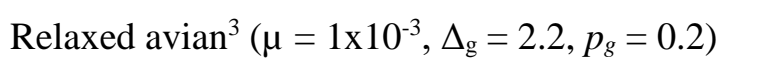 & 0.854 & 0.823 & \\
\hline & Averaged $\operatorname{avian}^{3}\left(\mu=6 \times 10^{-3}, \Delta_{g}=3.1, p_{g}=0.3\right)$ & 0.733 & 0.688 & \\
\hline & Conservative $\operatorname{avian}^{3}\left(\mu=8 \times 10^{-3}, \Delta_{\mathrm{g}}=4, p_{g}=0.4\right)$ & 0.641 & N/A & \\
\hline
\end{tabular}

${ }^{1}=$ Garza and Williamson $(2001),{ }^{2}=$ Ortego et al. $2008,{ }^{3}=$ see review by Peery et al. 2012 


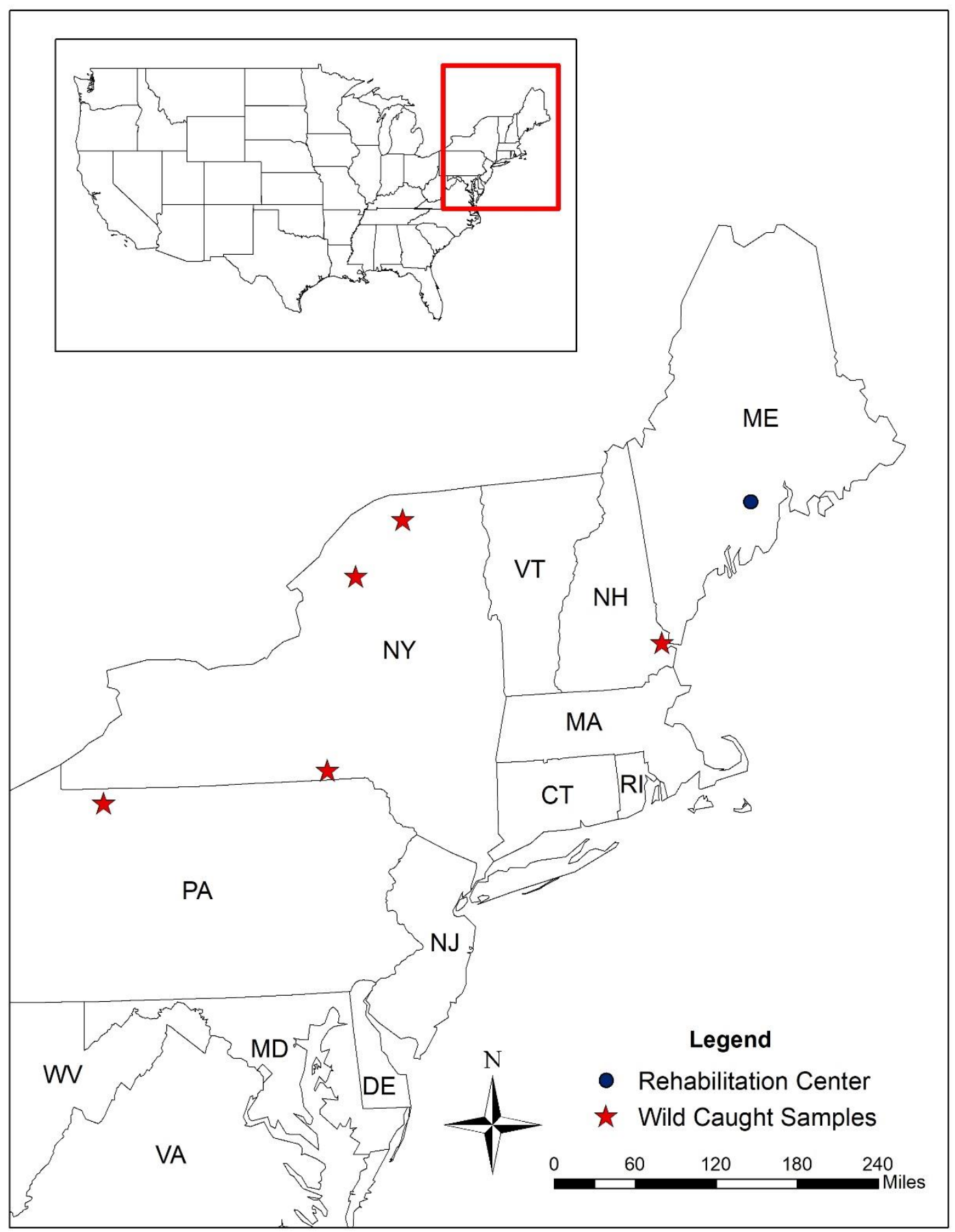

Figure 4.1: Sample collection locations for 98 northern goshawks in the northeastern United States during 2000 - 2017. 


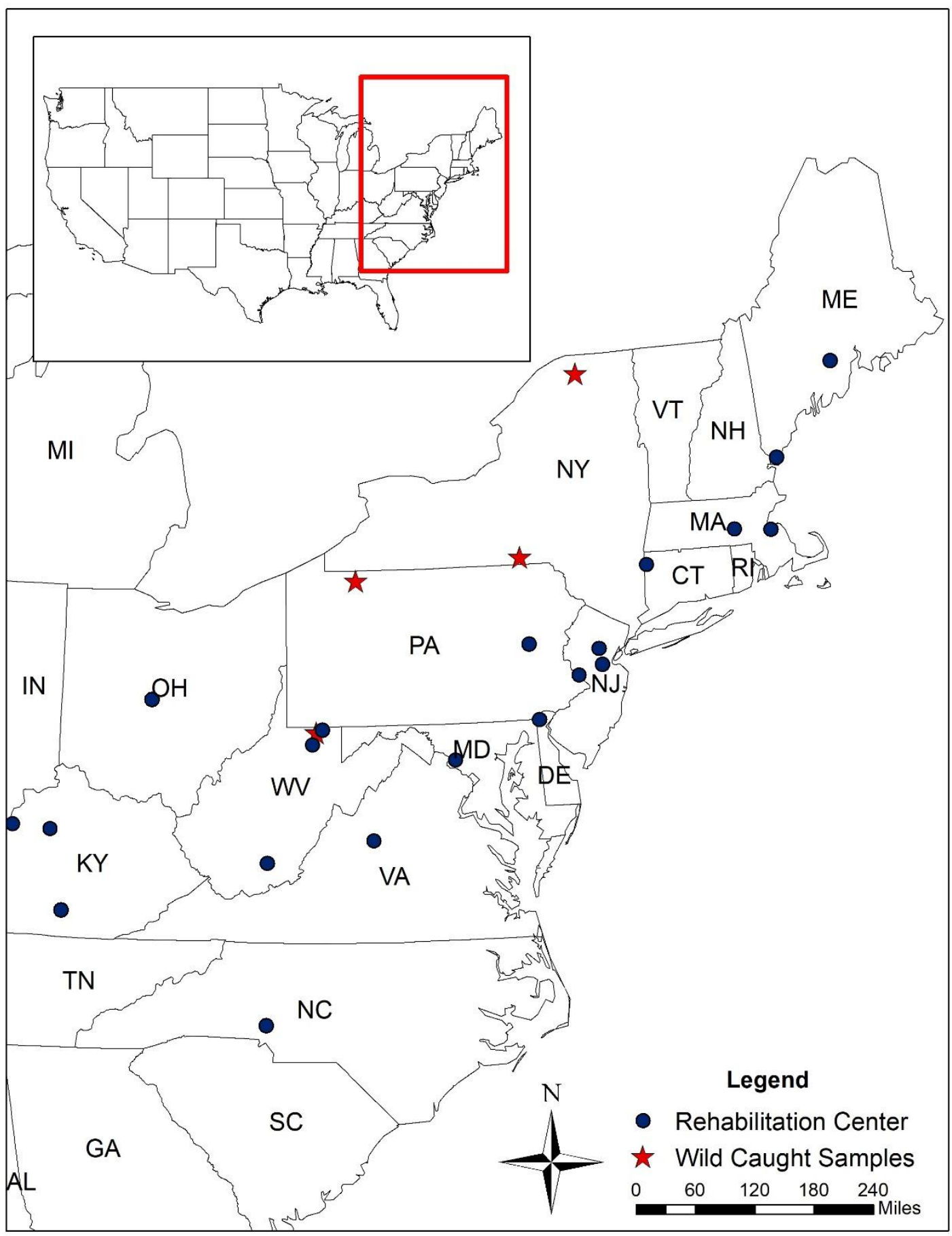

Figure 4.2: Sample collection locations for Cooper's hawks in the northeastern United States. Total $n=192$ and sampling years ranged from $2000-2017$. 


\title{
Chapter 5: Effectiveness of commercial RNA stabilization reagents when preserving avian blood for downstream RNA-seq analysis
}

\author{
Abstract \\ Transcriptomic research has the potential to provide substantial insight into how wild \\ populations respond to environmental change. The first step in transcriptomic study requires \\ stabilization and preservation of high quality RNA for downstream processing. Tools available \\ for preserving RNA were developed for mammalian species studied in controlled lab conditions. \\ However, their applicability to the study of wild, non-mammalian populations remains largely \\ untested. I tested two field-appropriate RNA stabilization buffers, RNAprotect ${ }^{\circledR}$ and RNAlater ${ }^{\circledR}$ \\ on blood samples collected from two raptor species, to compare their performance in preserving \\ avian RNA. I evaluated reagent performance under a variety of freeze treatments, room \\ temperature incubation periods, and extraction protocols with a goal to optimize RNA extraction \\ from both buffers. I found that only RNAlater ${ }^{\circledR}$ reliably provided avian RNA for downstream \\ processing regardless of sample treatment; however, these extracts had highly variable RNA \\ integrity numbers (RIN). I performed a preliminary Illumina MiSeq run on RNA extracted from \\ Cooper's hawks (Accipiter cooperii) blood. I generated relatively high-quality mRNA reads but \\ the alignment to the golden eagle (Aquila chrysaetos) reference genome had relatively low \\ sensitivity $(<14 \%)$ and a wide range of precision $(10-61 \%)$ across multiple genomic levels. \\ Although RNAlater produced better quality RNA, there is a clear need to improve commercial \\ RNA stabilization buffers for use with avian blood collected in the field. Further research is \\ warranted to develop and test buffers on a variety of sample types from an array of taxa in field \\ settings to optimize RNA stabilization for downstream RNA sequencing.
}




\section{Introduction}

Characterizing the way in which organisms respond to environmental change is a central focus of ecological research (Scheiner and Willig 2011). This may be especially important given the major human-driven environmental changes occurring on a global scale. Recent advances in genomic technologies have allowed researchers to start investigating the molecular mechanisms underlying organism responses to environmental change (Alvarez et al. 2015). RNA-seq is one of the most powerful recent transcriptomic techniques and in the last decade it has been used widely for gene expression studies (Alvarez et al. 2015). Research using RNA-seq applies highthroughput sequencing technologies to examine mRNA expression levels across the entire genome (Wang et al. 2009). The majority of this work, however, focuses on model organisms in laboratory settings. Yet, a key future pathway of transcriptomic research lies in answering ecological questions in wild systems.

Recently, several RNA-seq studies have been used to answer pertinent ecological questions. These studies commonly use wild organisms that can be collected alive and transported to a laboratory for controlled experiments (e.g. thermal tolerance in fish and gastropods, see Smith et al. 2013, Gleason and Burton 2015; gene expression in migratory versus resident fish, see McKinney et al. 2015; effects of pollutants on copepods, see Legrand et al. 2016; stress response in bivalves, see Husmann et al. 2014; senescence in insects, see Lucas et al. 2016). However, this is not an option with many wild organisms and thus methodology for RNA-seq must be optimized for use with samples collected directly in the field. Then, this research on wild systems can be used in conjunction with laboratory studies to better understand genomic and transcriptomic processes and their relationship with the environment (Alvarez et al. 2015). 
A crucial first step to investigating ecological questions in wild non-model populations is to stabilize and preserve high-quality RNA for downstream processing. Because RNA is highly unstable, stabilization can be especially challenging when sampling wild organisms in adverse field conditions. In general, it is thought that the best way to preserve high quality RNA is by snap-freezing a freshly collected sample in liquid nitrogen (Gorokhova 2005; Riesgo et al. 2012; Camacho-Sanchez et al. 2013). However, this technique is not always logistically feasible (Camacho-Sanchez et al. 2013; Kono et al. 2016). Alternatively, there are several commercial reagents that can be used for RNA stabilization in the field until samples can be returned to the laboratory for further processing. Some of the most popular commercial reagents include phenolbased products (e.g. Invitrogen TRIzol®, BD TRI Reagent), Qiagen RNAprotect ${ }^{\circledR}$, and Ambion RNAlater ${ }^{\circledR}$. Phenol, though, is considered hazardous and may not be the best choice for work in uncontrolled settings (Kono et al. 2016). Therefore, because of their convenience and relative safety, RNAprotect ${ }^{\circledR}$ and RNAlater ${ }^{\circledR}$ are often the reagents of choice for field studies.

Only a few studies have examined and compared the efficacy of RNA preservation techniques from organisms sampled outside of the lab. These studies primarily focused on mammalian tissue samples (e.g. Schwochow et al. 2012; Camacho-Sanchez et al. 2013) and the results may not be applicable to samples collected from other taxa. Thus, some researchers have further investigated these techniques using samples from non-model organisms belonging to other taxonomic groups (e.g. echinoderms, Perez-Portela and Riesgo 2013; arachnids, Kono et al. 2016). However, even in these cases, most of the studies involving non-model organisms have focused on invertebrates that can be harvested from the wild and brought back to a laboratory alive prior to tissue sampling. Such studies have little relevance to animals that may not thrive in captivity or for whom legal protections preclude laboratory studies. 
Given the potential for transcriptomic research on wild populations, it is important to test reagents on a wide array of species from taxonomic groups other than mammals. Further, these methodologies should be evaluated in the field and tested on select tissues that can be obtained from wild organisms without sacrificing individuals. Birds are protected under the Migratory Bird Treaty Act and therefore, blood is the only tissue that can feasibly be sampled for largescale transcriptomic studies on any wild bird species, including rare or endangered species. In addition, avian blood contains nucleated red blood cells and thus presents a unique challenge for RNA preservation when using buffers developed for mammalian species with non-nucleated red blood cells. This is because nucleated red blood cells contain higher levels of DNA and nucleases which makes RNA degrade more rapidly (Chiari and Galtier 2011).

The objective of this study was to test two different field-appropriate, phenol-free and commercially available RNA preservation reagents, RNAprotect ${ }^{\circledR}$ and RNAlater ${ }^{\circledR}$, to evaluate their efficacy in stabilizing RNA from avian blood for downstream RNA-seq analysis. In addition, because RNA degrades faster in harsher field conditions (e.g. higher temperatures and with increased exposure to UV light, Vincek et al. 2003; Sidova et al. 2015), I tested the quality of RNA extracted from avian blood collected in a desert environment using a preliminary RNAseq analysis.

\section{Materials and Methods}

\section{Sample Collection}

I collected blood samples from wild-hatched red-tailed hawks (Buteo jamaciensis, RTHA n=10) and Cooper's hawks (Accipiter cooperii, COHA, n=26). Red-tailed hawks were sampled at a local avian conservation center approximately $20 \mathrm{~min}$ away from the laboratory at West Virginia 
University. I chose to use red-tailed hawk blood for the experiment because this was the closest related species to Cooper's hawks that was also available at the time of the study. I used standard raptor trapping techniques (Bloom et al. 2007) to capture wild Cooper's hawks in Albuquerque, New Mexico during June and July of 2014 and 2015.

Blood was drawn from the brachial or jugular vein of all birds using a sterile syringe. I placed whole blood, in the amount specified by the manufacturer's protocol (RNAprotect ${ }^{\circledR}$ $100 \mu \mathrm{L}, \mathrm{RNAlater}{ }^{\circledR} 200-300 \mu \mathrm{L}$ ), in a screw-cap $1.5 \mathrm{~mL}$ microcentrifuge tube. I then gently inverted the tube to thoroughly mix the contents. Tubes were kept in a dark cooler at ambient temperature until frozen or until further processing. Samples collected in New Mexico were frozen after 2-8 $\mathrm{h}$ then shipped overnight on dry ice to the laboratory at West Virginia University.

\section{RNA Stabilization Experiment}

I tested the effectiveness of RNAprotect ${ }^{\circledR}$ and RNAlater ${ }^{\circledR}$ to stabilize avian blood preserved under a variety of different protocols on a subset of blood samples collected. The protocols varied by freeze treatment, length of room temperature incubation, RNA extraction kit, and RNA extraction protocols (Table 5.1). I tested two replicates for eight protocols. Because of financial and logistical constraints, I did not test all possible combinations of treatments, but I selected treatments that appeared most reasonable from within the suggested ranges of the manufacturers' recommended protocols.

Ambion protocols state that RNAlater ${ }^{\circledR}$ keeps RNA stable for up to a week at room temperature $\left(25^{\circ} \mathrm{C}\right)$ and up to 3 days at $37^{\circ} \mathrm{C}$. However, Qiagen protocols recommend that samples in RNAprotect ${ }^{\circledR}$ remain at room temperature for no more than $48 \mathrm{~h}$. I initially evaluated 
each buffer by testing its stabilization effectiveness with minimum recommended incubation times and no freezing. If RNA extraction was successful, then I evaluated the buffers with increasing durations of room temperature incubation and the addition of a freeze cycle to mimic field situations.

All samples were kept at room temperature for the time period suggested by the manufacturer (RNAprotect $\AA$ : 2 h, RNAlater ${ }^{\circledR}: 12$ h). However, for some samples stored in RNAlater ${ }^{\circledR}$, I incubated the sample for 2-8 $\mathrm{h}$, froze it, and then finished the remainder of the incubation period after thawing, prior to extraction. Interrupted incubation is an option described in the manufacturer's protocol. All frozen samples were kept in a $-20^{\circ} \mathrm{C}$ freezer until further processing.

I extracted RNA using either the RNeasy Animal Blood Kit (Qiagen) or the RiboPure Blood Kit (Ambion). I extracted replicates independently to eliminate potential human error during RNA extraction. I followed the manufacturer's detailed protocol for all samples stored in RNAlater ${ }^{\circledR}$. When extracting from the RNAprotect ${ }^{\circledR}$ reagent, I either used the manufacturer's protocol or a modified protocol developed by Chiari and Galtier (2011) for extracting RNA from sauropsid blood. All samples were eluted in a final volume of $20-50 \mu \mathrm{L}$.

I ran extracted RNA on a 1\% agarose gel and I quantified extracts on a Thermo Scientific NanoDrop Lite. For each treatment that successfully produced visible $18 \mathrm{~s}$ and $28 \mathrm{~s}$ bands, I ran at least one replicate on an Agilent 2100 BioAnalyzer. I determined RNA quality by assessing the BioAnalyzer-calculated RNA integrity number (RIN). 


\section{Preliminary RNA-seq}

I conducted a preliminary RNA-seq analysis on RNA extracted from whole blood from 10 Cooper's hawks trapped in 2014 and 16 trapped in 2015 in Albuquerque New Mexico (Table 5.2). Four of these samples were used in the RNA stabilization experiment described above. I stored blood collected in 2014 in RNAprotect ${ }^{\circledR}$ and that collected in 2015 in RNAlater ${ }^{\circledR}$. All samples were frozen within $\sim 2-8 \mathrm{~h}$ after collection. I extracted, quantified, and quality-tested RNA as described above. For all samples with usable RNA, globin RNA was removed and a library was prepared using the Illumina TruSeq ${ }^{\circledR}$ Stranded Total RNA LT kit with Ribo-Zero ${ }^{\mathrm{TM}}$ Globin, then RNA was sequenced on the Illumina MiSeq platform.

I performed a quality assessment of the results using FastQC (Babraham Bioinformatics, http://www.bioinformatics.babraham.ac.uk/projects/fastqc/). Since the Cooper's hawk genome has not been sequenced, I mapped RNA reads to the closest available reference genome, the golden eagle (Aquila chrysaetos, Doyle et al. 2014) using HISAT2 (Kim et al. 2015, Pertea et al. 2016). I used program StringTie to assemble reads into transcripts and to merge transcripts from all individuals for quantification (Pertea et al. 2015). Finally, I used the gffcompare utility (Pertea et al. 2016) to determine the sensitivity and precision of mRNA reads when aligned to the golden eagle reference genome. Sensitivity is defined as the proportion of genes from the annotation that are reconstructed correctly, and precision as the proportion of the RNA-seq output that overlaps with the annotation (Pertea et al. 2016). 


\section{Results}

\section{RNA Stabilization Experiment}

Only two of eight samples stored in RNAprotect ${ }^{\circledR}$ produced visible $18 \mathrm{~s}$ and $28 \mathrm{~s}$ bands (Table

5.1). Both of these were taken from red-tailed hawks, they were never frozen, and they were extracted following the manufacturer's extraction protocol immediately after the manufacturer's recommended $2 \mathrm{~h}$ incubation at room temperature. One sample yielded $80.1 \mathrm{ng} / \mu \mathrm{L}$ of RNA with a RIN of 2.3 , and the second yielded $123.3 \mathrm{ng} / \mu \mathrm{L}$ of RNA with a RIN of 6.2 (Table 5.1 ). All other blood stored in RNAprotect ${ }^{\circledR}$ resulted in no RNA or degraded RNA; this was true for all treatments, species, and extraction protocols (Table 5.1). This was also the case when I used the protocol developed by Chiari and Galtier (2011) for sauropsid blood stored in RNAprotect@.

I successfully extracted RNA from all blood stored in RNAlater ${ }^{\circledR}$, regardless of treatment or species, and in every case, visible $18 \mathrm{~s}$ and $28 \mathrm{~s}$ bands were generated after extraction (Table 5.1). RNA concentrations ranged from 40.9 to $1293.7 \mathrm{ng} / \mu \mathrm{L}$ (Table 5.1). The unfrozen sample and the sample frozen after $2 \mathrm{~h}$ produced RIN values of 7.9 and 8.2 , respectively. However, samples frozen between 2-8 $\mathrm{h}$ and after 3 days failed to generate a RIN on the BioAnalyzer, regardless of the fact that peaks were often present in graphical depictions of the data (Figure 5.1).

\section{Preliminary RNA-seq}

Since I was unable to obtain usable RNA from any of the ten Cooper's hawk blood samples stored in RNAprotect ${ }^{\circledR}$, I performed a preliminary RNA-seq analysis using only those 16 stored in RNAlater® (see Table 5.2). I successfully extracted RNA from all 16 samples and all produced a visible $18 \mathrm{~s}$ and $28 \mathrm{~s}$ band on the agarose gel. Average RNA concentration was 
$408.2 \mathrm{ng} / \mu \mathrm{L}$ (range: 40.9 to $1293.7 \mathrm{ng} / \mu \mathrm{L}$, Table 5.2). Only four of the 16 samples generated a RIN (Table 5.2).

The FASTQC quality assessment of the Illumina MiSeq reads suggested uniformly high sequence quality for all samples, irrespective of RIN values. I achieved a $49.7 \%$ average alignment rate when mapping the RNA-seq reads to the golden eagle reference genome (range = $44.5 \%-55.0 \%$, Table 5.2). The percentage of uniquely aligned reads ranged from $34.9 \%$ to 45.6\% (Table 5.2). The percentage of reads that mapped multiple times was much lower, ranging from $7.4 \%$ to $9.8 \%$ (Table 5.2). The gffcompare-estimated sensitivity of the alignment was relatively low across all genomic levels (<14\%; Table 5.3). The precision of alignment was greater than sensitivity at all genomic levels and ranged from 9.8 to $60.9 \%$ (Table 5.3).

\section{Discussion}

Interpreting Experimental Results

For the stabilization of RNA from avian whole blood collected in the field, RNAlater ${ }^{\circledR}$ outperformed RNAprotect ${ }^{\circledR}$. A large percentage of samples stored in RNAprotect ${ }^{\circledR}$ produced either no RNA or highly degraded RNA, indicating that this buffer may be unreliable for field studies on avian species. Further, of the two samples stored in RNAprotect $®$ that produced visible $18 \mathrm{~s}$ and $28 \mathrm{~s}$ bands on an agarose gel, one of these showed signs of degradation as it generated a low RIN on the BioAnalyzer.

Since RNA preservation reagents were developed for species with non-nucleated red blood cells (such as mammals), others have suggested that the extra nucleases and DNA in the nucleated red blood cells of birds degrades the RNA and thus, reduces the potential stabilization ability of RNAprotect ${ }^{\circledR}$ (Chiari and Galtier 2011). In spite of this, Chiari and Caltier (2011) were 
able to successfully extract RNA from both reptiles and birds using a modified protocol.

However, they found that RNAprotect ${ }^{\circledR}$ yielded less total RNA and had a higher likelihood of degradation when compared to BD TRI Reagent. Even when using this modified protocol for extracting RNA from nucleated whole blood in RNAprotect ${ }^{\circ}$, I was unable to reliably obtain usable RNA from raptor blood. This may be because my handling procedures were not identical to those reported by Chiari and Galtier (2011). In that study, the authors state that they collected samples at ambient temperature and immediately stored them at $4-10^{\circ} \mathrm{C}$ for up to 5 days before freezing. I was unable to successfully extract RNA from any samples stored in RNA protect and subsequently frozen, regardless of treatment. I only obtained RNA from the unfrozen samples which were extracted immediately after the recommended $2 \mathrm{~h}$ room temperature incubation. Unfortunately, immediate $4-10^{\circ} \mathrm{C}$ storage or immediate extraction may not be feasible in some field studies, suggesting that RNAprotect ${ }^{\circledR}$ may not be practical for these types of studies.

I was able to consistently obtain usable RNA from all avian whole blood stored in RNAlater ${ }^{\circledR}$. This suggests that RNAlater ${ }^{\circledR}$ might be more suitable for birds and potentially other species with nucleated red blood cells, especially when tissues are collected in the field and cannot be frozen for an extended period of time. In addition, I obtained usable RNA from samples stored in RNAlater ${ }^{\circledR}$ using both the RiboPure Blood Kit (Ambion), recommended for downstream processing of RNAlater ${ }^{\circledR}$, as well as the Qiagen RNeasy Protect Animal Blood Kit. I was even able to obtain RNA from samples that remained at room temperature for 3 days before freezing. Schwochow et al. (2012) found that RNAlater ${ }^{\circledR}$ outperformed four other RNA preservation methods in terms of total RNA yield from mammalian blood. However, they also found that RNA extracted from blood stored in RNAlater ${ }^{\circledR}$ had highly variable and inconsistent RIN values. This trend towards low quality RNA was also evident in echinoderm and arachnid 
tissues stored in RNAlater ${ }^{\circledR}$ (Perez-Portela and Riesgo 2013; Kono et al. 2016). This study is consistent with these findings as the RIN values for The samples in RNAlater ${ }^{\circledR}$ were either undetectable (13 of 19 tested) or highly variable (1.7-8.2).

This trend of low quality RNA is of concern since RIN values are thought to be correlated with RNA quality, and using RNA with low RIN values in downstream processing (e.g. RNA-seq) can result in a significant loss of cDNA library complexity (Romero et al. 2014). Further, Romero et al. (2014) suggested that RNA-seq studies should only include RNA with a RIN value above a threshold between $6.4-7.9$. However, that same study suggested that having high statistical power (a larger sample size) may be more important than including samples with only high RIN values, provided that low quality samples are evenly distributed between groups being compared. Thus, in the absence of a superior RNA stabilization buffer, RNAlater ${ }^{\circledR}$ may suffice for RNA-seq studies on wild populations as long as results are interpreted with care.

Given the low and variable RIN values generated from samples stored in RNAlater ${ }^{\circledR}$, and the inconsistent extraction success of RNAprotect ${ }^{\circledR}$, further study on commercial RNA stabilization buffers is warranted for non-mammalian taxa in field conditions. While RNAlater ${ }^{\circledR}$ typically yields more total RNA, the low RIN values may be cause for concern in downstream processing and may complicate interpretation of results. Other work has shown that although RNAprotect ${ }^{\circledR}$ yielded lower quantities of RNA, this buffer generated consistently higher RIN values when compared to RNAlater ${ }^{\circledR}$ (Schwochow et al. 2012). However, it is important to note that that study tested RNAlater ${ }^{\circledR}$ and RNAprotect ${ }^{\circledR}$ only on mammalian tissues in the field. I was only able to obtain RIN values for two avian samples using RNAprotect ${ }^{\circledR}$. These data are therefore insufficient to assess average RIN values and no other studies of which I am aware have reported RIN values when using RNAprotect ${ }^{\circledR}$ on species with nucleated red blood cells. 
Since RNAprotect ${ }^{\circledR}$ may potentially produce higher quality RNA, further studies using altered protocols might be useful in determining if this buffer can be used for nucleated red blood collected in the field.

\section{Downstream Processing}

Desert environments may be one of the most challenging for maintaining stable RNA for transcriptomic studies as RNA degrades more quickly with increasing temperature and exposure to ultraviolet light (Vincek et al. 2003; Sidova et al. 2015). In spite of these challenges, I was able to successfully perform RNA-seq on all field-collected Cooper's hawk samples stored in RNAlater ${ }^{\circledR}$. Only $50 \%$ of the RNA reads from the Cooper's hawk field samples mapped to the golden eagle reference genome and the precision and sensitivity of alignment was relatively low across all genomic levels. There are multiple factors that may have contributed to this low mapping success rate. First, this is likely in part a result of genomic differences between the two species. Although reference genomes of divergent species can be used for mapping in the absence of a same-species reference genome (Hornett and Wheat 2012), mapping errors are known to increase with increasing divergence time. In general, these effects are thought to be relatively small if the species diverged less than 100 million years before present (Hornett and Wheat 2012). Cooper's hawks and golden eagles are both Acciptriformes, an order that diverged 60-70 million years before present (Prum et al. 2015) and the estimated divergence time between these two species is thought to be approximately 28.4 million years ago (Hedges et al. 2006). Therefore, I would expect relatively reliable mapping, especially of highly conserved genes (Hornett and Wheat 2012). Regardless, it is impossible to predict what proportion of the genome overlaps between these two species without complete reference genomes for both organisms. 
Second, the 50\% mapping rate and low sensitivity and precision of alignment may be a result of RNA degradation. While it is clear that at least some of the RNA was preserved in the stabilization buffer, a portion of the RNA in each sample was likely degraded. This is apparent from the wide range of RIN values as well as the failure of certain samples to produce RIN values at all. Even though the samples were placed into a dark cooler immediately after collection, it is entirely possible that the high temperatures and UV light of the desert environment contributed somewhat to degradation of RNA in some or all of the samples. Degraded RNA can lead to low sensitivity values as degraded RNA will result in incomplete or incorrect reconstruction of genes in the reference genome.

Finally, biased RNA preservation of the stabilization buffer may also undermine mapping accuracy. Some RNAs may degrade faster than others and low abundance RNA may be difficult to preserve (Romero et al. 2014). As a consequence, stabilization reagents may only preserve highly stable RNA molecules. This bias in preservation could result in the loss of data associated with low abundance or highly unstable RNA molecules. The loss of such data would lead to low overall mapping rates as well as low alignment precision. Results from studies using buffers with preservation bias should be interpreted with caution until these preservation biases are better understood.

It is difficult to determine how much each of these factors contributed to the low precision and sensitivity of read mapping in this study. It is likely a combination of the use of a divergent species reference genome, RNA degradation, and RNA preservation bias. Sequencing the Cooper's hawk genome, further study on RNA degradation in the field, and research into preservation biases of commercial reagents would help improve our understanding of the relative impact of each of these factors for interpreting transcriptomic data in future research. 


\section{Conclusions}

Transcriptomic research has the potential to provide important insights into the ecology of wild populations. This type of research is especially important for the study of rare or endangered species for which laboratory studies are not feasible. However, to execute these types of studies, it is imperative that high quality RNA be preserved under challenging field conditions for reliable downstream processing. Most commercially available buffers were manufactured for laboratory studies on mammalian species and this study shows the importance of testing these buffers on various taxa under adverse field conditions.

This work demonstrates that existing commercial RNA stabilization buffers can be used for field studies but also that each buffer comes with its own set of challenges. These challenges may be overcome with additional field trials and modified protocols for specific taxa. Future research would benefit from the development of commercial RNA stabilization buffers specifically for taxa with nucleated red blood cells. Such buffers should be tested under a wide array of potential field conditions and storage scenarios and to understand RNA preservation bias of each buffer. As sequencing technologies continue to improve and become more accessible for non-model organisms, it is important that RNA stabilization buffers are optimized to ensure that high quality RNA is collected for answering pertinent ecological and evolutionary questions.

\section{Literature Cited}

Alvarez M, Schrey AW, Richards CL (2015) Ten years of transcriptomics in wild populations: what have we learned about their ecology and evolution? Mol Ecol 24:710-725

Bird DM, Bildstein KL (eds) (2007) Raptor Research and Management Techniques. Hancock House Publishers, Surrey, British Columbia

Camacho-Sanchez M, Burraco P, Gomez-Mestre I, Leonard JA (2013) Preservation of RNA and DNA from mammal samples under field conditions. Mol Ecol Resour 13:663-673 
Chiari Y, Galtier N (2011) RNA extraction from sauropsids blood: evaluation and improvement of methods. Amphib-Reptil 32:136-139

Doyle J, Katzner T, Bloom P, Ji Y, Wijayawardena B, DeWoody J (2014) The genome sequence of a widespread apex predator, the golden eagle (Aquila chrysaetos). PLoS One 9:e95599

Gleason LU, Burton RS (2015) RNA-seq reveals regional differences in transcriptome response to hear stress in the marine snail Chlorostoma funebralis. Mol Ecol 24:610-627

Gorokhova E (2005) Effects of preservation and storage of microcrustaceans in RNAlater on RNA and DNA degradation. Limnol Oceanogr-Meth 3:143-148

Hedges SB, Dudley J, Kumar S (2006) TimeTree: A public knowledge-base of divergence times among organisms. Bioinformatics 22:2971-2972

Hornett E, Wheat C (2012) Quantitative RNA-seq analysis in non-model species: assessing transcriptome assemblies as a scaffold and the utility of evolutionary divergent genomic reference species. BMC Genomics 13:361-377

Husmann G, Abele D, Rosenstiel P, Clark MS, Kraemer L, Philipp EER (2014) Age-dependent expression of stress and antimicrobial genes in the hemocytes and siphon tissue of the Antarctic bivalve, Laternula elliptica, exposed to injury and starvation. Cell Stress Chaperon 19:15-32

Kim D, Langmead B, Salzberg SL (2015) HISAT: a fast-spliced aligner with low memory requirements. Nat Methods 12:357-360.

Kono N, Nakamura H, Ito Y, Tomita M, Arakawa K (2016) Evaluation of the impact of RNA preservation methods of spiders for de novo transcriptome assembly. Mol Ecol Resour 16:662-672

Legrand E, Forget-Leray J, Duflot A, Olivier S, Thome J, Danger J, Boulange-Lecomte C (2016) Transcriptome analysis of the copepod Eurytemora affinis upon exposure to endocrine disruptor pesticides: Focus on reproduction and development. Aquat Toxicol 176:64-75

Lucas ER, Privman E, Keller L (2016) Higher expression of somatic repair genes in long-lived ant queens than workers. Aging 8:1940-1949

McKinney GJ, Hale MC, Goetz G, Gribskov M, Thrower FP, Nichols KM (2015) Ontogenic changes in embryonic and brain gene expression in progeny produced from migratory and resident Onchorhynchus mykiss. Mol Ecol 24:1792-1809

Perez-Portela R, Riesgo A (2013) Optimizing preservation protocols to extract high-quality RNA from different tissues of echinoderms for next-generation sequencing. Mol Ecol Resour 13:884-889

Pertea M, Pertea GM, Antonescu CM, Chang T, Mendell JT, Salzberg SL (2015) StringTie enables improved reconstruction of a transcriptome from RNA-seq reads. Nat Biotechnol 33:290-295 
Pertea M, Kim D, Pertea G, Leek J, Salzberg S (2016) Transcript-level expression analysis of RNA-seq experiments with HISAT, StringTie, and Ballgown. Nat Protoc 11:1650-1667

Prum R, Berv J, Dornburg A, Field D, Townsend J, Lemmon E, Lemmon A (2015) A comprehensive phylogeny of birds (Aves) using targeted next-generation sequencing. Nature 526:569-577

Riesgo A, Perrez-Porro AR, Carmona S, Leys SP, Giribet G (2012) Optimization of preservation and storage time of sponge tissues to obtain quality mRNA for next-generation sequencing. Mol Ecol Resour 12:312-322

Romero IG, Pai AA, Tung P, Gilad Y (2014) RNA-seq: impact of RNA degredation on transcript quantification. BMC Biol 12:42

Scheiner SM, Willig MR (eds) (2001) The Theory of Ecology. University of Chicago Press, Chicago, Illinois

Schwochow D, Serieys LEK, Wayne RK, Thalmann O (2012) Efficient recovery of whole blood RNA - a comparison of commercial RNA extraction protocols for high-throughput applications in wildlife species. BMC Biotechnol 12:33-44

Sidova M, Tomankova S, Abaffy P, Kubista M, Sindelka R (2015) Effects of post-mortem and physical degradation on RNA integrity and quality. Biomol Detect Quantif 5:3-9

Smith S, Bernatchez L, Beheregaray LB (2013) RNA-seq analysis reveals extensive transcriptional plasticity to temperature stress in a freshwater fish species. BMC Genomics 14:375-387

Vincek V, Nassiri M, Knowles J, Nadji M, Morales AR (2003) Preservation of tissue RNA in normal saline. Lab Invest 83:137

Wang Z, Gerstein M, Snyder M (2009) RNA-seq: a revolutionary tool for transcriptomics. Nat Rev Genet 10:57-63 
Table 5.1: Sample and treatment parameters and information on extracted RNA for nucleated avian blood treated with two different RNA stabilization buffers. Quotation (") indicates that treatments were identical to the previous row (i.e. they are replicates). Redtailed hawk (RTHA) samples were collected from captive birds at an avian conservation center in Morgantown, WV while Cooper's hawk (COHA) samples were collected in the field in Albuquerque, NM during the summer of 2014 or 2015. The modified protocol is that from Chiari and Galtier (2011)

\begin{tabular}{|c|c|c|c|c|c|c|c|}
\hline $\begin{array}{l}\text { Stabilization } \\
\text { Buffer }\end{array}$ & Species & $\begin{array}{l}\text { Freeze Treatment } \\
\text { (Room temp. } \\
\text { incubation) } \\
\end{array}$ & $\begin{array}{l}\text { Extraction } \\
\text { Kit/Protocol }\end{array}$ & Gel Results & RIN & $\mathrm{ng} / \mu \mathrm{L}$ & $260 / 280$ \\
\hline \multirow[t]{8}{*}{ RNAprotect $\AA$} & RTHA & Not frozen $(2 \mathrm{~h})$ & Qiagen/Manufacturers & 2 Bands & 2.3 & 80.1 & 1.9 \\
\hline & RTHA & “ & “ & 2 Bands & 6.2 & 123.2 & 2.21 \\
\hline & RTHA & Frozen $(2 \mathrm{~h})$ & Qiagen/Modified & No Bands & - & - & - \\
\hline & RTHA & “ & “ & No Bands & - & - & - \\
\hline & COHA & Frozen $(2-8 \mathrm{~h})$ & Qiagen/Manufacturers & Degraded & - & - & - \\
\hline & COHA & “ & “ & No Bands & - & - & - \\
\hline & COHA & Frozen $(2-8 \mathrm{~h})$ & Qiagen/Modified & Degraded & - & - & - \\
\hline & COHA & “ & “ & Degraded & - & - & - \\
\hline \multirow[t]{8}{*}{ RNAlater ${ }^{\circledR}$} & RTHA & Not frozen $(12 \mathrm{~h})$ & Qiagen/Manufacturers & 2 Bands & 7.9 & 246.5 & 2.01 \\
\hline & RTHA & “ & “ & 2 Bands & - & 315.2 & 2.02 \\
\hline & RTHA & Frozen $\left(2 \mathrm{~h}^{\mathrm{b}}\right)$ & Qiagen/Manufacturers & 2 Bands & 8.2 & 190.5 & 2.08 \\
\hline & RTHA & “ & “ & 2 Bands & - & 378.2 & 2.08 \\
\hline & $\mathrm{COHA}^{\mathrm{a}}$ & Frozen $\left(8 \mathrm{~h}^{\mathrm{b}}\right)$ & Ambion/Manufacturers & 2 Bands & N/A & 40.9 & 1.85 \\
\hline & $\mathrm{COHA}^{\mathrm{a}}$ & “ & “ & 2 Bands & 6.8 & 1293.7 & 1.95 \\
\hline & RTHA & Frozen (3 days) & Qiagen/Manufacturers & 2 Bands & N/A & 629 & 2.05 \\
\hline & RTHA & ، & “ & 2 Bands & - & 508.9 & 2.06 \\
\hline
\end{tabular}

${ }^{a}$ Indicates samples that were also used for the preliminary RNA-seq analysis in this study; these two samples are included as sample \#1 and \#2 in Table 5.2.

${ }^{\mathrm{b}}$ Indicates interrupted incubation protocol: Initial incubation time prior to freezing listed in table, total incubation time is $12 \mathrm{~h}$ as per manufacturers protocol. 
Table 5.2: RNA integrity number (RIN), RNA quantity (ng/ $\mu \mathrm{L}$ ), and 260/280 ratio for 16 RNA samples collected from Cooper's hawks in Albuquerque, NM during July 2015. Data on total number of reads, number of uniquely aligned reads, number of reads that aligned multiple times, and the overall alignment percentage from the Illumina MiSeq run are also included for all samples. All 16 samples were preserved in RNAlater, frozen between 2-8 h of collection and extracted using the manufacturer's protocol for the Ambion RiboPure Blood Kit. COHA samples collected in 2014 into RNAprotect are not shown because all samples produced degraded, unusable RNA.

\begin{tabular}{cccccccc}
\hline Sample \# & RIN & $\mathbf{n g} / \mathbf{\mu L}$ & $\mathbf{2 6 0 / 2 8 0}$ & Total Reads & $\begin{array}{c}\text { Aligned Uniquely } \\
(\mathbf{1 x})\end{array}$ & $\begin{array}{c}\text { Aligned Multiple } \\
\text { Times (>1x) }\end{array}$ & $\begin{array}{c}\text { Total } \\
\text { Alignment } \\
\text { Percentage }\end{array}$ \\
\hline \hline 1 & N/A & 40.9 & 1.85 & 818361 & $315079(38.5 \%)$ & $60680(7.4 \%)$ & $45.9 \%$ \\
2 & 6.8 & 1293.7 & 1.95 & 781529 & $353249(45.2 \%)$ & $76456(9.8 \%)$ & $55.0 \%$ \\
3 & 7.5 & 199.9 & 2.06 & 1088682 & $480506(44.1 \%)$ & $100163(9.2 \%)$ & $53.3 \%$ \\
4 & N/A & 302.4 & 2.07 & 1070768 & $457891(42.7 \%)$ & $90724(8.5 \%)$ & $51.2 \%$ \\
5 & N/A & 131.2 & 1.89 & 791140 & $360459(45.6 \%)$ & $59687(7.5 \%)$ & $53.1 \%$ \\
6 & N/A & 463.4 & 2.07 & 802459 & $317803(39.6 \%)$ & $68435(8.5 \%)$ & $48.1 \%$ \\
7 & N/A & 393.6 & 2.05 & 770068 & $268943(34.9 \%)$ & $74006(9.6 \%)$ & $44.5 \%$ \\
8 & 2.5 & 389.3 & 2.07 & 800399 & $338894(42.3 \%)$ & $69410(8.7 \%)$ & $51.0 \%$ \\
9 & N/A & 193.2 & 2.08 & 894141 & $400539(44.8 \%)$ & $77509(8.7 \%)$ & $53.5 \%$ \\
10 & N/A & 421.3 & 2.07 & 1076379 & $446659(41.5 \%)$ & $90520(8.4 \%)$ & $49.9 \%$ \\
11 & N/A & 413.5 & 2.07 & 944833 & $3880655(41.1 \%)$ & $89588(9.5 \%)$ & $50.6 \%$ \\
12 & N/A & 939 & 1.92 & 1015152 & $396989(39.1 \%)$ & $92177(9.1 \%)$ & $48.2 \%$ \\
13 & N/A & 374.7 & 2.04 & 1044965 & $375360(35.9 \%)$ & $95291(9.1 \%)$ & $45.0 \%$ \\
14 & 1.7 & 333.9 & 1.95 & 1325941 & $535823(40.4 \%)$ & $96326(7.3 \%)$ & $47.7 \%$ \\
15 & N/A & 340.1 & 2.03 & 1114903 & $444400(39.9 \%)$ & $91916(8.2 \%)$ & $48.1 \%$ \\
16 & N/A & 300.8 & 2.08 & 1182138 & $485644(41.1 \%)$ & $102178(8.6 \%)$ & $49.7 \%$ \\
\hline
\end{tabular}


Table 5.3: Sensitivity and precision of Cooper's hawk RNA-seq reads when mapping to the golden eagle reference genome at six different genomic levels. Samples were collected in RNAlater in Albuquerque, NM during the summer of 2015. RNA was extracted and sequenced on the Illumina MiSeq then mapped to the golden eagle reference genome using HISAT2 and evaluated for sensitivity and precision using gffcompare.

\begin{tabular}{lcc}
\hline Genomic Level & Sensitivity & Precision \\
\hline \hline Base Level & 13.8 & 49.1 \\
Exon Level & 8.4 & 41.4 \\
Intron Level & 9.4 & 60.9 \\
Intron Chain Level & 4.2 & 9.8 \\
Transcript Level & 6.2 & 10.3 \\
Locus Level & 6.2 & 11.8 \\
\hline
\end{tabular}




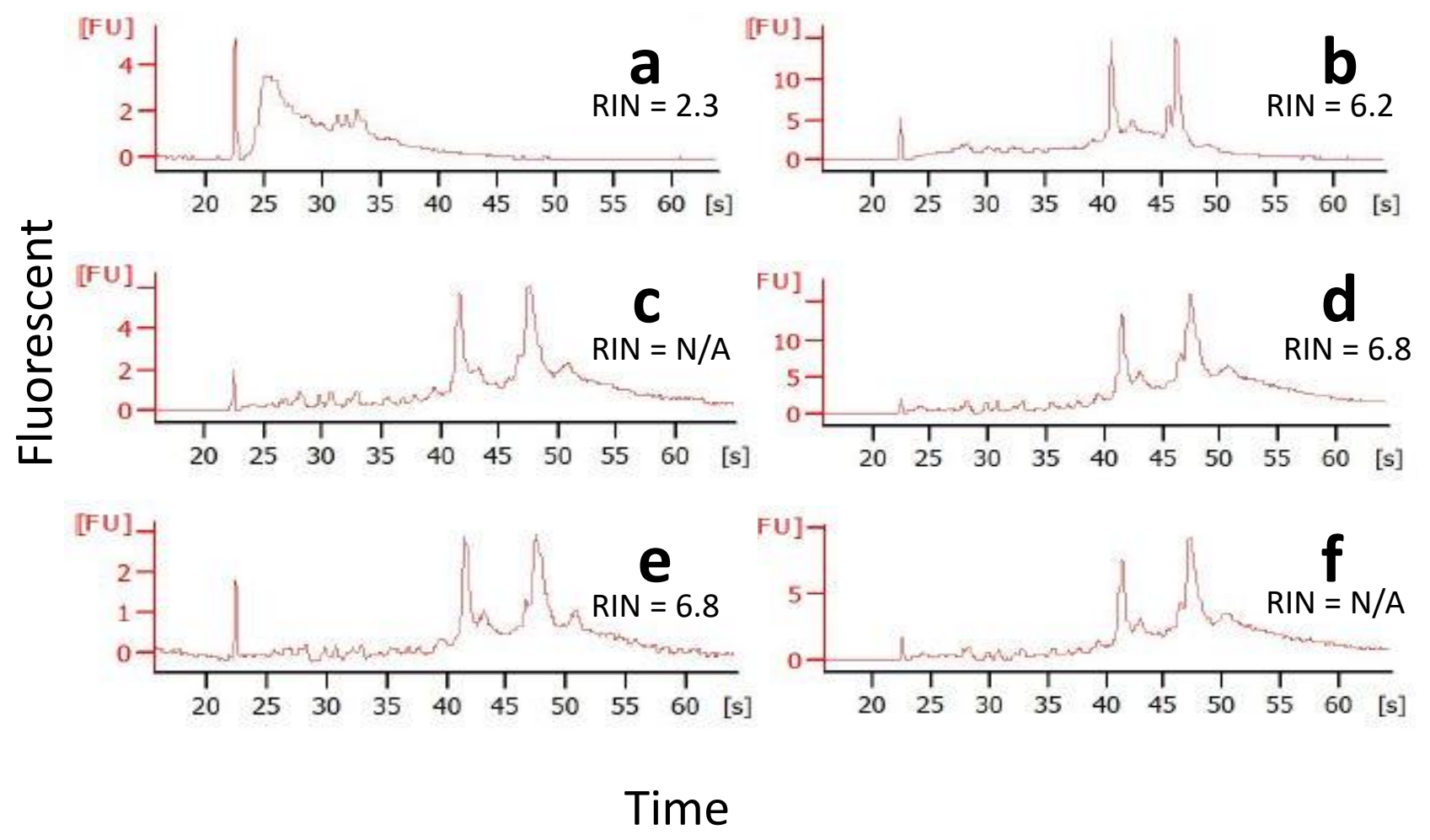

Figure 5.1: Example graphical results from six BioAnalyzer reads. A = red-tailed hawk (RTHA) sample stored in RNAprotect ${ }^{\circledR}$ and never frozen (the only highly degraded sample depicted), B $=$ RTHA sample stored in RNAprotect ${ }^{\circledR}$ and never frozen, $\mathrm{C}=$ Cooper's hawk (COHA) sample stored in RNAlater ${ }^{\circledR}$ and frozen within 2-8 h (also used for Illumina MiSeq run, sample \#1) D = COHA sample stored in RNAlater ${ }^{\circledR}$ and frozen in 2-8 h (also used for Illumina MiSeq run, sample \#2) $\mathrm{E}=$ RTHA sample stored in RNAlater ${ }^{\circledR}$ and never frozen, $\mathrm{F}=$ RTHA samples stored in RNAlater ${ }^{\circledR}$ and frozen after 3 days. 


\title{
Chapter 6: Urbanization, gene expression, and acclimation: A case study of a recent urban exploiter
}

\author{
Abstract \\ Urbanization is rapidly increasing on a global scale. An important question in modern ecological \\ research is how species are dealing with stressors associated with urban environments. Previous \\ studies have shown phenotypic changes in urban-associated species, however, understanding the \\ molecular mechanisms for these changes remains largely unexplored. While many species may \\ adapt via heritable genetic changes, some species, such as those that are highly mobile may \\ simply acclimate via phenotypic plasticity. I investigated gene expression patterns, using RNA- \\ sequencing, in urban and exurban adult and fledgling Cooper's hawks (Accipiter cooperii) in the \\ greater Albuquerque, NM area. Cooper's hawks are a highly mobile predator species that have \\ recently exploited urban environments but also experienced high nestling mortality rates from an \\ urban-associated disease (Trichomoniasis). I found 13 transcripts that were differentially \\ expressed (DE) in urban and exurban fledglings, and one DE transcript in urban and exurban \\ adults. More abundant transcripts in urban environments mostly involved nucleic acid \\ processing, and the transcript identified in the adult group is also involved in metal ion binding \\ and platelet production in humans. Most of the transcripts that were expressed at higher levels in \\ exurban fledglings were associated with immune response, despite the fact that Trichomonas \\ spp. were detected in equal numbers of urban and exurban fledglings. Based on evidence from \\ previous studies, it is possible that urban fledglings have suppressed immune systems due to \\ toxin loading. Future research could be used to investigate toxin levels in urban and exurban \\ hawks in conjunction with gene expression analysis, as well as examine potential genetic or \\ epigenetic mechanisms for differences between individuals inhabiting the two environments.
}




\section{Introduction}

Understanding the way in which species adapt to the drastic changes that accompany urbanization is an immediate interest to ecologists (Harris et al., 2013). This is because urbanization is rapidly accelerating (Seto et al., 2010; United Nations, 2011) and humans are driving the fastest rates of evolution on a global scale (Hendry \& Kinnison, 1999). Urbanization can have a profound effect on ecosystems and their functions (Shochat et al., 2006). Some of these effects include a decrease in biodiversity (McKinney, 2006; McKinney, 2008; Harris et al., 2013), diminished ecosystem services (Walsh et al., 2005, Felson et al., 2013), lowered habitat quality (Desender et al., 2005), increased habitat fragmentation and isolation (Gortat et al., 2013), changes in abiotic conditions (Gortat et al., 2013), and increased pollution (e.g. noise, light, air, water, and soil; Harris et al., 2013; Isaksson, 2015).

Native wildlife inhabiting urban areas are subjected to a suite of novel environmental factors including new and more abundant parasites and pathogens (Peluc et al., 2008), new predators and competitors (Sih et al., 2011), as well as different food resources, altered abiotic factors, and novel or high concentrations of toxins (Whitehead et al., 2010; Gortat et al., 2013). Despite these challenges, there is growing evidence that many species are fully capable of surviving in urban environments and in some cases, they even thrive in these areas by exploiting human-created resources ("urban exploiters", Shochat et al., 2006; Harris et al., 2013; Isaksson, 2015). There is also evidence to suggest that specific observable phenotypic changes occur in species associated with urban habitats (see Alberti et al., 2017). However, there are few studies that link these phenotypic differences to their molecular mechanisms. Therefore, a major question that still remains in urban ecology is whether species are adapting, acclimating, or simply coping with the challenges associated with urban-living (Isaksson, 2015). 
Recent advances in genomic techniques offer a unique opportunity to investigate the specific molecular changes a species undergoes when colonizing an urban area (Hohenlohe et al., 2011). While numerous studies have identified genetic differences between urban and rural wildlife populations, the vast majority of these studies involved the use of neutral genetic markers (e.g. microsatellites, see Wood \& Pullin, 2002; Wanderler et al., 2003; Desender et al., 2005; Munshi-South \& Kharchenko, 2010; Gortat et al., 2013; Kajdacsi et al., 2013; Serieys et al., 2014). Because they do not experience selection pressure, these types of markers cannot be used to distinguish between genetic isolation (via genetic drift) and evolution (via natural selection). To estimate the potential impact of future urban development on new wildlife species, it is important to understand how species are dealing with urban related stressors (Isaksson, 2015). Changes in urban species could be driven by fixed, heritable changes in the genome (adaptation) or through phenotypic plasticity (acclimation; see Isaksson, 2015). High throughput sequencing is a useful tool for investigating these potential mechanisms. Examining selective markers (e.g. single nucleotide polymorphisms, hereafter SNPs) across the genome or transcriptome may reveal genetic changes while studying gene expression (RNA-seq) can provide evidence of phenotypic plasticity.

Only a few studies have demonstrated a link between urbanization and genetic or epigenetic changes in organisms. Reduced migratory behavior was found to be genetically mediated in male European blackbirds (Turdus merula; Partecke \& Gwinner, 2007). In addition, genes associated with anxiety behaviors are selected for in numerous urban European blackbird populations (Mueller et al., 2013). White-footed mouse (Peromyscus leucopus) populations in New York City showed genetic divergence from rural populations. SNPs were identified throughout the mouse transcriptome revealing selection pressure on genes associated with 
xenobiotic processing, immune response, metabolism, and spermatogenesis (Harris et al., 2013). To my knowledge, no studies have identified epigenetic or plastic changes specifically associated with urban environments. However, many have identified epigenetic changes (e.g. methylation) along pollution gradients, which is relevant to urbanization given the high levels of pollution observed in cities (see Hansen et al., 2006; Aniagu et al., 2007; Kohno et al., 2008; Santoyo et al., 2011; Basu et al., 2013).

By researching molecular differences in urban vs. exurban environments, we can gain insights into which genes are important for wildlife in urban ecosystems and how anthropogenic factors affect natural selection and diversity. Also, by understanding what stressors are inducing genetic or plastic responses, future planning for urban developments can be improved (Felson et al., 2013). This information could be useful to mitigate species loss from urban areas and potentially improve ecosystem function (Donihue \& Lambert, 2015).

\section{Study Species}

The Cooper's hawk (Accipiter cooperii) is an ideal model for understanding the molecular underpinnings of a rapid expansion into urban environments. This species was historically associated with large intact forest habitats but more recently has been found living and breeding in high densities in urban settings (Rosenfield \& Bielefeldt, 1993; Rosenfield et al., 1996; Boal \& Mannan, 1998; Boal \& Mannan, 1999; Mannan \& Boal, 2000; Estes \& Mannan, 2003, Stout \& Rosenfield, 2010). An extensive body of research has revealed differences between urban and exurban Cooper's hawks including home range size (Rosenfield et al., 1996; Boal \& Mannan, 1998, Mannan \& Boal, 2000), prey selection (Estes \& Mannan, 2003), prey delivery rates to nests (Estes \& Mannan, 2003), nest site selection (Boal \& Mannan, 1998) and nesting success 
(Boal \& Mannan, 1999, Rosenfield et al. 1996; Chiang et al. 2012). In addition, this species was strongly affected by an urban-associated disease in the southwestern United States. Boal and Mannan (1999) found a high rate of nestling mortality in urban Cooper's hawks from avian Trichomoniasis infection. This infection is caused by a protozoan (Trichomonas gallinae) primarily carried by species in the Family Columbidae, a common prey item for Cooper's hawks (Stabler, 1954; Estes \& Mannan, 2003; Roth \& Lima 2003). Infected raptors, which may get the disease by feeding on pigeons with virulent strains of the protozoan, show cankerous growths in their digestive tracts, and can eventually die of starvation.

The major goal of my research was to investigate the molecular patterns underlying the differences between urban and exurban adult and fledgling Cooper's hawks. Cooper's hawks are highly mobile and telemetry data suggest that adults often move between urban and exurban areas (Millsap, unpublished data). Kark et al. (2007) suggested that species that are able to migrate between urban and exurban settings may be more likely to acclimate (via plasticity) to urban environments rather than adapt (via heritable genetic/epigenetic changes). Some research suggests that developmental and phenotypic plasticity may be the most likely mechanism for acclimatization to environmental stressors (Donelson et al., 2011; Correia et al., 2013; Burris \& Baccarelli, 2014; Horowitz, 2016; Šrut et al., 2017). Therefore, I used RNA-seq to investigate differences between urban and exurban individuals because I hypothesize that gene expression is the primary mechanism for urban tolerance in this species. Further, because young hawks have only been exposed to the environment in which they were hatched and develop in the presence of urban stressors, I expect to find more differentially expressed genes between urban and exurban fledglings as compared to adults. Based on previous research on molecular patterns in urban species, I expect that genes with expression differences between the two environments may be 
involved in immune function, xenobiotic processing, or stress, as a result of the novel challenges that urban Cooper's hawks experience when inhabiting a human-dominated environment.

\section{Methods}

\section{Field Sampling}

Samples were collected from wild Cooper's hawks during the 2015 breeding season in Albuquerque, NM. All individuals were aged and sexed using standard measurements and plumage (Pyle, 2008). I targeted nests in single-family residential areas, in public recreational parks, and in large contiguous tracts of undeveloped forest outside the city in the adjacent mountains and riparian areas (see Figure 6.1). Samples were obtained from highly mobile breeding adults and from fledglings which had only experienced the environment associated with the immediate area surrounding their nest. When possible, I sampled only a single fledgling from the same nest to prevent a relatedness bias in the analysis. Whole blood was drawn from the brachial or jugular vein using a sterile syringe and $300 \mu \mathrm{L}$ was placed in RNAlater® and frozen at $-20^{\circ} \mathrm{C}$ within 8 hours of collection. To test for the presence of $T$. gallinae, esophageal swabs were taken using a sterile cotton swab moistened with sterile saline solution. The swab was then used to inoculate a InPouch TF culture pack (BioMed Diagnostics, San Jose, CA; Bunbury et al., 2005). Inoculates were incubated for $72 \mathrm{~h}$ at $38^{\circ} \mathrm{C}$, then frozen at $-20^{\circ} \mathrm{C}$. I also noted if there was any visible evidence of Trichomoniasis infection in the birds' oral cavity (e.g. cankers, unable to close mouth, etc.). 


\section{Defining Nest Sites}

The definitions of "urban" and "exurban" often vary across geographic regions and depend on the specific context in which they are being used (Nilon et al., 2003). In general, urban areas are subjected to large-scale landscape modifications that can create high concentrations of food, water, energy, materials, garbage, pollution, and sewage (McDonnell \& Pickett, 1990; Roodman, 1996). One of the most common methods for defining an urban area consists of using a minimum population density threshold for the area of interest (McDonnell et al., 1997; MacGregor-Fors, 2011). However, this definition fails to classify large industrial areas as urban, since population density is based on census data of where people live, not where they work. Therefore, I used an alternate metric to define urban areas: percent imperviousness, which is an indicator of the amount of permanent human-made structures in a given area.

In ArcMap 10.3.1 (ESRI, 2011), I created 385m buffer zones around each sampled nest that represent the average territory size of a nesting pair of Cooper's hawks in Albuquerque (Millsap, unpublished data). Next, I determined the average, median and majority percent imperviousness (National Land Cover Database, Xian et al., 2011) values for each nest territory using the zonal statistics as table tool. It has been suggested that urban areas can be defined as those with >50\% impermeable surfaces (MacGregor-Fors, 2011). Therefore, if the majority of cells within the nest territory buffer zone were positive values, I defined the nest as "urban". In contrast, "exurban" nests had a majority value of zero.

\section{Laboratory Methods}

I extracted RNA using the Ambion RiboPure ${ }^{\mathrm{TM}}$-Blood RNA Isolation Kit. Extracts were quantified on a Thermo Scientific Nanodrop ${ }^{\mathrm{TM}}$ Lite Spectrophotometer and quality was assessed 
by determining an RNA-integrity number (RIN) on an Agilent 2100 BioAnalyzer. RNA from blood is comprised largely of hemoglobin mRNA, which can interfere with detection of other relevant transcripts in gene expression analysis (Liu et al., 2006). So, to remove hemoglobin mRNA from all samples, the TruSeq® Stranded Total RNA LT kit with RiboZero ${ }^{\mathrm{TM}}$ Globin was used. A cDNA library was created for each sample at the West Virginia University (WVU) Genomics Core using Illumina's TruSeq Stranded mRNA Library Prep Kit. For all kits, the manufacturers' recommended protocol was followed. A preliminary RNA-sequencing run (paired-end) was performed for the adult samples using the Illumina MiSeq platform at the WVU Genomic Core Facility. Then, paired-end RNA-seq reads were generated for all samples on an Illumina HiSeq1000 Platform at the Marshall University Genomics Core Facility. Because of logistical and financial constraints, adult and juvenile samples were prepared and run separately. Inoculated InPouch TF culture packs were thawed and half of the volume $(\sim 1.5 \mathrm{~mL})$ was transferred to a $1.5 \mathrm{~mL}$ microcentrifuge tube. Next, I followed the animal cell protocol in the Qiagen DNeasy Blood and Tissue Kit to extract DNA. DNA quality and quantity were determined using the Thermo Scientific Nanodrop ${ }^{\mathrm{TM}}$ Lite Spectrophotometer. To identify $T$. gallinae in the extracts, I used family-specific Trichomonadidae primers in a polymerase chain reaction following a previously described protocol (Ecco et al., 2012). PCR products were run on a 1\% agarose gel: the presence of a single band between $~ 100-200 \mathrm{bp}$ confirmed Trichomonas positive samples. Samples without a band indicated no Trichomonas spp. in the individual at the time of collection, however could not be used to confirm that an individual was never exposed to the parasite. 


\section{RNA-seq Analysis}

A quality assessment was performed on RNA-seq results for all samples using FastQC (Babraham Bioinformatics). I concatenated paired-end reads and mapped them to the golden eagle (Aquila chrysaetos) genome using HISAT2 (Doyle et al., 2014; Kim et al., 2015; Pertea et al., 2016). In the absence of a same-species reference genome, the genome from the closest related species can be used for read mapping. The effect of mapping errors is relatively small as long as divergence time is $<100$ million years before present (Hornett \& Wheat, 2012). Current estimates suggest that the Cooper's hawk and the golden eagle diverged approximately 28.4 million years ago (Prum et al., 2015). Next, StringTie was used to assemble the reads into transcripts and merge the transcripts from all individuals (Pertea et al., 2015).

Differential expression (DE) analyses were performed using Ballgown in R (R Core Team, 2013; Frazee et al., 2014). I used a previously described protocol for detecting significant DE transcripts between urban and exurban Cooper's hawks (Pertea et al., 2016). Briefly, this analysis compares the fragments per kilobase of transcripts per million reads (FPKM), which are raw counts normalized in respect to library size and gene length. The analysis accounts for highly-skewed FPKM values by applying a log transformation then fitting the values to a standard linear model (Pertea et al., 2016). In addition, to deal with low abundance genes, this pipeline employs a variance filter to remove all transcripts with a variance $<1$ (Pertea et al. 2016). A major benefit of the Ballgown program is that it allows for the inclusion of potential confounders. I performed four DE tests; first I compared transcripts of all urban and exurban individuals using age (adult or fledgling) and sex as confounders. Next, I performed the analysis again for adults and juveniles separately, including sex as a confounder for each analysis. Last, I combined the technical replicates from the adult samples for a second DE analysis using both 
sequencing datasets (Illumina HiSeq and MiSeq). To account for multiple comparisons, q values are reported along with $\mathrm{p}$ values in the Ballgown output for each transcript (Storey \& Tibshirani, 2003; Frazee et al. 2014). Transcripts with a q value of $<0.05$ were considered significant.

I compared the number of DE transcripts in the adult and juvenile analyses. Since the adults and juveniles were run separately, the results could be influenced by batch effects (Hicks et al. 2015). To determine if differences in the number of DE transcripts between the separate adult and fledgling analyses could be from an unequal number of mapped reads, I tested the distribution of read numbers for normality using a Shapiro-Wilk test (Zar, 2010). Then, I used a t-test in R (R Core Team 2013) to compare the total number of mapped reads between adult and fledgling samples. I performed this test twice, first using the HiSeq data only for both fledgling and adult samples, then using the HiSeq fledgling data compared to the HiSeq and MiSeq data combined for the adult samples.

To identify transcripts, I extracted sequences from the genome with the Integrative Genome Viewer (Robinson et al., 2011; Thorvaldsdóttir et al., 2013). Next, I used National Center for Biotechnology Information (NCBI) nucleotide Basic Local Alignment Search Tool (BLAST) to search for similar sequences in the $\mathrm{nr} / \mathrm{nt}$ nucleotide collection database. The best match was reported for each transcript based on percent identity and an e-value cut-off of $10^{-5}$ (Rawat et al., 2012). To determine gene ontology terms, I searched multiple databases such as Ensembl, GO_Central, and UniProt as well as relevant literature regarding transcripts identified in BLAST searches. 


\section{Results}

Field Sampling and Site Classification

I collected samples from a total of 32 Cooper's hawks from 23 nests in the greater Albuquerque, NM area (Figure 6.1). Of these nests, 9 were classified as exurban and 14 were classified as urban. Within the $385 \mathrm{~m}$ exurban nest territories, the majority of the cells had a percent imperviousness of zero, while this value was $\geq 35$ for all urban nests (Table 6.1). The median percent imperviousness value for exurban nest areas was always zero, and averages ranged from $0-19.6 \%$ (Table 6.1). Both the median and average percent imperviousness values were greater at all urban nests, ranging from 39-64\% and 35-65\%, respectively (Table 6.1). Fourteen samples were collected from exurban nests (adults, $\mathrm{n}=8$; fledglings, $\mathrm{n}=6$ ) and 17 were collected from urban sites (adults, $\mathrm{n}=8$; fledglings, $\mathrm{n}=9$; Table 6.2). None of the captured birds presented with visual evidence of Trichomoniasis infection (e.g. cankers) when examined in the field.

\section{Laboratory Methods}

I successfully extracted RNA from all 32 Cooper's hawk blood samples. However, RIN values were highly variable among extracts $(1.7-9.4$, Table 6.2$)$ and $55 \%$ of samples did not produce RIN values on the BioAnalyzer. Six individuals tested positive for the presence of Trichomonas spp. by PCR. All six of these samples were from fledgling hawks and three each were sampled at

urban and exurban nest sites (Table 6.2). I did not detect Trichomonas spp. in any of the adult hawks (Table 6.2). 


\section{RNA-seq Analysis}

One exurban juvenile sample was dropped from the analysis due to evidence of bacterial contamination revealed by the quality assessment using FastQC. All other samples had uniformly high sequence quality, regardless of RIN value. On average, approximately $52 \%$ and $54 \%$ of reads aligned to the golden eagle reference genome for adult and fledgling samples, respectively (adult range $=47.9-55.7 \%$, fledgling range $43.0-58.5 \%$; Table 6.3). When all samples were used for the DE analysis of urban and exurban individuals, I detected no differentially expressed transcripts. When comparing urban and exurban samples using only the HiSeq data for adults and fledglings separately, I found zero and 13 significant DE transcripts, respectively (Table 6.4). However, after combining the technical replicates from adult samples (MiSeq and HiSeq data), I found one significant DE expressed transcript between the urban and exurban samples (Table 6.4).

There were significantly more mapped reads in the fledgling samples when compared to the adult samples when using the HiSeq data alone (Table 6.3; average for adults $=9,171,962$, juveniles $=12,039,311 ; \mathrm{t}=6.24, \mathrm{df}=28.95, \mathrm{p}$-value $<0.0001)$. When I used the HiSeq and MiSeq data combined for the adult samples, there were still significantly more mapped reads in the fledgling samples (HiSeq data only; Table 6.3; average for adults $=9,661,189$, juveniles $=$ $12,039,311 ; \mathrm{t}=5.06, \mathrm{df}=28.81, \mathrm{p}=<0.001)$. However, I would still expect to find approximately $10 \mathrm{DE}$ transcripts between the urban and exurban fledgling samples if I correct for the lower average total mapped read count seen in the adult samples.

Of the $13 \mathrm{DE}$ transcripts in the fledgling samples, five and eight were more abundant in urban and exurban individuals, respectively (Table 6.4). BLAST searches revealed that the best match for all but one transcript was a sequence in the golden eagle genome (Table 6.4). General 
gene ontology terms for the transcripts were mostly associated with molecular function (11/13) and biological processes (3/13; Table 6.4). One transcript was associated with a cellular component and the remaining transcript was uncharacterized (Table 6.4). More than half of the genes expressed at higher levels in exurban environments were associated with immune function (4/7) and for urban environments, the majority were associated with nucleic acid processing (3/5; Table 6.4). The two transcripts with the highest fold change are associated with an interferoninduced guanylate-binding protein (GBP), and both were expressed at higher levels in exurban fledglings. These transcripts are expressed at higher levels in exurban fledglings and have been shown to be important in vertebrate host defense against a wide variety of pathogens (Kim et al., 2016; Table 6.4). The single DE transcript identified in the adult samples (with technical replicates combined) was more abundant in urban individuals and associated with multiple biological processes and molecular functions. In humans, this gene is involved in DNA/RNA binding, transcription, as well as metal ion binding and platelet production (human homolog TCF20; UniProt, 2017).

\section{Discussion}

This study provides evidence to suggest that phenotypic plasticity via gene expression may play a role for species inhabiting urban environments. In particular, this mechanism may be especially important for the sedentary offspring of a highly mobile species. Researchers have previously suggested that some species may not adapt (via heritable genetic changes), but rather acclimate (via developmental or phenotypic plasticity) to urban ecosystems (Kark et al. 2007; Isaksson, 2015). They suggest that acclimation is common in mobile species, since individuals can move to avoid stressors. However, young hawks are obligated to remain in the nest area for several 
weeks during their development. As a result, there may be increased pressure for gene expression changes to allow offspring to handle potential stressors. Thus, as expected, I found more significant differentially expressed transcripts in fledgling hawks as compared to adults.

\section{Evolutionary Implications}

It is possible that higher numbers of DE transcripts in fledglings suggest that developmental plasticity through gene expression in offspring may contribute to the long-term tolerance of adults to urban areas (see Donelson et al., 2011; Burris \& Baccarelli, 2014). The majority of the transcripts expressed at higher levels in urban fledglings are involved in molecular function, specifically nucleic acid processing. This could imply that young hawks require increased molecular activity as compared to exurban fledglings during the late portion of their development. Another transcript expressed at higher levels in urban fledglings is involved in spermatogenesis. This result was unexpected since I included both males and females in the analysis, and this transcript was expressed in both sexes. It is possible that this gene is involved in other processes, besides male gamete production. This result is also in concordance with a study on urban vs. exurban white-footed mice, in which differential SNPs were detected in genes involved in spermatogenesis (Harris et al. 2013).

Another notable result from this study was that the majority of the transcripts expressed at higher levels in exurban fledgling hawks were associated with immune response, including the two transcripts with the highest fold change between the samples in the two environments. This trend was consistent as there were no immune-related transcripts expressed at higher levels in urban individuals. Based on previous research that reported high rates of Trichomoniasis infection in urban Cooper's hawks (Boal and Mannan, 1998, 1999), I had expected to find 
immune genes to be more abundant in urban birds. Yet, screening for Trichomonas spp. in the study revealed exposure to the parasite in both urban and exurban fledglings. It is quite possible that exurban adult hawks still encounter Columbidae spp. carrying the protozoan and feed them to their young, especially since many of the exurban sites are in riparian areas immediately adjacent to the city. Indeed, the three exurban individuals that tested positive for Trichomonas spp. were all from such nests. Therefore, the current definition of "urban" and "exurban" may not be indicative of the likelihood of Trichomonas spp. exposure. Still, based on the definition of urban and exurban used for this study, it is clear that the immune response may be more pronounced in the exurban fledglings, regardless of Trichomonas spp. exposure.

There are a few possible explanations for this observation. First, it is possible that the high mortality rates associated with Trichomoniasis in southwestern cities caused genetic adaptation of urban individuals to allow them to survive the parasite. However, telemetry data suggest that adult Cooper's hawks may switch between urban and exurban areas during breeding seasons (Millsap, unpublished data). In addition, genetic research suggests high gene flow in this species across relatively large geographic regions throughout the United States (see Chapter 3; Sonsthagen et al. 2012; Morinha et al. 2016). Therefore, it is unlikely that urban individuals are isolated enough from the exurban population to evolve a genetic adaptation independently.

Another potential explanation could be that exurban birds require an elevated immune response due to increased exposure to more diverse or abundant pathogens. It is also possible that stress elicits a stronger immune response when exurban individuals are exposed to $T$. gallinae or other pathogens. There is evidence to suggest that young exurban Cooper's hawks are fed less than their urban counterparts. Estes and Mannan (2003) found that urban nesting hawks delivered approximately twice as much prey biomass per hour to their young compared to rural 
nesting pairs. This lack of food could result in reduced body condition and higher levels of stress (Kitaysky et al. 1999). However, despite the fact that urban food is more plentiful, there is evidence to suggest that it is also of lower quality (see Isaksson, 2015). Therefore, further research would be necessary to determine if gene expression differences in immune genes are driven by variation in body condition between urban and exurban fledgling hawks.

A third hypothesis is that genes associated with immune response are downregulated in urban environments because of toxin loading. Various pollutants are found in heavy concentrations in urban settings (Harris et al., 2013; Isaksson, 2015). For example, trace metals have generally been found to increase along a rural to urban gradient, and those metals can accumulate in wild organisms (Scheifler et al., 2006; Roux \& Marra, 2007; Bichet et al. 2013; Meillère et al. 2016). Further, there is extensive evidence to suggest that the immune system is sensitive to toxins, and acute or chronic exposure can lead to immunosuppression (Grasman, 2002). Numerous studies have demonstrated a link between toxin loading and increased infection rates of various pathogens in a variety of wildlife species. Polychlorinated biphenyls (PCBs) increase the susceptibility of young mallard ducks (Anas platyrhynchos) to duck hepatitis virus (Friend and Trainer, 1970). Heavy metals have been shown to disrupt immune response in insects (Sorvari et al., 2007; Borowska \& Pyza, 2011). Rats (Rattus norvegicus) are more vulnerable to bacterial infection when exposed to high levels of lead and cadmium (Cook et al., 1975), and mercury can affect immunity in chickens (Gallus gallus; Bridger \& Thaxton, 1983). High lead concentrations can also lead to increased prevalence of the protozoan Plasmodium relictum in house sparrows (Passer domesticus; Bichet et al., 2013). Finally, lead exposure has been linked to Coccidiosis in Canada geese (Branta canadensis, Locke and Bagley, 1967a) and 
increased effects of Trichomoniasis in mourning doves (Zenaida macroura, Locke and Bagley, 1967b).

In general, high trophic level species, such as birds of prey, bioaccumulate toxins in higher concentrations compared to low trophic level organisms (Abbasi et al. 2014). In fact, a recent study found an urban Cooper's hawk in Vancouver, Canada to be so contaminated with flame retardants that it is thought to be the most contaminated bird ever recorded (Elliot et al. 2015). In addition, a study on a common Cooper's hawk prey item, feral pigeons, found relatively high levels of four heavy metals (cadmium, copper, lead, and zinc) in Paris, France (Frantz et al. 2012). Thus, it is evident that Cooper's hawks in urban ecosystems are likely exposed to, and suffer from, higher levels of heavy metals than exurban individuals. Previous research has provided clear evidence of increased rates of Trichomoniasis infection in urban Accipiter populations (Cooper's hawks, Boal et al. 1998, Boal \& Mannan, 1999; northern goshawks, Accipiter gentilis, Krone et al., 2005).

The results of this study may provide some explanation for the high mortality previously observed in urban Cooper's hawks from Trichomoniasis infection. Urban fledglings may be subjected to higher levels of toxins such as heavy metals, which could cause immunosuppression. The clear difference in expression of transcripts related to immune response in urban and exurban fledglings suggest that this may be the case. However, more recent data suggests that mortality rates are low in urban centers in the southwestern United States (Millsap, unpublished data). In fact, I found the same number of fledglings with Trichomonas spp. in their oral cavity in both urban and exurban environments, although sample sizes were low. In addition, none of the fledglings presented with symptoms of an infection from the parasites. Thus, it could be the case that Cooper's hawks have adapted or acclimated to the disease via 
some other mechanism. One potential mechanism worth exploring could be $\mathrm{pH}$ levels in the saliva of Cooper's hawks in urban and exurban environments. Urban and Mannan (2014) found that the acidic saliva of urban fledgling and adult Cooper's hawks could potentially lessen their susceptibility to the effects of $T$. gallinae. Yet, there are no current data on the saliva $\mathrm{pH}$ trends in exurban populations.

\section{Differential Expression Analysis}

There were few significant DE transcripts in my comparison of urban and exurban Cooper's hawks, but this relatively low number could be drastically underestimated for several reasons. First, the selection process for statistical significance in DE analysis is highly stringent, correcting for the vast number of comparisons made on large genomic datasets. In addition, there is currently no Cooper's hawk reference genome available. While I used a genome from a closely related species, which contains about 16,500 annotated genes, approximately half of the read data did not align to the reference genome and remains unexplored. Another issue could be the zero or low abundance transcripts that are common in RNA-seq data (Pertea et al. 2016). It is not possible to differentiate if the low abundance is a result of a failure to detect the transcripts in the laboratory methods or if it is real and biologically significant. Therefore, in DE analysis, these low abundance transcripts must be filtered out and thus, there is likely a loss of some relevant data.

There is also evidence to suggest that RNA preservation methods are subject to biases and as a result data are also lost during this crucial step (McCarthy et al., 2015). For example, highly unstable RNA molecules or large RNA molecules may be too degraded to be detected using current methods (Romero et al., 2014). One potential improvement could be an increase in 
technical replicates to ensure maximum alignment across the genome (Mortazavi et al., 2008). This method worked, in part, for the adult dataset. I found zero DE transcripts when using the Illumina HiSeq data alone but was able to identify one DE transcript after combining both the MiSeq and HiSeq data. Finally, many studies examining DE apply specific treatments to organisms in controlled laboratory settings, and my study lacks that level of control since it is one of the first to compare gene expression profiles in individuals from a wild population.

\section{Future Directions and Conclusions}

Future studies could investigate the genetic differences between urban and exurban hawks in larger numbers and in other cities. If urbanization does in fact lead to specific characteristics in wildlife living in close proximity to humans, I would expect to see similar patterns in studies carried out in different cities (Donihue \& Lambert, 2015). Genetic differences such as SNPs should be investigated in conjunction with gene expression to better understand the relative roles of these mechanisms for wildlife in urban settings. In addition, investigating pollutants in the blood of Cooper's hawks could help determine if immune genes expression levels in urban individuals are is correlated with high concentrations of toxins. Finally, increasing the sample size and using siblings from multiple nests in urban and exurban environments could be used as a control to verify the results of this study.

This study is one of the first to demonstrate gene expression changes as a possible mechanism for a highly mobile species acclimating to urban ecosystems. In addition, the results suggest that differential gene expression may be especially important for offspring that cannot escape the stressors in the urban landscape. Finally, this study may also provide insights into the reason for recent high morality of young Cooper's hawks from an urban-associated disease. This 
contributes to the body of evidence potentially linking bioaccumulation of toxins with immunosuppression and increased rates of infection.

\section{Literature Cited}

Abbasi, N. A., Jaspers, V. L. B., Chaudhry, M. J. I., Ali, S., Malik, R. N. (2015). Influence of taxa, trophic level, and location on bioaccumulation of toxic metals in bird's feathers: a preliminary biomonitoring study using multiple bird species from Pakistan. Chemosphere, 120, 527-537.

Alberti, M., Correa, C., Marzluff, J. M., Hendry, A. P., Palkovacs, E. P., Gotanda, K. M., Hunt, V. M., Apgar, T. M., \& Zhou, Y. (2017). Global urban signatures of phenotypic change in animal and plant populations. PNAS, 114, 8951-8956.

Aniagu, S.O., Willimans, T. D., Allen, Y., Katsiadaki, I., \& Chipman, J. K. (2008). Global genomic methylation levels in the liver and gonads of the three-spine stickleback (Gasterosteus aculeatus) after exposure to hexabromocyclododecane and 17- $\beta$ oestradiol. Environment International, 34, 310-317.

Basu, N., Head, J., Name, D., Pilsner, J. R., Carvan, M. J., Chan, H. M., Goetz, F. W., Murphy, C. A., Rouvinen-Watt, K., \& Scheuhammer, A. M. (2013). Effects of methylmercury on epigenetic markers in three model species: Mink, chicken, and yellow perch. Comparative Biochemistry and Physiology, Part C 157, 322-327.

Bichet, C., Scheifler, R., Coeurdassier, M., Julliard, R., Sorci, G., \& Loiseau, C. (2013). Urbanization, trace metal pollution, and malaria prevalence in the house sparrow. PLoS One, 8, e53866.

Boal, C.W., \& Mannan, R. W. (1998). Nest-site selection by Cooper's hawks in an urban environment. Journal of Wildlife Management, 62, 864-871.

Boal, C. W., Mannan, R. W., \& Hudelson, K. S. (1998) Trichomoniasis in Cooper's hawks from Arizona. Journal of Wildlife Diseases, 34, 590-593.

Boal, C.W., \& Mannan, R. W. (1999). Comparative breeding ecology of Cooper's hawks in urban and exurban areas of southeastern Arizona. Journal of Wildlife Management, 63, $77-84$.

Borowksa, J., \& Pyza, E. (2011). Effects of heavy metals on insect immunocompetent cells. Journal of Insect Physiology, 57, 760-770.

Bridger, M. A., \& Thaxton, J. P. (1983). Humoral immunity in the chicken as affected by mercury. Archives of Environmental Contamination and Toxicology, 12, 45-49. 
Bunbury, N., Bell, D., Jones, C., Greenwood, A., \& Hunter, P. (2005). Comparison of the InPouch TF culture system and wet-mount microscopy for diagnosis of Trichomonas gallinae infections in the pink pigeons Columba mayeri. Journal of Clinical Microbiology, 43, 1005-1006.

Burris, H. H., \& Baccarelli, A. A. (2014). Environmental epigenetics: from novelty to scientific discipline. Journal of Applied Toxicology, 34, 113-116.

Chiang, S. N., Bloom, P. H., Bartuszevige, A. M., \& Thomas, S. E. (2012). Home range and habitat use of Cooper's hawks in urban and natural areas. Online (wee.ucpress.edu/go/sab) in Lepczyk, C. A., \& Warren, P. S. (eds.). Urban bird ecology and conservation. Studies in Avian Biology (no. 45), University of California Press, Berkeley, CA.

Cook, J. A., Hoffman, E. O., \& Diluzio, N. R. (1975). Influence of lead and cadmium on susceptibility of rats to bacterial challenge. Proceedings of the Society for Experimental Biology and Medicine, 150, 741-747.

Correia, B., Valledor, L., Meijón, M., Rodriguez, J. L., Dias, M. C., Santos, C., Cañal, M. J., Rodriguez, R., \& Pinto, G. (2013). Is the interplay between epigenetic markers related to the acclimation of cork oak plants to high temperatures? PLOS ONE, 8, e53543.

Desender, K., Small, E., Gaublomme, E., \& Verdyck, P. (2005). Rural-urban gradients and the population genetic structure of woodland ground beetles. Conservation Genetics, 6, 5162.

Donelson, J. M., Munday, P. L. McCormick, M. I., \& Nilsson, G. E. (2011). Acclimation to predicted ocean warming through developmental plasticity in a tropical reef fish. Global Change Biology, 17, 1712-1719.

Donihue, C. M., \& Lambert, M. R. (2015). Adaptive evolution in urban ecosystems. Ambio, 44, 194-203.

Doyle J., Katzner, T., Bloom, P., Ji, Y., Wijayawardena, B., \& DeWoody, J. (2014). The genome sequence of a widespread apex predator, the golden eagle (Aquila chrysaetos). PLoS One, 9, e95599.

Ecco, R., Preis, I. S., Vilela, D. A. R., Luppi, M. M., Malta, M. C. C., Beckstead, R. B., Stimmelmayer, R., Gerhold, R. W. (2012). Molecular confirmation of Trichomonas gallinae and other parabasalids from Brazil using the 5.8S and ITS-1 rRNA regions. Veterinary Parasitology, 190, 36-42.

Elliot, J. E., Brogan, J., Lee, S. L., Drouillard, K. G., \& Elliott, K. H. (2015). PBDEs and other POPs in urban birds of prey partly explained by trophic level and carbon source. Science of the Total Environment, 524-525, 157-165.

Environmental Systems Research Institute (ESRI). (2011). ArcGIS Desktop: Release 10.3.1 Redlands, CA. 
Estes, W.A., Mannan, R. W. (2003). Feeding behaviors of Cooper's hawks at urban and rural nests in southeastern Arizona. The Condor, 105, 107-116.

Felson, A. J., Oldfield, E. E., \& Bradford, M. A. (2013). Involving ecologists in shaping largescale green infrastructure projects. BioScience, 63, 882-890.

Frantz, A., Pottier, M., Karimi, B., Corbel, H., Aubry, E., Haussy, C., Gasparini, J., \& CastrecRouelle, M. (2012). Contrasting levels of heavy metals in the feathers of urban pigeons from close habitats suggest limited movements at a restricted scale. Environmental Pollution, 168, 23-28.

Frazee, A.C., Pertea G., Jaffe, A.E., Langmead, B., Salzberg, S. L., \& Leek, J. T. (2014) Flexible isoform-level differential expression analysis with Ballgown. bioRxiv

Friend, M., \& Trainer, D. O. (1970). Polychlorinated biphenyl: interaction with duck hepatitis virus. Science, 170, 1314-1316.

Gortat, T., Rutkowski, R., Gryczynska-Siemiatkowska, A., Kozakiewicz, A., \& Kozakiewicz, M. (2013). Genetic structure in urban and rural populations of Apodemux agrarius in Poland. Mammalian Biology, 78, 171-177.

Grasman, K. A. (2002). Assessing immunological function in toxicological studies of avian wildlife. Intergative and Comparative Biology, 42, 34-42.

Hansen, B.H., Romma, S., Garmo, O. A., Olsvik, P. A., \& Andersen, R. A. (2006). Antioxidative stress proteins and their gene expression in brown trout (Salmo trutta) from three rivers with different heavy metal levels. Comparative Biochemistry and Physiology, Part C, $143,263-274$.

Harris, S.E., Munshi-South, J., Obergfell, C., \& O’Neill, R. (2013). Signatures of rapid evolution in urban and rural transcriptomes of white-footed mice (Peromyscus leucopus) in the New York metropolitan area. PLoS ONE, 8, e74938.

Hendry, A. P., \& Kinnison, M. T. (1999). The pace of modern life: measuring rates of contemporary microevolution. Evolution, 53, 1637-1653.

Hicks, S. C., Teng, M., \& Irizarry, R. A. (2015). On the widespread and critical impact of systematic bias. bioRxiv

Hohenlohe, P. A., Phillips, P. C., \& Cresko, W. A. (2011). Using population genomics to detect selection in natural populations: Key concepts and methodological considerations. International Journal of Plant Science, 171, 1059-1071.

Hornett, E., \& Wheat, C. (2012). Quantitative RNA-seq analysis in non-model species: assessing transcriptome assemblies as a scaffold and the utility of evolutionary divergent genomic reference species. BMC Genomics, 13, 361-377.

Horowitz, M. (2016). Epigenetics and cytoprotection with heat acclimation. Journal of Applied Physiology, 120, 702-710. 
Isaksson, C. (2015). Urbanization, oxidative stress and inflammation: a question of evolving, acclimating or coping with urban environmental stress. Functional Ecology, 29, 913-923.

Kajdacsi, B., Costa, F., Hyseni, C., Porter, F., Brown, J., Rodrigues, G., Farias, H., Reis M. G., Childs, J. E., Ko, A. I., \& Caccone, A. (2013). Urban population genetics of slumdwelling rats (Rattus norvegicus) in Salvador, Brazil. Molecular Ecology, 22, 5056-5070.

Kark, S., Iwaniuk, A., Schalimtzek, A., \& Banker, E. (2007). Living in the city: can anyone become an 'urban exploiter'? Journal of Biogeography, 34, 638-651.

Kim, D., Langmead, B., \& Salzberg, S. L. (2015). HISAT: a fast-spliced aligner with low memory requirements. Nature Methods, 12, 357-360.

Kim, B., Chee, J. D., Bradfield, C. J., Park, E., Kumar, P. \& MacMicking, J. D. (2016). IFNinduced guanylate binding proteins in inflammasome activation and host defense. Nature Immunology, 19, 481-489.

Kitaysky, A. S., Wingfield, J. C., \& Piatt, J. F. (1999). Dynamics of food availability, body condition and physiological stress response in breeding black-legged kittiwakes. Functional Ecology, 13, 577-584.

Kohno, S., Bermudez, D. S., Katsu, Y., Iguchi, T., \& Guillette, Jr., L. J., (2008). Gene expression patterns in juvenile American alligators (Alligator mississippiensis) exposed to environmental contaminants. Aquatic Toxicology, 88, 95-101.

Krone, O., Altenkamp, R., \& Kenntner, N. (2005). Prevalence of Trichomoniasis gallinae in northern goshawks from the Berlin area of northeastern Germany. Journal of Wildlife Diseases, 41, 304-309.

Liu, J., Walter, E., Stenger, D., \& Thach, D. (2006). Effects of globin mRNA reduction methods on gene expression profiles from whole blood. Journal of Molecular Diagnostics, 8, 551558 .

Locke, L. N., \& Bagley, G. E. (1967a). Case report: coccidiosis and lead poisoning in Canada geese. Chesapeake Science, 8, 68-69.

Locke, L. N., \& Bagley, G. E. (1967b). Lead poisoning in a sample of Maryland mourning doves. Journal of Wildlife Management, 31, 515-518.

MacGregor-Fors, I. (2011). Misconceptions or misunderstandings? On the standardization of basic terms and definitions in urban ecology. Landscape and Urban Planning, 100, 347349.

Mannan, R.W., \& Boal, C. W. (2000). Home range characteristics of male Cooper's hawks in an urban environment. Wilson Bulletin, 112, 21-27.

McCarthy, A., Chiang, E., Schmidt, M. L., \& Denef, V. J. (2015). RNA preservation agents and nucleic acid extraction method bias perceived bacterial community composition. PLoS ONE 10: e0121659. 
McDonnell, M. J., \& Pickett, S. T. A. (1990). The study of ecosystem structure and function along urban-rural gradients: an unexploited opportunity for ecology. Ecology, 71, 12311237.

McDonnell, M. J., Pickett, S. T. A., Groffman, P., Bohlen, P., Pouyat, R. V., Zipperer, W. C., Parmelee, R. W., Carreiro, M. M., Medley, K. (1997). Ecosystem processes along an urban-to-rural gradient. Urban Ecosystems, 1, 21-36.

McKinney, M. L. (2006). Urbanization as a major cause of biotic homogenization. Biological Conservation, 127, 247-260.

McKinney, M. L. (2008). Effects of urbanization on species richness: a review of plants and animals. Urban Ecosystems, 11, 161-176.

Meillère, A., Brischoux, F., Bustamante, P., Michaud, B., Parenteau, C., Marciau, C., \& Angelier, F. (2016). Corticosterone levels in relation to trace element contamination along an urbanization gradient in the common blackbird (Turdus merula). Science of the Total Environment, 566-567, 93-101.

Morinha, F., Ramos, P. S., Gomes, S., Mannan, R. W., Guedes-Pinto, H., \& Bastos, E. (2016). Microsatellite markers suggest high genetic diversity in an urban population of Cooper's hawks (Accipiter cooperii). Journal of Genetics, 95, e19-e24.

Mortazavi, A., Williams, B. A., McCue, K., Schaeffer, L., \& Wold, B. (2008). Mapping and quantifying mammalian transcriptomes by RNA-Seq. Nature Methods, 5, 621-628.

Mueller, J. C., Partecke, J., Hatchewell, B. J., Gaston, K. J., \& Evans, K. L. (2013). Candidate gene polymorphisms for behavioral adaptations during urbanization in blackbirds. Molecular Ecology, 22, 3629-3637.

Munshi-South, J., \& Kharchenko, K. (2010). Rapid, pervasive genetic differentiation of urban white-footed mouse (Peromyscus leucopus) populations in New York City. Molecular Ecology, 19, 4242-4254.

Nilon, C., Berkowitz, A., \& Hollweg, K. (2003). Introdiction: ecosystem understanding is a key to understanding cities. In: Berkowitz, A., Nilon, C., \& Hollweg, K. (eds.). Understanding Urban Ecosystems - A New Frontier for Science and Education. SpringerVerlag, New York, NY, pp 1-14.

Partecke, J., \& Gwinner, E. (2007). Increased sedentariness in European blackbirds following urbanization: a consequence of local adaptation? Ecology, 88, 882-890.

Peluc, S.I., Sillett, T. S., Rotenberry, J. T., \& Ghalambor, C. K. (2008). Adaptive phenotypic plasticity in an island songbird exposed to a novel predation risk. Behavioral Ecology, 19, 830-835.

Pertea, M., Pertea, G. M., Antonescu, C. M., Chang, T., Mendell, J. T., \& Salzberg, S. L. (2015). StringTie enables improved reconstruction of a transcriptome from RNA-seq reads. Nature Biotechnology, 33, 290-295. 
Pertea, M., Kim, D., Pertea, G., Leek, J., \& Salzberg, S. (2016). Transcript-level expression analysis of RNA-seq experiments with HISAT, StringTie, and Ballgown. Nature Protocols, 11, 1650-1667.

Prum, R., Berv, J., Dornburg, A., Field, D., Townsend, J., Lemmon, E., \& Lemmon, A. (2015). A comprehensive phylogeny of birds (Aves) using targeted next-generation sequencing. Nature, 526, 569-577.

Pyle, P. (2008). Identification Guide to North American Birds. Slate Creek Press Point Reyes Station, CA.

R Core Team. (2013). R: a language and environment for statistical computing. $R$ foundation for Statistical Computing, Vienna, Austria URL http://www.R-project.org/.

Rawat, A., Elasri, M. O., Gust, K. A., George, G., Phan, D., Scanlan, L. D., Vulpe, C., \& Perkins, E. J. (2012). CAPRG: Sequence assembling pipeline for next generation sequencing of non-model organisms. PLoS One, e30370.

Robinson, J. T., Thorvaldsdóttir, H., Winckler, W., Guttman, M., Lander, E. S., Getz, G., \& Mesirov, J. P. (2011). Integrative Genomics Viewer. Nature Biotechnology, 29, 24-26.

Romero, I. G., Pai, A. A., Tung, P., \& Gilad, Y. (2014). RNA-seq: impact of RNA degradation on transcript quantification. BMC Biology, 12, 42.

Roodman, D. M. (1996). Rapid urbanization continues: In Starke, L., Vital Signs 1996, pp. 9495. W. W. Norton and Company, Inc. New York, NY.

Rosenfield, R.N., \& Bielefeldt, J. (1993). Cooper's hawk (Acciptier cooperii). In: Poole, A., \& Gill, F. (eds.), The Birds of North America, no. 75. The Academy of Natural Sciences, Philadelphia, PA.

Rosenfield, R.N., Bielefeldt, J., Affeldt, J. L., \& Beckmann, D. J. (1996). Urban nesting biology of Cooper's hawks in Wisconsin. In: Bird, D.M., Varian, D. E., \& Negro, J. J. (eds.), Raptors in Human Landscapes: Adaptation to Build and Cultivated Environments. Academic Press, New York, NY.

Roth, T.C. II, \& Lima, S. L. (2003). Hunting behavior and diet of Cooper's hawks: An urban view of the small-bird-in-winter paradigm. The Condor, 105, 474-483.

Roux, K. E., \& Marra, P. P. (2007). The presence and impact of environmental lead in passerine birds along an urban to rural land use gradient. Archives of Environmental Contamination and Toxicology, 53, 261-268.

Santoyo, M.M., Flores, C. R., Torres, A. L., Wrobel, K., \& Wrobel, K. (2011). Global DNA methylation in earthworms: A candidate biomarker of epigenetic risks related to the presence of metals/metalloids in terrestrial environments. Environmental Pollution, 159, 2387-2392. 
Scheifler, R., Coeurdassier, M., Morilhat, C., Bernard, N., Faivre, B., Flicoteaux, P., Giraudoux, P., Noël, M., Piotte, P., Reiffel, D., de Vaufleury, A., \& Badot, P. M. (2006). Lead concentrations in feathers and blood of common blackbirds (Turdus merula) and in earthworms inhabiting unpolluted and moderately polluted urban areas. Science of the Total Environment, 371, 197-205.

Serieys, L.E.K., Lea, A., Pollinger, J. P., Riley, S. P. D., \& Wayne, R. K. (2014). Disease and freeways drive genetic change in urban bobcat populations. Evolutionary Applications doi: 10.1111/eva.12226.

Seto, K. C., Sanchez-Rodriguez, R., \& Fragkias, M. (2010). The new geography of contemporary urbanization and the environment. Annual Review of Environmental Resources, 35, 167-194.

Shochat, E., Warren, P.S., Faeth, S.H., McIntyre, N.E., \& Hope, D. (2006). From patterns to emerging processes in mechanistic urban ecology. Trends in Ecology \& Evolution, 21, 186-191.

Sih, A., Ferrari, M. C. O., \& Harris, D. J. (2011). Evolution and behavioural responses to humaninduced rapid environmental change. Evolutionary Applications, 4, 367-387.

Sonsthagen, S. A., Rosenfield, R. N., Bielefeldt, J., Murphy, R. K., Stewart, A. C., Stout, W. E., Driscoll, T. G., Bozek, M. A., Sloss, B. L., \& Talbot, S. L. (2012). Genetic and morphological divergence among Cooper's hawk (Accipiter cooperii) population breeding in north-central and western North America. The Auk, 129, 427-437.

Sorvari, J., Rantala, L. M. Rantala, M. J., Hakkarainen, H., \& Eeva, T. (2006). Heavy metal pollution disturbs immune response in wild ant populations. Environmental Pollution, $145,324-328$.

Šrut, M., Drechsel, V., \& Höckner, M. (2017). Low levels of Cd induce persisting epigenetic modifications and acclimation mechanisms in the earthworm Lumbricus terrestris. PLoS ONE, 12, e0176047.

Stabler, R.M. (1954). Trichonmonas gallinae: a review. Experimental Parasitology, 3, 368-402.

Storey, J. D., \& Tibshirani, R. (2003). Statistical significance for genomewide studies. PNAS, 100, 9440-9445.

Stout, W. E., \& Rosenfield, R. N. (2010). Colonization, growth, and density of a pioneer Cooper's hawk population in a large metropolitan environment. Journal of Raptor Research, 44, 255-267.

The UniProt Consortium. (2017). UniProt: the universal protein knowledgebase. Nucleic Acids Research, 45, D158-D169.

Thorvaldsdóttir, H., Robinson, J. T., \& Mesirov, J. P. (2013). Integrative Genomics Viewer (IGV): high-performance genomics data visualization and exploration. Briefings in Bioinformatics, 14, 178-192. 
United Nations. (2011). World urbanization prospects the 2011 Revision. UN Department of Economic and Social Affairs.

Urban, E. H., Mannan, R. W. (2014). The potential role of oral pH in the persistence of Trichomonas gallinae in Cooper's hawks (Accipiter cooperii). Journal of Wildlife Diseases, 50, 50-55.

Walsh, C. J., Roy, A. H., Feminella, J. W., Cottingham, P. D., Groffman, P. M., \& Morgan II, R. P. (2005). The urban stream syndrome: current knowledge and the search for a cure. Journal of the North American Benthological Society, 24, 706-723.

Wandeler, P., Funk, M., Largiader, C. R., Gloors, S., \& Breitenmoser, U. (2003). The city-fox phenomenon: Genetic consequences of a recent colonization of urban habitat. Molecular Ecology, 12, 647-656.

Whitehead, A., Triant, D. A., Champlin, D., \& Nacci, D. (2010). Comparative transcriptomics implicates mechanisms of evolved pollution tolerance in a killifish population. Molecular Ecology, 19, 5186-5203.

Wood, B.C., \& Pullin, A. S. (2002). Persistence of species in a fragmented urban landscape: The importance of dispersal ability and habitat availability for grassland butterflies. Biodiversity and Conservation, 11, 1451-1468.

Xian, G., Homer, C., Dewitz, J., Fry, J., Hossain, N., and Wickham, J., (2011). The change of impervious surface area between 2001 and 2006 in the conterminous United States. Photogrammetric Engineering and Remote Sensing, 77, 758-762.

Zar, J. H. (2010). Biostatistical analysis $5^{\text {th }}$ Ed. Prentice Hall Inc. Upper Saddle River, NJ. 
Table 6.1: Average, median, and majority percent imperviousness values for Cooper's hawk nest territories in the Albuquerque, New Mexico area. Based on telemetry data, average nest territories are approximately $385 \mathrm{~m}$ apart (Millsap, unpublished data). Territories were established by making a 385 buffer around sampled nests in ArcMap 10.3.1 (ESRI, 2011). Values were extracted using the zonal statistics as table tool from an imperviousness environmental layer (NLCD, 2011).

\begin{tabular}{|c|c|c|c|c|}
\hline \multicolumn{5}{|c|}{ Percent $(\%)$ Imperviousness } \\
\hline Nest \# & Average (Std Dev) & Median & Majority & Classification \\
\hline 1 & $7.9(15.8)$ & 0 & 0 & Exurban \\
\hline 2 & $0.0(0.0$ & 0 & 0 & Exurban \\
\hline 3 & $0.0(0.0)$ & 0 & 0 & Exurban \\
\hline 4 & $4.8(15.5)$ & 0 & 0 & Exurban \\
\hline 5 & $0.0(0.0)$ & 0 & 0 & Exurban \\
\hline 6 & $0.2(1.3)$ & 0 & 0 & Exurban \\
\hline 7 & $4.6(11.8)$ & 0 & 0 & Exurban \\
\hline 8 & $19.6(28.0)$ & 0 & 0 & Exurban \\
\hline 9 & $0.1(1.0)$ & 0 & 0 & Exurban \\
\hline 10 & $55(22.9)$ & 57 & 50 & Urban \\
\hline 11 & $45.1(19.1)$ & 45 & 39 & Urban \\
\hline 12 & $61.1(19.0)$ & 61 & 56 & Urban \\
\hline 13 & $47.6(16.3)$ & 48 & 51 & Urban \\
\hline 14 & $49.4(21.1)$ & 51 & 55 & Urban \\
\hline 15 & $35(23.8)$ & 39 & 35 & Urban \\
\hline 16 & 41.7 (13.7) & 42 & 52 & Urban \\
\hline 17 & $43.9(16.1)$ & 44 & 50 & Urban \\
\hline 18 & $45.7(23.2)$ & 48 & 51 & Urban \\
\hline 19 & $40.5(15.7)$ & 42 & 43 & Urban \\
\hline 20 & $43.5(15.0)$ & 45 & 46 & Urban \\
\hline 21 & $60.8(19.8)$ & 64 & 65 & Urban \\
\hline 22 & $45.6(19.0)$ & 48 & 54 & Urban \\
\hline 23 & $43.4(18.2)$ & 44 & 45 & Urban \\
\hline
\end{tabular}


Table 6.2: Information on Cooper's hawks sampled during the breeding season in 2015 in the Albuquerque, New Mexico area. Age, sex ( $\mathrm{F}=$ female, $\mathrm{M}=$ male), nest number (see Figure 6.1), RNA integrity number (RIN) from extracts (N/A = RIN value could not be detected by bioanalyzer), and PCR results from Trichomonas screening $((+)=$ positive or $(-)=$ negative; protocol from Ecco et al. 2012) are included for each sample. One sample, E15, is not included due to bacterial contamination of RNA revealed by the quality analysis and subsequent removal from all further analyses.

\begin{tabular}{|c|c|c|c|c|c|c|}
\hline Sample ID & Classification & Age & Sex & Nest \# & RIN & Trichomonas spp. \\
\hline E1 & Exurban & Adult & $\mathrm{F}$ & 2 & 1.7 & - \\
\hline E2 & Exurban & Adult & $\mathrm{F}$ & 3 & N/A & - \\
\hline E3 & Exurban & Adult & $\mathrm{F}$ & 7 & 6.8 & - \\
\hline E4 & Exurban & Adult & $\mathrm{F}$ & 8 & N/A & - \\
\hline E5 & Exurban & Adult & $\mathrm{F}$ & 9 & N/A & - \\
\hline E6 & Exurban & Adult & M & 2 & N/A & - \\
\hline E7 & Exurban & Adult & M & 7 & N/A & - \\
\hline E8 & Exurban & Adult & M & 9 & 7 & - \\
\hline E9 & Exurban & Fledgling & $\mathrm{F}$ & 4 & 6 & + \\
\hline E10 & Exurban & Fledgling & $\mathrm{F}$ & 6 & N/A & - \\
\hline E11 & Exurban & Fledgling & M & 1 & 9.3 & + \\
\hline E12 & Exurban & Fledgling & M & 5 & 7.9 & - \\
\hline E13 & Exurban & Fledgling & M & 5 & 9.4 & - \\
\hline E14 & Exurban & Fledgling & M & 8 & 9.1 & + \\
\hline U1 & Urban & Adult & $\mathrm{F}$ & 10 & 7.5 & - \\
\hline $\mathrm{U} 2$ & Urban & Adult & $\mathrm{F}$ & 12 & N/A & - \\
\hline U3 & Urban & Adult & $\mathrm{F}$ & 16 & N/A & - \\
\hline U4 & Urban & Adult & $\mathrm{F}$ & 21 & N/A & - \\
\hline U5 & Urban & Adult & $\mathrm{F}$ & 23 & N/A & - \\
\hline U6 & Urban & Adult & M & 18 & N/A & - \\
\hline U7 & Urban & Adult & M & 21 & N/A & - \\
\hline U8 & Urban & Adult & M & 23 & 2.5 & - \\
\hline U9 & Urban & Fledgling & $\mathrm{F}$ & 14 & N/A & - \\
\hline U10 & Urban & Fledgling & $\mathrm{F}$ & 15 & N/A & - \\
\hline U11 & Urban & Fledgling & $\mathrm{F}$ & 19 & N/A & - \\
\hline U12 & Urban & Fledgling & $\mathrm{F}$ & 23 & 8.4 & + \\
\hline U13 & Urban & Fledgling & M & 11 & N/A & + \\
\hline U14 & Urban & Fledgling & M & 13 & N/A & - \\
\hline U15 & Urban & Fledgling & M & 17 & 8.9 & - \\
\hline U16 & Urban & Fledgling & M & 20 & 8.7 & - \\
\hline $\mathrm{U} 17$ & Urban & Fledgling & M & 22 & 7.8 & + \\
\hline
\end{tabular}


Table 6.3: Total reads, aligned reads, and total percent (\%) alignment from RNA-seq on Cooper's hawk blood samples collected from Albuquerque, NM in 2015. For adult samples, the data from the Illumina HiSeq run are reported in addition to the data combining technical replicates from both a HiSeq and MiSeq run. Fledgling samples were only sequenced on the HiSeq platform.

\begin{tabular}{cccccccc} 
& & \multicolumn{3}{c}{ HiSeq Data Only } & \multicolumn{3}{c}{ HiSeq/MiSeq Data Combined } \\
\cline { 3 - 7 } $\begin{array}{c}\text { Sample } \\
\text { ID }\end{array}$ & \multirow{2}{*}{ Age } & $\begin{array}{c}\text { Total } \\
\text { Reads }\end{array}$ & $\begin{array}{c}\text { Aligned } \\
\text { Reads }\end{array}$ & $\begin{array}{c}\% \\
\text { Alignment }\end{array}$ & $\begin{array}{c}\text { Total } \\
\text { Reads }\end{array}$ & $\begin{array}{c}\text { Aligned } \\
\text { Reads }\end{array}$ & Alignment \\
\hline \hline E1 & Adult & $19,436,141$ & $9,931,868$ & 51.1 & $20,762,082$ & $10,569,976$ & 50.9 \\
E2 & Adult & $20,263,001$ & $10,103,132$ & 49.9 & $21,065,460$ & $10,496,919$ & 49.8 \\
E3 & Adult & $17,297,325$ & $9,639,799$ & 55.7 & $18,078,854$ & $10,077,153$ & 55.7 \\
E4 & Adult & $21,136,702$ & $11,100,996$ & 52.5 & $22,213,081$ & $11,646,318$ & 52.4 \\
E5 & Adult & $17,018,873$ & $8,691,538$ & 51.1 & $17,963,706$ & $9,177,657$ & 51.1 \\
E6 & Adult & $13,140,908$ & $7,243,268$ & 55.1 & $13,932,048$ & $7,668,199$ & 55.0 \\
E7 & Adult & $14,753,590$ & $7,289,749$ & 49.4 & $15,798,555$ & $7,769,729$ & 49.2 \\
E8 & Adult & $17,510,393$ & $8,840,997$ & 50.5 & $18,525,545$ & $9,338,727$ & 50.4 \\
U1 & Adult & $19,344,570$ & $10,535,053$ & 54.5 & $20,433,252$ & $11,125,906$ & 54.5 \\
U2 & Adult & $13,963,194$ & $6,812,642$ & 48.8 & $14,781,555$ & $7,194,183$ & 48.7 \\
U3 & Adult & $19,941,408$ & $10,204,018$ & 51.2 & $21,056,311$ & $10,749,247$ & 51.1 \\
U4 & Adult & $18,315,307$ & $9,575,242$ & 52.3 & $19,386,075$ & $10,133,101$ & 52.3 \\
U5 & Adult & $16,842,360$ & $9,293,614$ & 55.2 & $17,736,501$ & $9,778,133$ & 55.1 \\
U6 & Adult & $20,497,765$ & $10,556,349$ & 51.5 & $21,679,903$ & $11,154,310$ & 51.5 \\
U7 & Adult & $15,255,964$ & $7,316,760$ & 48.0 & $16,026,032$ & $7,668,456$ & 47.9 \\
U8 & Adult & $18,069,077$ & $9,616,363$ & 53.2 & $18,869,476$ & $10,031,013$ & 53.2 \\
\hline & Average & $\mathbf{1 7 , 6 7 4 , 1 6 1}$ & $\mathbf{9 , 1 7 1 , 9 6 2}$ & $\mathbf{5 1 . 9}$ & $\mathbf{1 8 , 6 4 4 , 2 7 7}$ & $\mathbf{9 , 6 6 1 , 1 8 9}$ & $\mathbf{5 1 . 8}$ \\
\cline { 2 - 7 }
\end{tabular}

\begin{tabular}{ccccc} 
E9 & Fledgling & $19,939,486$ & $11,148,167$ & 55.9 \\
E10 & Fledgling & $21,367,588$ & $11,692,344$ & 54.7 \\
E11 & Fledgling & $21,085,413$ & $10,977,066$ & 52.1 \\
E12 & Fledgling & $22,711,486$ & $9,759,126$ & 43.0 \\
E13 & Fledgling & $22,979,194$ & $11,820,497$ & 51.4 \\
E14 & Fledgling & $22,212,976$ & $11,823,967$ & 53.2 \\
U9 & Fledgling & $23,837,047$ & $13,265,317$ & 55.7 \\
U10 & Fledgling & $23,483,380$ & $12,969,871$ & 55.2 \\
U11 & Fledgling & $25,233,101$ & $14,562,023$ & 57.7 \\
U12 & Fledgling & $22,698,416$ & $12,254,875$ & 54.0 \\
U13 & Fledgling & $22,533,151$ & $12,192,688$ & 54.1 \\
U14 & Fledgling & $20,598,014$ & $11,129,107$ & 54.0 \\
U15 & Fledgling & $20,063,045$ & $11,151,040$ & 55.6 \\
U16 & Fledgling & $24,590,701$ & $13,687,184$ & 55.7 \\
U17 & Fledgling & $20,765,951$ & $12,156,388$ & 58.5 \\
\hline & Average & $\mathbf{2 2 , 4 3 9 , 9 6 2}$ & $\mathbf{1 2 , 1 0 2 , 9 6 4}$ & $\mathbf{5 3 . 9}$
\end{tabular}


Table 6.4: Significant differentially expressed (DE) transcripts between urban and exurban fledgling and adult Cooper's hawks sampled in Albuquerque, NM, USA during the breeding season of 2015. Transcript names, fold change (Fc), p-values (pval), q-values (qval), and average fragments per kilobase per million reads (FPKM) are from Ballgown output after DE analysis. Fc values under 1 were more abundant in exurban environments, while more abundant transcripts in urban environments have Fc values greater than 1. The best match and species from a search using the Basic Local Alignment Search Tool (BLAST) for each transcript are reported. The best match was determined using the highest identity and e-values $\leq 10^{-5}$. Gene ontology terms are reported based on searches for the gene identified from the BLAST search and include molecular function (MF), biological processes (BP), or cellular components (CC). In addition, some common functions for each gene are listed based on information in Gene Ontology databases (e.g. Ensembl,

GO_Central, and UniProt) and/or current literature.

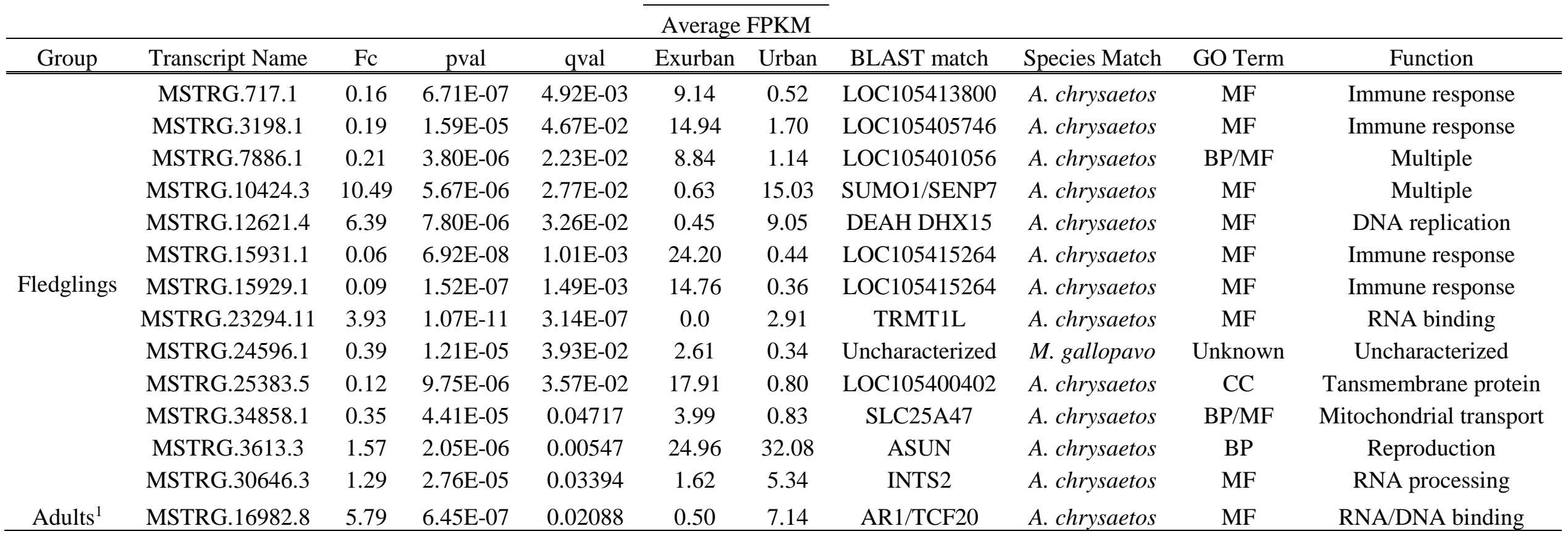




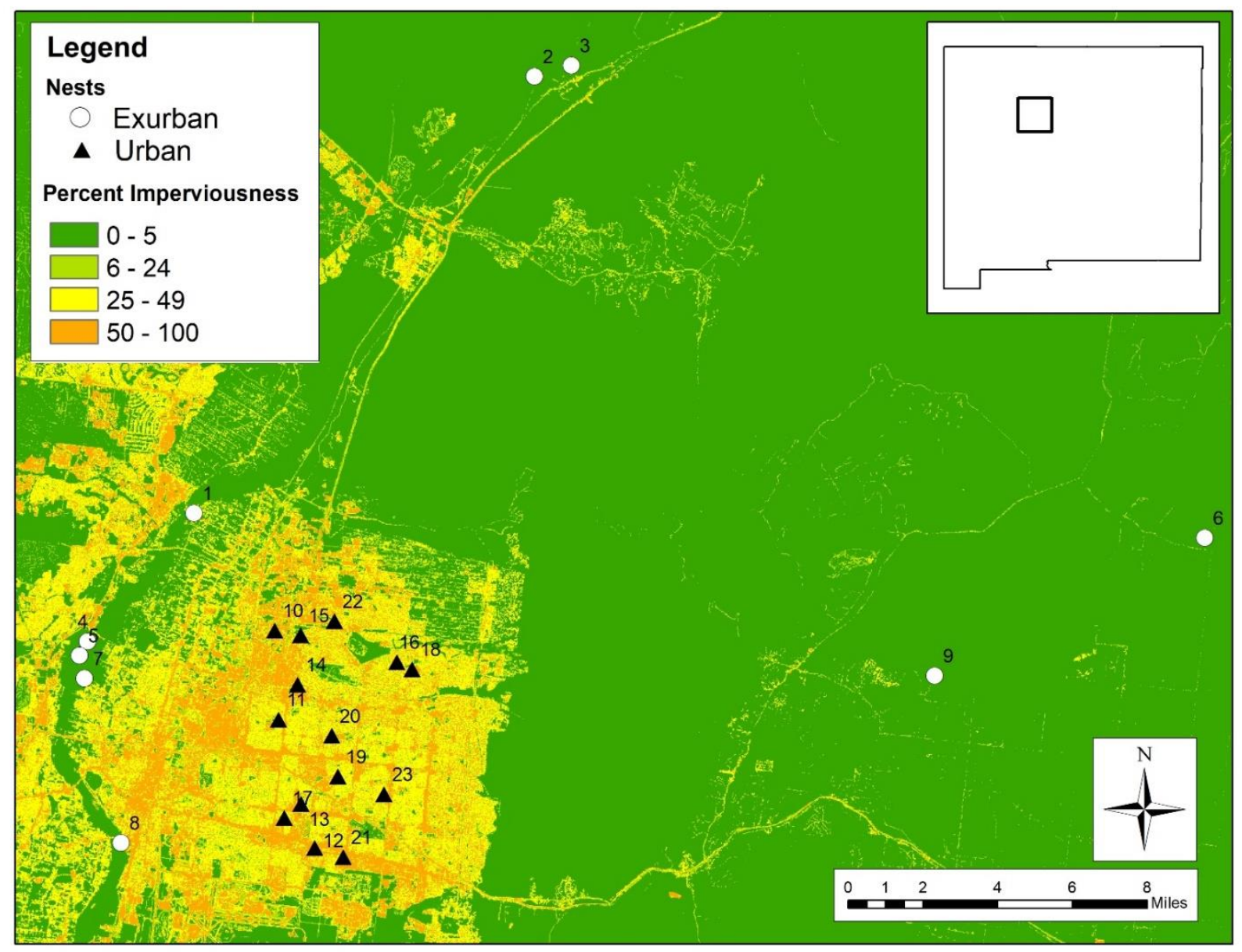

Figure 6.1: Nest locations of Cooper's hawks sampled in the greater Albuquerque, New Mexico area, USA. The basemap represents the percent imperviousness across the landscape (NLCD 2011). Nest territories (385m buffer around nest) were classified as either urban or exurban. In urban nest areas, the majority of cells had a positive percent imperviousness value, while exurban nests had a value of zero in the majority of cells. Nest numbers correspond to Table 6.1. 